Laila Romagueira Bichara dos Santos

\title{
PARTICIPAÇÃO DA NAD(P)H OXIDASE NO DIRECIONAMENTO DO METABOLISMO INDUZIDO PELO ÁCIDO OLÉICO DURANTE O PROCESSO DE SECREÇÃO DE INSULINA
}

Tese apresentada ao Programa de PósGraduação em Fisiologia Humana do Instituto de Ciências Biomédicas da Universidade de São Paulo, para obtenção do Título de Doutor em Ciências. 
Laila Romagueira Bichara dos Santos

\section{PARTICIPAÇÃO DA NAD(P)H OXIDASE NO DIRECIONAMENTO DO METABOLISMO INDUZIDO \\ PELO ÁCIDO OLÉICO DURANTE O PROCESSO \\ DE SECREÇÃO DE INSULINA}

Tese apresentada ao Programa de PósGraduação em Fisiologia Humana do Instituto de Ciências Biomédicas da Universidade de São Paulo, para obtenção do Título de Doutor em Ciências.

Área de Concentração: Fisiologia Humana

Orientador: Prof. Dr. Angelo Rafael Carpinelli

São Paulo

2010 
DADOS DE CATALOGAÇÃO NA PUBLICAÇÃO (CIP)

Serviço de Biblioteca e Informação Biomédica do

Instituto de Ciências Biomédicas da Universidade de São Paulo

reprodução não autorizada pelo autor

Santos, Laila Romangueira Bichara dos.

Participação da NAD(P)H oxidase no direcionamento do metabolismo induzido pelo acido oléico durante o processo de secreção de insulina / Laila Romangueira Bichara dos Santos. -- São Paulo, 2010.

Orientador: Angelo Rafael Carpinelli.

Tese (Doutorado) - Universidade de São Paulo. Instituto de Ciências Biomédicas. Departamento de Fisiologia e Biofísica. Área de concentração: Fisiologia Humana. Linha de pesquisa: Fisiologia da Secreção de Insulina

Versão do título para o inglês: $\mathrm{NAD}(\mathrm{P}) \mathrm{H}$ oxidase Participates in the Oleic Acid-Induced Metabolic Channelling During Insulin Secretion.

Descritores: 1. Secreção de Insulina 2. Ácidos graxos 3. Metabolismo I. Carpinelli, Angelo Rafael II. Universidade de São Paulo. Instituto de Ciências Biomédicas. Programa de Pós-Graduação em Fisiologia e Biofísica. III. Título. 
Candidato(a):

Laila Romagueira Bichara dos Santos.

Título da Tese:

Participação da NAD(P)H oxidase no direcionamento do metabolismo induzido pelo acido oléico durante o processo de secreção de insulina.

Orientador(a):

Angelo Rafael Carpinelli.

A Comissão Julgadora dos trabalhos de Defesa da Tese de Doutorado, em sessão pública realizada a I................................, considerou

\section{( ) Aprovado(a) \\ ( ) Reprovado(a)}

$\begin{array}{ll}\text { Examinador(a): } & \text { Assinatura: } \\ & \text { Nome: ....... } \\ & \text { Instituição: } \\ \text { Examinador(a): } & \text { Assinatura: } \\ & \text { Nome: ....... } \\ & \text { Instituição: } \\ \text { Examinador(a): } & \text { Assinatura: } \\ & \text { Nome: ........ } \\ & \text { Instituição: } \\ \text { Examinador(a): } & \text { Assinatura: } \\ & \text { Nome: ........ } \\ & \text { Instituição: } \\ & \text { Assinatura: } \\ \text { Presidente: } & \text { Nome: ......... } \\ & \text { Instituição: }\end{array}$


Aos meus pais, por me ensainarem o rela sentido da palavra caráter. 


\section{AGRADECIMENTOS}

Ao professor Angelo Carpinelli, que abriu as portas de seu laboratório para mim e me proporcionou muito aprendizado e se tornou um grande amigo, com seus conselhos sempre apaziguadores.

Ao Zé Maria, pela colaboração em todos os momentos, pela paciência e por colaborar para o andament o da pós-gradução em Fisiologia.

À Fundação de Amparo à Pesquisa do Estado de São Paulo (FAPESP) pelo apoio financeiro, que me proporcionou realizar o doutorado em uma instituição de ponta, o ICB-I da Universidade de São Paulo. Sem o auxílio desta instituição, a pesquisa em São Paulo não teria alcançado seu nível de excelência.

A todos os professores do Departamento de Fisiologia e Biofísica e dos outros departamentos do ICB-I da USP, os quais sempre se mostraram receptivos em me auxiliar.

À Professora Silvana Auxiliadora Bordin e os membros de seu laboratório, meus colegas, Camilo Lellis e Professora Luciana Caperuto.

À Professora Carla Roberta Carvalho por todos os reagentes emprestados e aos membros de seu laboratório, meus colegas, Felipe, Teca, Katherine, Gabriela e Mário.

À Professora Maria Tereza Nunes pelo seu carinho e amizade e ao Fran, membro de seu laboratório, pelo aprendizado durante as colaborações realizadas.

Ao Professor Rui Curi pelo coleguismo e todas as discussões durante a realização desse trabalho. E também a todos os membros do seu laboratório, em especial à Tatiana e a Thaís por toda a ajuda despendida e por muitas risadas.

Ao Professor Joel Claudio Heimann pela colaboração e aprendizado que me proporcionou.

À Professora Emiko Hirata pelo coleguismo e colaboração na banca de qualificação.

Ao Professor e amigo Fernando Abdulkader pelas discussões e muitas dúvidas esclarecidas e a todos os membros de seu laboratório Igor, Juan e Elisa. E, principalmente, pela paciência e amizade, que se fortaleceu em uma fase muito importante.

Aos colegas de departamento Adilson, Alice, Anselmo, Tatá, Dedé, Hilde, Rosana, Cleyton, Rodrigo, Leila entre outros que por ventura me esquecer.

Aos colegas de laboratório Dani, Maíra, Gabi, Camila, Elô, por todos os momentos de alegria e de muito trabalho, e, principalmente à Marlene por organizar a "creche" do professor Angelo. 
A colega de laboratório Fernanda pelo companheirismo e pela ajuda em nossos experimentos "loucos" de início da manhã (na realidade madrugada).

À amiga Tatiane Nogueira por todo seu carinho, por me aguentar chorando e pelos abraços acolhedores.

Ao amigo Professor Anderson Marçal, que me ajudou muito assim que me mudei para São Paulo e que até hoje me ajuda de longe.

Aos amigos que me acompanham há muito tempo Charles, Helô, Angela e Eli.

Ao amigo Daniel, pela amizade e pelas longas conversas.

Ao amigo Edu pelas discussões no fim desse trabalho e pela amizade nos últimos tempos e por ter tornado, junto com o Fernando, este último ano de doutorado mais leve com as cervejas depois dos experimentos.

Ao meu irmão de sangue e anjo da guarda Thiago, por toda amizade e paciência, pela força nas horas difíceis, pelo incentivo, pela cumplicidade, pelo amor e pelas brigas e broncas também.

Aos meus pais, grandes incentivadores e amigos, que são os grandes responsáveis pelo meu caráter e esforço para realizar meus sonhos.

E, finalmente, a Deus, por ter me dado força para trabalhar e sonhos a realizar. 
“O único lugar onde o sucesso vem antes do trabalho é no dicionário" 


\section{RESUMO}

Santos LRB. Participação da NAD(P)H oxidase no Direcionamento do Metabolismo Induzido pelo Ácido Oléico Durante o Processo de Secreção de Insulina. [tese (Doutorado em Fisiologia Humana)]. São Paulo: Instituto de Ciências Biomédicas da Universidade de São Paulo; 2010.

Ácidos graxos são requeridos para a manutenção da função celular. Em ilhotas pancreáticas possui função moduladora da secreção de insulina induzida pela glicose. O metabolismo das células é responsável pelo aumento de EROs e estes parecem estar envolvidos no processo de secreção de insulina. Dentre os importantes sítios de formação de EROs estão a mitocôndria e a NAD(P)H oxidase, a primeira pode induzir aumento ou queda na produção de EROs em função da atividade metabólica celular e a segunda a tem sua atividade regulada por diversos fatores, dentre eles a PKC .O ácido oléico, junto com o palmítico, é um dos AGs mais abundantes na circulação. O tratamento agudo (1 hora) com $100 \mu \mathrm{M}$ de ácido oléico (concentração fisiológica) induziu aumento na secreção de insulina associado ao aumento no metabolismo do AG em detrimento do metabolismo da glicose. A oxidação desse ácido graxo induziu aumento no conteúdo de EROs na presença de $16,7 \mathrm{mM}$ de glicose com participação da NAD(P)H oxidase. Apesar da reconhecida função da EROs como sinalizadores, a diminuição de EROs induzida pela inibição da $\mathrm{NAD}(\mathrm{P}) \mathrm{H}$ oxidase promoveu aumento relativo na oxidação da glicose, que estava inibida após estímulo com AO. A secreção relativa de insulina também aumentou após inibição da $\mathrm{NAD}(\mathrm{P}) \mathrm{H}$ oxidase, sugerindo, portanto, uma função regulatória das EROs geradas pelo metabolismo do AO através da ativação da NAD(P)H oxidase no metabolismo da glicose e, conseqüentemente, da secreção de insulina. Dessa forma, o ácido oléico é capaz de aumentar a secreção de insulina induzida pela alta concentração de glicose com participação da NAD(P)H oxidase e as EROs produzidas por essa enzima promovem a regulação do metabolismo da glicose, que parece ser mais susceptível à regulação por essas moléculas.

Palavras-chave: Ilhota pancreática. Ácidos Graxos. Metabolismo da glicose. NAD(P)H oxidase. Secreção de insulina. 


\begin{abstract}
Santos LRB. NAD(P)H oxidase Participates in the Oleic Acid-Induced Metabolic Channelling During Insulin Secretion. [Ph. D. thesis (Human Physiology)]. São Paulo: Instituto de Ciências Biomédicas da Universidade de São Paulo; 2010.

Fatty acids are required to maintain cellular functioning and are able to modulate glucose stimulated insulin secretion from pancreatic islets. The metabolism of cells is source of reactive oxygen species (ROS) and may be involved in the process of insulin release. The important sites of ROS production are the mitochondria and the NAD $(\mathrm{P}) \mathrm{H}$ oxidase. The mitochondrial ROS release depends on cellular activity and $\mathrm{NAD}(\mathrm{P}) \mathrm{H}$ oxidase activity depends on many factors, including PKC phosphorylation of $\mathrm{p} 47^{\mathrm{PHOX}}$. Oleic and palmitic acid are the most abundant fatty acids in the circulation. Acute (1 hour) exposure to a physiological concentration of oleic acid (100 $\mu \mathrm{M}+0.1 \%$ BSA) induced increased insulin secretion at high glucose concentration. The insulin secretion induced by OA was associated to increased fatty acid oxidation and decreased glucose metabolism. Also, at $16.7 \mathrm{mM}$ glucose, ROS production was increased by OA oxidation through modulation by $\mathrm{NAD}(\mathrm{P}) \mathrm{H}$ oxidase in pancreatic islets. The decreased ROS content induced by NAD(P)H oxidase inhibition induced re-establishment of glucose oxidation after OA stimulus. The relative secretion was stimulated by $\mathrm{NAD}(\mathrm{P}) \mathrm{H}$ oxidase inhibition after $\mathrm{OA}$ stimulus. This suggests that ROS produced by $\mathrm{NAD}(\mathrm{P}) \mathrm{H}$ oxidase act as glucose metabolism regulators in the pancreatic $\beta$ cell after OA stimulus. The consequence of glucose metabolism re-establishment was the insulin secretion raise. In conclusion, oleic acid was able to stimulate glucose induced insulin secretion through $\mathrm{NAD}(\mathrm{P}) \mathrm{H}$ oxidase induced ROS production. The ROS produced by $\mathrm{NAD}(\mathrm{P}) \mathrm{H}$ oxidase acted as regulators of glucose metabolism, that may be more susceptible to regulation by these molecules. The glucose metabolism may be in part responsible for the increased insulin secretion induced by ROS.
\end{abstract}

Key-words: Pancreatic islets. Fatty Acids. Glucose metabolism. NAD(P)H oxidase. Insulin secretion. 


\section{LISTA DE FIGURAS}

Figura 1. Representação do mecanismo de metabolização da glicose na mitocôndria.

Figura 2. Representação dos mecanismos de secreção de insulina induzidos pelos ácidos graxos (AGs) .22

Figura 3. Representação da ativação da enzima $\mathrm{NAD}(\mathrm{P}) \mathrm{H}$ oxidase em neutrófilos. 27

Figura 4. Avaliação da integridade do RNA e contaminação com DNA genômico. 36

Figura 5. Representação do conteúdo de superóxido após incubação com a PEG-SOD 41

Figura 6. Efeito da glicose e do ácido oléico na secreção de insulina de ilhotas pancreáticas isoladas.

Figura 7. Efeito da presença do ácido oléico na oxidação da glicose em ilhotas pancreáticas isoladas

Figura 8. Efeito da alta concentração de glicose na oxidação do ácido oleíco

Figura 9. Efeito do ácido oléico no conteúdo de superóxido de ilhotas isoladas e na linhagem de células $\beta$ (INS-1E) 50

Figura 10. Efeito da inibição da oxidação do ácido oléico e da inibição da PKC no conteúdo de superóxido de células INS-1E.

Figura 11. Efeito do ácido oléico no conteúdo protéico de GPR40, PKC e Nox2 de ilhotas pancreáticas isoladas

Figura 12. Efeito da inibição do receptor de ácidos graxos GPR40 na secreção de insulina induzida pelo ácido oléico em células $\beta$ INS-1E

Figura 13. Efeito da inibição do receptor GPRro no conteúdo de superóxido após incubação com ácido oláeico em células $\beta$ INS-1E 55

Figura 14. Efeito da transfecção de ilhotas pancreáticas isoladas com oligonucleotídeo antisense para ao subunidade $\mathrm{p} 47^{P H O X}$ da $\mathrm{NAD}(\mathrm{P}) \mathrm{H}$ oxidase no conteúdo protéico desta subunidade 56

Figura 15. Efeito do ácido oléico no conteúdo de superóxido de ilhotas pancreáticas isoladas após inibição da $447^{\text {PHOX }}$ 57

Figura 16. Efeito do ácido oléico na secreção de insulina de ilhotas pancreáticas isoladas após inibição da $47^{\text {PHOX }}$

Figura 17. Efeito do ácido oléico na razão de secreção de insulina em ilhotas pancreáticas isoladas após inibição da $4^{7 P H O X}$ 
Figura 18. Efeito do ácido oléico na oxidação da glicose em ilhotas pancreáticas isoladas após inibição da $447^{P H O X}$ 60

Figura 19. Efeito do ácido oléico na oxidação da glicose em ilhotas pancreáticas isoladas após inibição da $47^{\text {PHOX }}$ 61

Figura 20. Efeito do ácido oléico no conteúdo de superóxido de ilhotas pancreáticas isoladas de camundongos Nox2-KO 62

Figura 21. Efeito do ácido oléico na secreção de insulina de ilhotas pancreáticas isoladas de camundongos Nox2-KO 63

Figura 22. Efeito do ácido oléico na razão de secreção de insulina em ilhotas pancreáticas isoladas de camundongos Nox2-KO 


\section{LISTA DE TABELAS}

Tabela 1 - Sequência dos primers utilizados para reação de PCR em tempo real.................................43

Tabela 2 - Sequência de oligonucleotídeos antisense e "scrambled" para inibição da subunidade $\mathrm{p} 47^{\text {PHOX }}$ da NAD(P)H oxidase... .48

Tabela 3 - Sequência de RNAi testadas para inibição do GPR40 . .49 


\section{LISTA DE ABREVIATURAS}

ADP

AGE

AMPc

$\mathrm{AO}$

AS

ATP

CAT

$\mathrm{Ca}^{2+}$

CCSV

$\mathrm{CO}_{2}$

CPT-1

CTE

CuZnSOD

DAG

DAs

DEPC

DHE

DMSO

DNA

DPI

$\Delta \psi$

EM

ETC

EROs

$\mathrm{FADH}_{2}$

FAD $^{+}$

GK

GLUT

GPx

G3PDH

$\left[\mathrm{U}-{ }^{14} \mathrm{C}\right]-$ Glicose

$\left[1-{ }^{14} \mathrm{C}\right]$-Oleato adenosina difosfato

produto final de glicação avançada

adenosina monofosfato cíclico

ácido oleico

oligonucleotídeo antisense

adenosina trifosfato

catalase

íon cálcio

canal para $\mathrm{Ca}^{2+}$ sensível à voltagem

dióxido de carbono

carnitina palmitoil transferase 1

cadeia transportadora de elétrons

superóxido dismutase cobre-zinco

diacilglicerol

defesas antioxidantes

dietilpirocarbonato

dihidroetídeo

dimetilsulfóxido

ácido desoxirribonucléico

difenilenoiodônio

potencial de membrana

enzima málica

cadeia de transporte de elétrons

espécies reativas de oxigênio

- $\quad$ flavina adenina nucleotídeo reduzida

- $\quad$ flavina adenina nucleotídeo oxidada

glicoquinase

transportador de glicose

glutationa peroxidase

gliceraldeído-3-fosfato desidrogenase

glicose uniformemente marcada com carbono 14

oleato marcado no carbono 1 com carbono 14 


\begin{tabular}{|c|c|c|}
\hline GSH & - & glutationa reduzida \\
\hline $\mathrm{H}_{2} \mathrm{O}_{2}$ & - & peróxido de hidrogênio \\
\hline IP3 & - & $1,4,5$ inositol-trifosfato \\
\hline IR & - & receptor de insulina \\
\hline $\mathrm{KCl}$ & - & cloreto de potássio \\
\hline $\mathrm{KDa}$ & - & kilo dalton \\
\hline $\mathrm{K}^{+}$ & - & íon potássio \\
\hline $\mathrm{K}_{\mathrm{ATP}}$ & - & canal para $\mathrm{K}^{+}$sensível ao ATP \\
\hline $\mathrm{KH}$ & - & Krebs-Henseleit \\
\hline $\mathrm{Km}$ & - & constante de Michaelis-Menten \\
\hline $\mathrm{KO}$ & - & "Knockout" \\
\hline LC-CoA & - & acil-CoA de cadeia longa \\
\hline LDH & - & lacatato desidrogenase \\
\hline MAO & - & análogo não-metabolizável do oleato \\
\hline $\mathrm{MDH}$ & - & malato desidrogenase \\
\hline MnSOD & - & manganês superóxido dismutase \\
\hline $\mathrm{NAC}$ & - & N-acetil-L-cisteína \\
\hline NAD & - & nicotinamida adenina dinucleotídeo \\
\hline NADH & - & dinucleotídeo de nicotinamida adenina reduzida \\
\hline NADPH & - & dinucleotídeo de nicotinamida adenina fosfato reduzida \\
\hline NADP & - & nicotinamida adenina dinucleotídeo fosfato \\
\hline $\mathrm{NaHCO}_{3}$ & - & bicarbonato de sódio \\
\hline $\mathrm{NO}^{\bullet}$ & - & óxido nítrico \\
\hline NOS & - & óxido nítrico síntase \\
\hline Nox & - & homólogos da subunidade citocromo da NAD $(\mathrm{P}) \mathrm{H}$ oxidase \\
\hline Noxa & - & ativador de NOX \\
\hline Noxo & - & organizador de NOX \\
\hline $\mathrm{O}_{2}^{\bullet-}$ & - & radical ânion superóxido \\
\hline $\mathrm{OH}^{\bullet}$ & - & radical hidroxila \\
\hline $\mathrm{PC}$ & - & piruvato carboxilase \\
\hline $\mathrm{PDH}$ & - & piruvato desidrogenase \\
\hline PFK - 1 & - & fosofofrutoquinase 1 \\
\hline PI3-K & - & fosfatidilinositol 3-quinase \\
\hline PKA & - & proteína quinase $\mathrm{A}$ \\
\hline
\end{tabular}


PKC

proteína quinase $\mathrm{C}$

PLC

fosfolipase $\mathrm{C}$

PEG-SOD

- $\quad$ superóxido dismutase peguilada

RIA

- $\quad$ radioimunoensaio

RNAi

- $\quad$ RNA de interferência

RNAr

RNA ribossômico

SOD

superóxido dismutase

TG

triglicérides 


\section{SUMÁRIO}

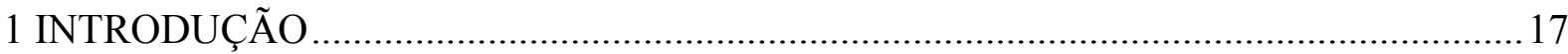

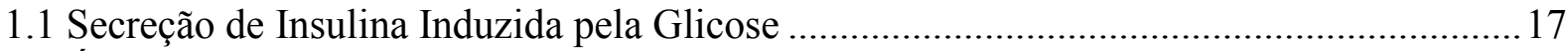

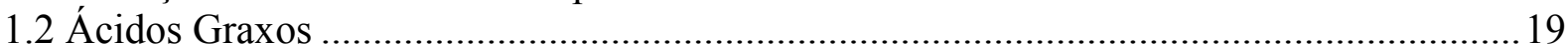

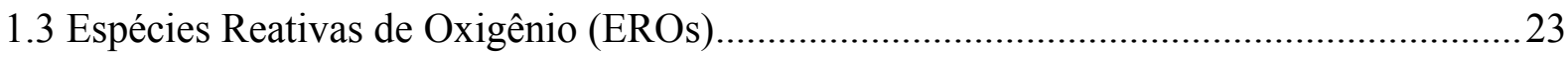

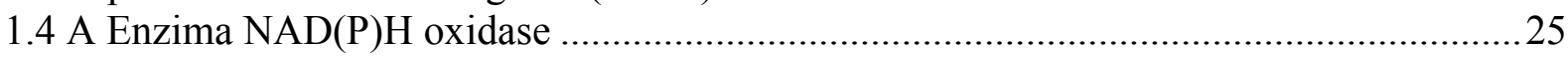

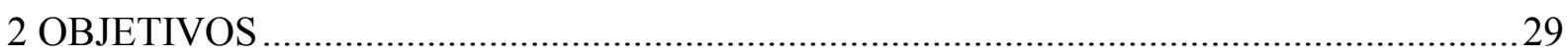

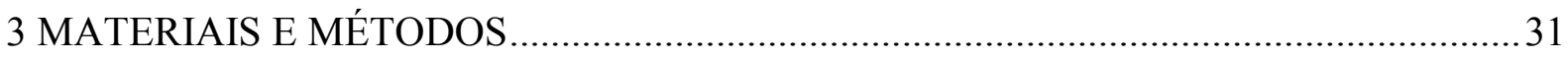

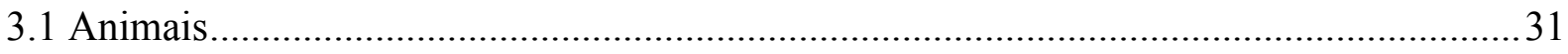

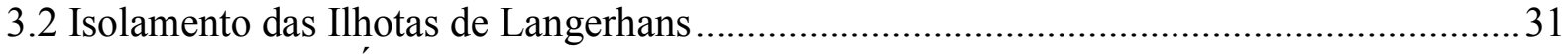

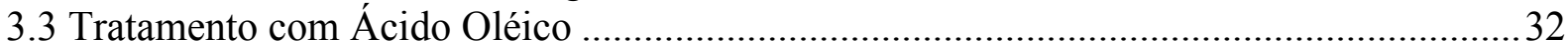

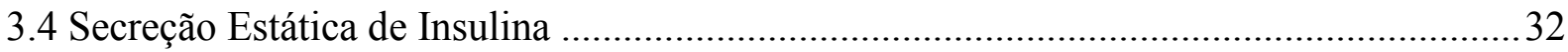

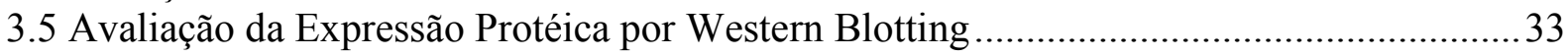

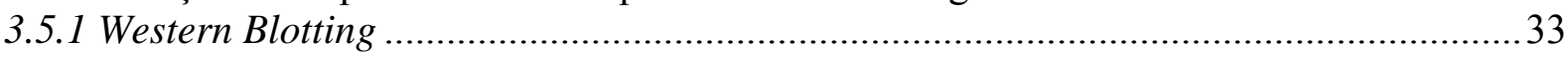

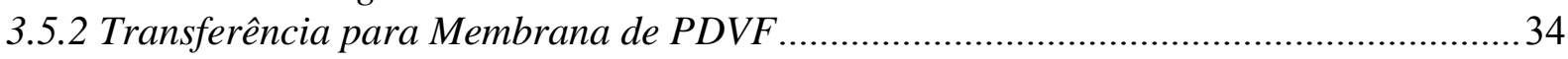

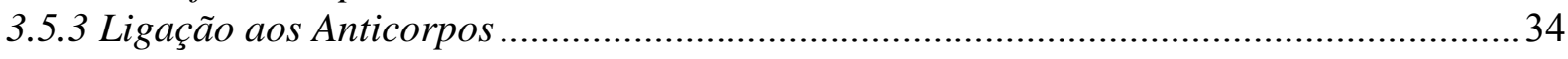

3.6 Avaliação da Expressão Gênica por PCR em Tempo Real ............................................. 35

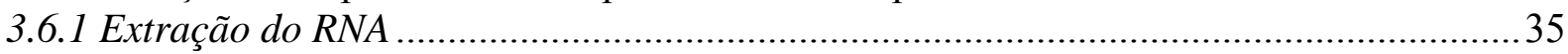

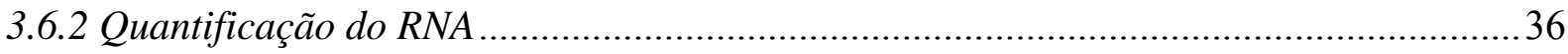

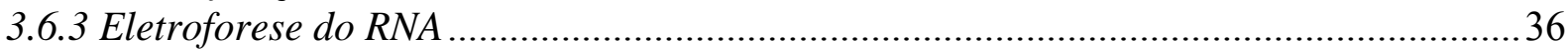

3.6.4 RT-PCR ("Reverse Transcriptase Polymerase Chain Reaction") .................................. 37

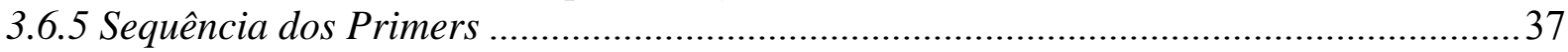

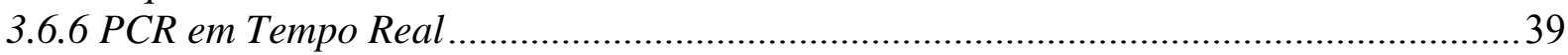

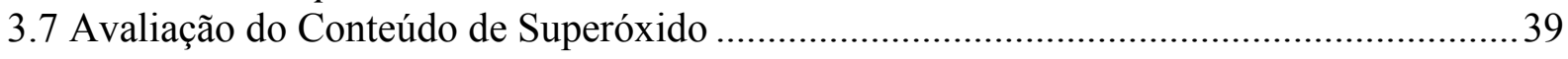

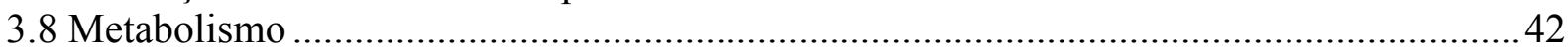

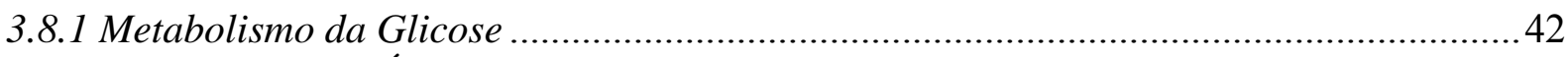

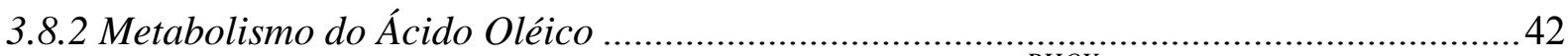

3.9 Oligonucleotídeo Antisense (AS) para o Componente p $47^{P H O X}$ da NAD(P)H oxidase ...... 42

3.10 RNA de Interferência (RNAi) para o Receptor de Ácidos Graxos GPR40 ......................43

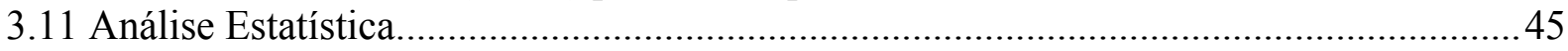

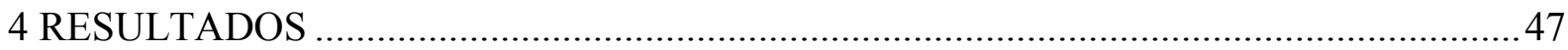

4.1 Avaliação da Ação do Ácido Oléico em Ilhotas Isoladas ................................................ 47

4.1.1 Secreção Estática de Insulina47Figura 6. Efeito da glicose e do ácido oléico na secreção

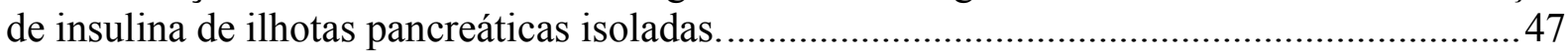

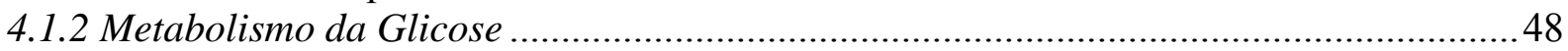

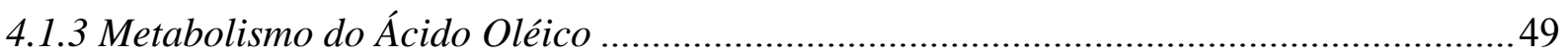

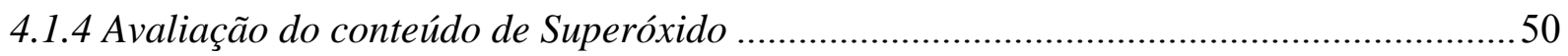

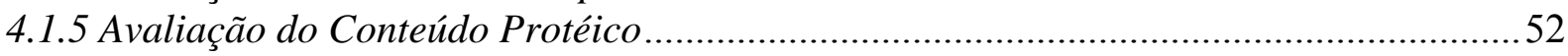

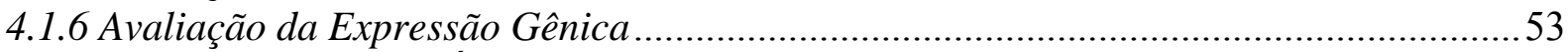

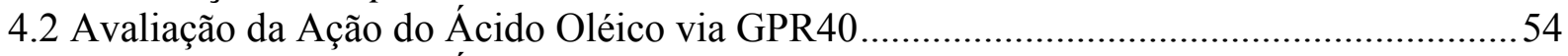

4.3 Avaliação da Ação do Ácido Oléico via NAD(P)H oxidase...............................................56

4.3.1 "Knockdown" da subunidade p4 $7^{P H O X}$ da NAD(P)H oxidase (Oligonucleotídeo

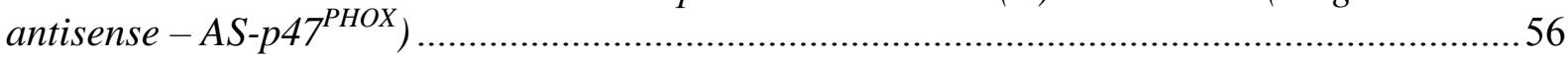

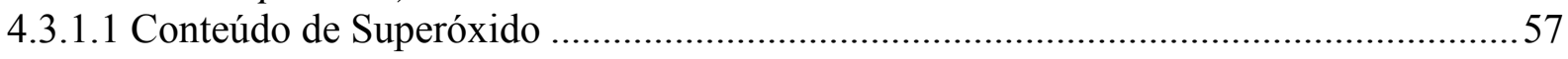

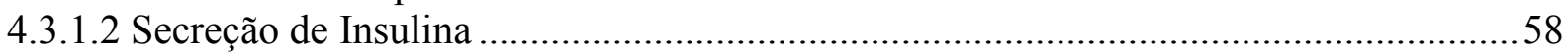

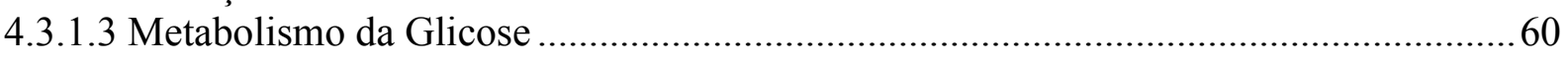


4.3.2 "Knockout" da Subunidade Nox2 NAD $(P) H$ oxidase (Nox2 - KO) 62

5 DISCUSSÃO 66

6 CONCLUSÃO 75

REFERENCIAS* 77

ANEXO A - Artigo 1 91

ANEXO B - Artigo 2 92 
1 INTTRODUÇ ̃̃o 


\subsection{Secreção de Insulina Induzida pela Glicose}

As células $\beta$ das ilhotas pancreáticas são responsáveis pela produção e liberação de insulina, hormônio responsável pela manutenção dos níveis plasmáticos de glicose. A glicose é, portanto, o principal estimulador da célula $\beta$ a secretar o hormônio. A glicose do plasma entra na célula $\beta$ sem restrição, pois o transportador de glicose dessa célula, o GLUT2, apresenta grande capacidade de transporte e não é saturado por altas concentrações glicose. Assim, a concentração de glicose dentro da célula $\beta$ está sempre em equilíbrio com o plasma. Em seguida à sua entrada a glicose é prontamente fosforilada a glicose-6-fosfato por ação da enzima de alto $\mathrm{Km}$, a glicoquinase (GK), que é determinante para manutenção do fluxo de substrato para a glicólise. Uma vez fosforilada a glicose é metabolizada pela glicólise, onde dará origem a piruvato, NADH e ATP. O piruvato é posteriormente oxidado na mitocôndria, onde será convertido em $\mathrm{NADH}$ e $\mathrm{FADH}_{2}$ e dará origem à maior parte do ATP gerado durante o metabolismo da glicose.

Segundo diversos autores a indução da secreção de insulina pela glicose é desencadeada pelo aumento na produção de ATP e, consequentemente, da razão ATP/ADP, através de sua metabolização a piruvato e posterior oxidação no ciclo de $\operatorname{Krebs}^{1}{ }^{2-4}$. O aumento na razão ATP/ADP, induzido pelo metabolismo da célula $\beta$, gera inibição dos canais de $\mathrm{K}^{+}$sensíveis ao ATP $\left(\mathrm{K}_{\mathrm{ATP}}\right)$ e consequente despolarização celular, que promove a abertura dos canais de cálcio $\left(\mathrm{Ca}^{2+}\right)$ voltagem dependentes (VDCC). O aumento na concentração de $\mathrm{Ca}^{2+}$ intracelular é reconhecido como principal indutor de secreção de insulina. $\mathrm{O}$ envolvimento de proteínas cinases foi inferido ao se observar aumento na translocação de algumas de suas isoformas para a membrana após aumento de $\mathrm{Ca}^{2+}$ intracelular ${ }^{5}$. A fosfolipase $\mathrm{C}$ (PLC) é ativada levando à formação de inositol trifosfato $\left(\mathrm{IP}_{3}\right)$ e diacilglicerol (DAG). Este último ativa a proteína cinase $\mathrm{C}(\mathrm{PKC})$ e pode interagir diretamente com proteínas envolvidas na sinalização celular ${ }^{6,7}$. $\mathrm{O} \mathrm{IP}_{3}$ também promove a abertura dos canais de $\mathrm{Ca}^{2+}$ presentes na membrana do retículo endoplasmático liberando mais $\mathrm{Ca}^{2+}$ para o citosol, o que potencializa o processo secretório.

O metabolismo da glicose é o principal regulador da secreção de insulina ao aumentar a produção de ATP, que é gerado principalmente na mitocôndria. O metabolismo mitocondrial participa da geração de outros sinais intracelulares indutores de secreção de insulina além do ATP, tais como intermediários metabólicos e NADPH ${ }^{8,9}$. O cálcio intracelular controla muitas funções na célula $\beta$, dentre elas o metabolismo mitocondrial. $\mathrm{O}$ 
$\mathrm{Ca}^{2+}$ intracelular alcança a mitocôndria e aumenta o $\mathrm{Ca}^{2+}$ na organela com consequente estímulo às NADH desidrogenases, induzindo potencialização no aumento da razão ATP/ADP ${ }^{10}$. A importância da mitocôndria no processo de secreção de insulina induzido pela glicose foi comprovada em estudos realizados com células Rho (deficientes em DNA mitocondrial) nas quais subunidades catalíticas da cadeia respiratória estão ausentes e impossibilitam a geração de ATP mitocondrial. Essas células mantém resposta frente ao $\mathrm{KCl}$ e maquinaria exocitótica intacta, porém a ausência de aumento na concentração de ATP induzido pela glicose impossibita secreção de insulina normal frente a glicose e substratos mitocondriais ${ }^{11}$.

Umas das características da célula $\beta$ é o forte acoplamento entre glicólise e o metabolismo mitocondrial. $\mathrm{O}$ acoplamento entre a glicólise e o metabolismo mitocondrial decorre da baixa atividade da lactato desidrogenase (LDH) na célula $\beta$, que prioriza a entrada de piruvato na mitocôndria e posterior metabolização no ciclo de Krebs ${ }^{12}$. Para que o piruvato entre na mitocôndria e possa ser catalisado há duas vias possíveis: a da piruvato desidrogenase $(\mathrm{PDH})$, formadora de acetil-CoA, ou a da piruvato carboxilase (PC) geradora de oxalacetato. Em muitas células a via da PDH predomina, mas a ilhota pancreática apresenta alta concentração e atividade da PC em níveis semelhantes aos de tecidos com atividade gliconeogênica como fígado e rins, dessa forma, em ilhotas pancreáticas, o piruvato é metabolizado tanto pela PDH, quanto pela PC ${ }^{13}$ (Figura 1). A PC é essencial para anaplerose, que é necessária para a manutenção do ciclo de Krebs e de seus intermediários, que são exauridos por muitos processos como lipogênese e síntese de certos aminoácidos ${ }^{14}$, ${ }^{15}$. Na célula $\beta$ o armazenamento de lipídios não é função primordial, assim, a liberação de intermediários do ciclo de Krebs para o citosol apresenta relevância no processo de secreção de insulina. O oxalacetato formado a partir de piruvato pode ser exportado para o citosol, onde ocorre a formação de malato pela malato desidrogenase (MDH). Enzima MDH utiliza como co-fator o $\mathrm{NADH}$, que, ao ser oxidado, gera $\mathrm{NAD}+$, essencial para o funcionamento da via glicolítica, o que implica na grande associação entre a glicólise e o metabolismo mitocondrial. Em seguida o malato é convertido novamente a piruvato pela enzima málica (EM) e retorna para a mitocôndria, pelo chamado desvio malato-piruvato com a concomitante formação de NADPH, um importante agente redutor que está altamente relacionado com a secreção de insulina induzida pela glicose ${ }^{16}$. 


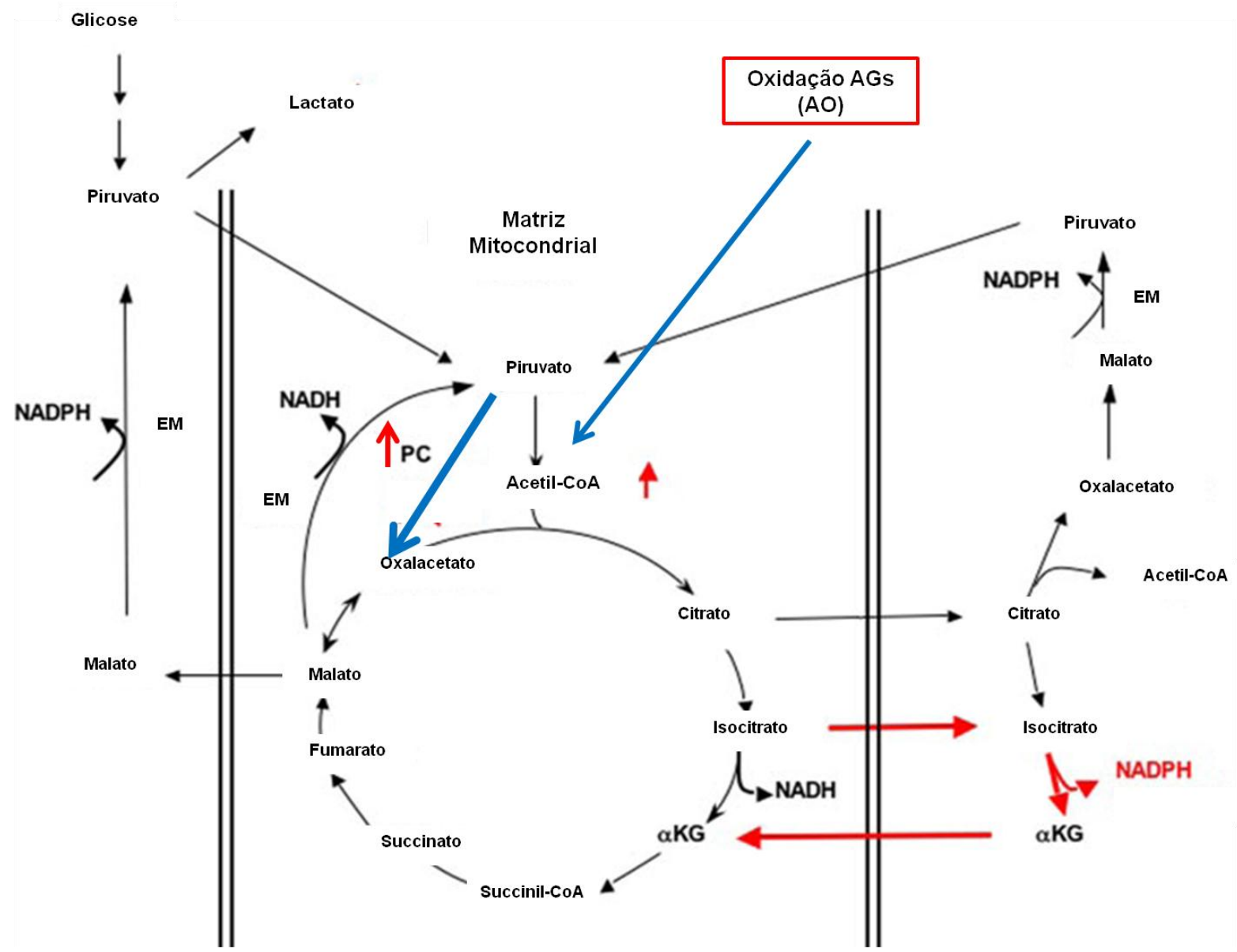

Figura 1. Representação do mecanismo de metabolização da glicose na mitocôndria.

Mecanismos através dos quais a glicose pode ser metabolizada após a entrada do piruvato (Pir) na mitocôndria. Há duas vias de entrada do piruvato na mitocôndria: via piruvato desidrogenase (PDH) ou piruvato carboxilase (PC), e dar origem a metabólitos importantes no processo de secreção de insulina. Os ácidos graxos entram no Ciclo de Krebs sob a forma de acetil-CoA regulando a atividade da PC e da PDH.

Fonte: modificada de ${ }^{17,18}$.

No diabetes tipo II a falha da célula beta coincide com a reduzida atividade da PC e $\mathrm{PDH}^{19-22}$. Estudos demonstraram também, em células e ilhotas pancreáticas, a coincidência entre a redução na resposta secretória de insulina e a menor expressão ou atividade da PC após tratamento crônico com glicose e/ou ácidos graxos ${ }^{23}$.

\section{2 Ácidos Graxos}

Além da glicose, outros nutrientes são capazes de controlar a secreção de insulina, dentre eles estão os ácidos graxos (AGs), que provêm energia para as células e contribuem 
para a manutenção de componentes celulares ${ }^{5,24-26}$. A exposição a altas concentrações de glicose e palmitato induz aumento de LC-CoA, leva à síntese de lipídios complexos como o ácido fosfatídico, ou diacilglicerol (DAG) e triglicérides (TG), que modulam a PKC e aumentam a secreção de insulina ${ }^{27}$. Por outro lado, o excesso de AG pode provocar danos à célula $\beta$, os quais são causados pelo acúmulo de metabólitos derivados desses ácidos graxos ${ }^{2}$. Dentre outros efeitos, o aumento excessivo de LC-CoA resultante de exposição prolongada aos ácidos graxos, pode abrir canais $\mathrm{K}_{\mathrm{ATP}}$ e hiperpolarizar a célula. Reduzindo a probabilidade de fechamento desse canal a consequente despolarização da membrana não ocorre e a secreção é prejudicada ${ }^{28}$. Efeitos crônicos dos AGs também geram alteração do metabolismo da célula $\beta$, elevação do estado redox e aumento do consumo de oxigênio basal, o que sugere um efeito via geração de ATP ${ }^{29-31}$. O tratamento crônico com ácidos graxos saturados aumenta a concentração de ceramidas na célula. Em células $\beta$ os efeitos crônicos e deletérios de altas concentrações de ácidos graxos saturados forma associados à menor oxidação dos mesmos e posterior acúmulo sob a forma de ceramidas ao invés de lipídios neutros ${ }^{32}$. Foi demonstrado que ceramidas podem alterar a atividade do complexo III mitocondrial e diminuir a formação de ATP em mitocôndrias de tecido cardíaco ${ }^{33,34}$. O excesso de oleato parece ser menos danoso às células $\beta$ uma vez que, se comparado ao palmitato e linoleato, praticamente não induz apoptose e diminui a formação de ceramidas induzida por AGs saturados ${ }^{35-38}$. No entanto, os mecanismos pelos quais os ácidos graxos interferem na secreção e expressão da insulina ainda não estão totalmente esclarecidos, mesmo porque agudamente aumentam e cronicamente reduzem a secreção do hormônio ${ }^{39}$.

A oxidação dos ácidos graxos apresenta grande importância no processo de secreção de insulina ${ }^{40}$. Para que os ácidos graxos entrem na mitocôndria e sejam oxidados há a necessidade de formação de LC-CoA e transporte via enzima carnitina palmitoil transferase $(\mathrm{CPT}-1)^{25}$. Foi observado um rápido aumento na expressão gênica da CPT-1 após tratamento da célula B (INS-1) com ácidos graxos ${ }^{41}$. No entanto, já foi demonstrado que a indução de aumento da expressão dessa enzima está associado à perda da resposta frente a glicose observada após tratamento prolongado com ácidos graxos ${ }^{42,43}$.

A administração de ácidos graxos em diversos tipos celulares pode alterar também o metabolismo da glicose $\mathrm{e}$, ao menos em células $\beta$, diminuir a oxidação de açúcares concomitantemente com a secreção de insulina. Foi caracterizado primeiramente em músculo uma fina regulação entre o metabolismo de ácidos graxos e glicose em diversos tipos celulares, posteriomente caracterizada também na célula $\beta^{13}$. Nesse ciclo, que fícou conhecido como ciclo de Randle, foi proposto que o acetil-CoA produzido pelo metabolismo 
dos ácidos graxos inibiria o metabolismo da glicose tanto diretamente, quanto pela geração de citrato. $\mathrm{O}$ acetil-CoA é um potente inibidor de enzimas importantes da via glicolítica, como a fosfofrutoquinase-1 (PFK-1) e PDH, e é ativador alostérico da $\mathrm{PC}^{44,45}$. Com a inibição da via glicolítica a oxidação da glicose é prejudicada, mas a secreção pode ser elevada, ao menos durante a ação aguda dos ácidos graxos.

Apesar de não estar totalmente estabelecida a relação entre oxidação de ácidos graxos e secreção de insulina, esta é uma via importante de modulação da secreção de insulina induzida por AGs. Nos últimos anos porém tem emergido outra via de ação dos ácidos graxos em ilhotas pancreáticas da qual participam receptores acoplados a proteínas Gq. Esses receptores são ativados especificamente por ácidos graxos e são chamados GPRs ${ }^{46}$. Os GPR41 e GRP43 são ativados por ácidos graxos de cadeia curta e o GPR40, expresso principalmente em ilhotas pancreáticas, é ativado por ácidos graxos de cadeia média e longa 47 tendo como seus principais ligantes oleato, linoleato e palmitato ${ }^{48,49}$. Essa família de receptores apresenta grande homologia ${ }^{50}$ apresentando sete domínios transmembrana ${ }^{51-54}$.

A indução na secreção de insulina por ácidos graxos via GPR40 está acoplada a proteínas $\mathrm{Gq}_{\alpha}$, via PKC ${ }^{55}$. Shapiro e colaboradores (2005) demonstraram ação do palmitato atua na linhagem de célula B INS-1E via GPR40 e sugerem um mecanismo para indução da secreção de insulina que consiste na ativação do receptor seguida de ativação da PLC. A PLC ativada promoveria a formação de IP3, que, ao se ligar a receptores no retículo endoplasmático promoveria a liberação de cálcio. Esse cálcio liberado de estoques intracelulares induziria entrada de cálcio a partir de canais de cálcio CCSV e promoveriam a secreção de insulina na presença de AGs e concentrações estimulatórias de glicose.

Estudos realizados com camundongos "knockout" (KO) ou que super-expressam o GPR40 sugerem grande importância desse receptor nas ações agudas e crônicas dos ácidos graxos ${ }^{55}$. A super-expressão do GPR40 induz redução da expressão do RNAm da proteína GLUT-2 em células $\beta$ de ratos. Esse resultado é semelhante ao observado em ilhotas expostas a concentrações elevadas de ácidos graxos, sugerindo papel do GPR40 nos processos fisiológicos e fisiopatológicos envolvendo o processo secretório de insulina induzidos por AG. Animais "knockout" (KO) para o GPR40 não desenvolvem esteatose hepática após alimentação com dieta hiperlipídica ${ }^{56}$. No entanto, o GPR40 parece não estar envolvido no processo de lipotoxicidade na ilhota, pois as ilhotas pancreáticas dos animais KO não foram protegidas dos efeitos deletérios dos ácidos graxos ${ }^{55,56}$. Além disso, a maioria dos trabalhos realizados utilizou ilhotas isoladas ou linhagens celulares que apresentaram efeitos evidentes do GPR40, mas sem interferência do metabolismo celular nesse processo. Essas respostas são 
diferentes do que ocorre in vivo, onde o metabolismo dos ácidos graxos também é bastante importante para o processo de secreção de insulina ${ }^{46}$ (Figura 2). Portanto, ainda há controvérsias quanto aos efeitos do GPR40 no diabetes e também em indivíduos normais.

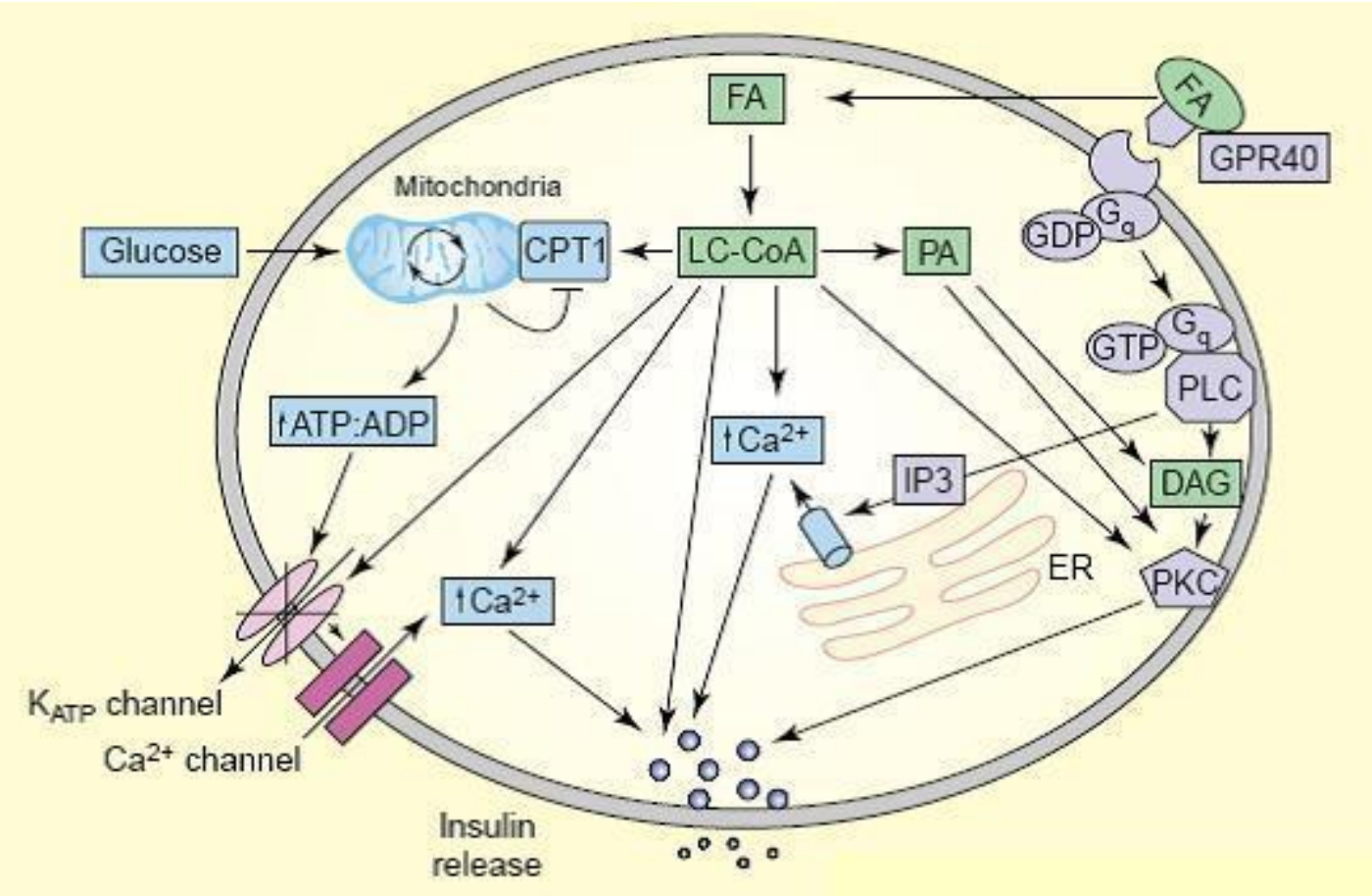

Figura 2. Representação dos mecanismos de secreção de insulina induzidos pelos ácidos graxos (AGs).

Possíveis mecanismos envolvidos na secreção de insulina induzida por ácidos graxos. Através do o metabolismo de AGs na mitocôndria após formação de LC-CoA e entrada na mitocôndria ou através da via GPR40. GPR40 é ativado pelo ácido graxo, estimula $\mathrm{Gq}_{\alpha}-$ PLC - PKC e aumenta $\mathrm{Ca}^{2+}$ intracelular e entrada de $\mathrm{Ca}^{2+}$ por canais sensíveis a voltagem. Fonte: modificada de ${ }^{57}$.

O ácido oléico (C18:1) é um ácido graxo de cadeia longa monoinsaturado (omega-9), tornando-o muito menos susceptível à oxidação do que os ácidos graxos polinsaturados ${ }^{58}$. Junto com o palmitato é um dos mais abundantes no plasma de ratos e humanos e seus efeitos também podem ser mediados via GPR40 ${ }^{59-62}$. Em humanos o oleato e palmitoleato (C16:1) reduzem a apoptose e a citotoxicidade induzida por citocinas e revertem a diminuição da viabilidade celular induzida pelo palmitato em células B e células de câncer de mama ${ }^{63}$. Em cardiomiócitos, onde a alta concentração de AGs também está relacionada com citotoxicidade, o aumento na produção de espécies reativas de oxigênio e apoptose induzidos pelo palmitato pode ser revertido após aumento na oxidação desse ácido graxo quando se coadministra $\mathrm{AO}^{64}$. Coll e colaboradores (2008) também observaram efeito protetor do AO em 
diminuir a resposta inflamatória induzida pelo palmitato em células musculares. A reversão da citotoxicidade gerada pelo palmitato se deve à maior incorporação em triglicérides e aumento da $\beta$-oxidação, que protegem células como linfócitos da citotoxicidade induzida pelos ácidos graxos ${ }^{31,65}$. Como já visto o AO exerce alguns efeitos diferentes de ácidos graxos saturados promovendo muitas vezes proteção frente aos efeitos deletérios de AGs saturados. O AO não foi capaz de provocar respostas significativas em células musculares, por isso alguns autores o denominam como ácido graxo "neutro", pois não induziria efeitos significativos nas células quando não é administrado em a associação com outros ácidos graxos. Porém, em células INS-1 a administração de AO durante 3 dias induziu alterações tais como aumento do consumo de $\mathrm{O}_{2}$, aumento da sua oxidação associada à diminuição da oxidação da glicose e aumento de EROs ${ }^{35,66,67}$.

Apesar de alguns estudos terem estabelecido ações benéficas da exposição crônica ao ácido oléico, poucos trabalhos avaliaram o efeito agudo deste AG na secreção de insulina. Os trabalhos até hoje realizados avaliaram a secreção após infusão com diferentes AGs ou após administração de rica em ácido oléico ${ }^{68-70}$. Apenas avaliações indiretas da funcionalidade da célula $\beta$ foram avaliadas recentemente tais como o influxo de $\mathrm{Ca}^{2+}$ e atividade de canais importantes para a secreção de insulina ${ }^{71,72}$.

\subsection{Espécies Reativas de Oxigênio (EROs)}

Apesar de serem associadas ao desenvolvimento de diversas patologias, as EROs são produzidas fisiologicamente durante o metabolismo celular e cerca de $3-5 \%$ do $\mathrm{O}_{2}$ consumido pela célula sofre redução incompleta formando radical superóxido $\left(\mathrm{O}_{2}{ }^{\bullet-}\right)$ ao invés de $\mathrm{H}_{2} \mathrm{O}$ no fim da cadeia transportadora de elétrons ${ }^{72}$. Portanto, alterações no metabolismo das células frente a diferentes estímulos podem induzir maior ou menor produção de EROs e, consequentemente, alterar a geração de ATP mitocondrial.

Dentre as espécies reativas de oxigênio, ou radicais de oxigênio, amplamente denominadas como pró-oxidantes há espécies radicais, como o ânion superóxido $\left(\mathrm{O}_{2}{ }^{\bullet-}\right)$ e os radicais hidroxila $\left(\mathrm{OH}^{\bullet}\right)$ e espécies não radicais como o peróxido de hidrogênio $\left(\mathrm{H}_{2} \mathrm{O}_{2}\right)$. As espécies radicais apresentam pelo menos um elétron desemparelhado que é capaz de sequestrar um elétron ou átomo de hidrogênio de outra molécula e as espécies não radicais são capazes de gerar novos pró-oxidantes ${ }^{71}$.

Para combater o excesso desses radicais as células apresentam o sistema de defesa antioxidantes (DAs), composto por sequestradores de radicais como as vitaminas $\mathrm{E}$ e $\mathrm{C}$ e a 
glutationa reduzida (GSH); quelantes como a ceruloplasmina e a metalotioneína; e por enzimas antioxidantes como a superóxido dismutase (SOD - CuZn-SOD citoplasmática e MnSOD mitocondrial), a catalase (CAT) e a glutationa peroxidase (GPx) ${ }^{73,74}$. A SOD é uma das mais importantes, pois ao promover a dismutação do $\mathrm{O}_{2}{ }^{\bullet-}$ evita a geração de radicais hidroxila, que é o mais reativo dos radicais. Em ilhotas pancreáticas o aumento na concentração de glicose ativa a SOD, que a partir do superóxido produz $\mathrm{H}_{2} \mathrm{O}_{2}$, um reconhecido sinalizador intracelular ${ }^{71,75}$. A Mn-SOD é muito importante, pois evita a geração de danos às enzimas presentes na mitocôndria.

A produção de espécies reativas de oxigênio na mitocôndria ocorre na cadeia transportadora de elétrons (CTE), na qual agentes redutores como $\mathrm{FADH}_{2}$ e $\mathrm{NADH}$ doam elétrons para o complexo enzimático presente na membrana mitocondrial. Há vários complexos distribuídos em sequencia na membrana mitocondrial dispostos de I a IV. Os elétrons doados pelo NADH entram no complexo I, enquanto a conversão de succinato a fumarato gera elétrons no complexo II. O fluxo de elétrons é direcionado para o intermediário ubiquinona, seguido pela oxidação do ubiquinol pelo complexo III. Os elétrons em seguida são transferidos para a citocromo c, a qual direciona o fluxo para o complexo IV.O complexo $\mathrm{V}$, ou ATP sintase, consiste em uma ATPase responsável pelo acoplamento entre o fluxo de prótons e a conversão de ADP a ATP. Esses complexos recebem elétrons de substratos e transferem prótons para o espaço intermembrana da mitocôndria e produzem uma diferença de potencial $(\Delta \psi)$ que é responsável pela força motriz com energia suficiente para formar ATP a partir de ADP. Porém durante o transporte de elétrons alguns podem "escapar" e reduzir o oxigênio parcialmente formando $\mathrm{O}_{2}^{\bullet-76-78}$.

Quando há produção em excesso de EROs, e/ou expressão ou atividade das enzimas antioxidantes reduzida, associada a danos aos componentes celulares como DNA, proteínas e membranas pode ocorrer estresse oxidativo. Cronicamente, como no diabetes tipo 2, a presença de altas concentrações de glicose e ácidos graxos pode aumentar a produção de EROs, que podem não ser totalmente eliminadas pelas defesas antioxidantes e promover danos à funcionalidade da célula $\beta^{65}$. A inibição da secreção de insulina induzida por ácidos graxos está associada ao aumento de EROs em ilhotas isoladas e "in vivo", pois a administração de antioxidantes como taurina, N-acetilcisteína (NAC) e TPO (mimetiza a SOD) reduz os efeitos de ácidos graxos como oleato ${ }^{79-81}$. A ação deletéria de EROs na célula $\beta$ é comprovada após diminuição de disfunções induzidas por altas concentrações de glicose e ácidos graxos em células $\beta$ após administração de antioxidantes ${ }^{82}$. 
Os ácidos graxos são oxidados na mitocôndria, pela $\beta$-oxidação, e durante esse processo podem ser geradas EROs. A relação entre a oxidação dos ácidos graxos e a produção de EROs é conhecida. Ácidos graxos podem alterar a produção de EROs na mitocôndria ao interagir com subunidades da cadeia transportadora de elétrons; ou ao atuar como desacopladores, dissipando a diferença de potencial na membrana mitocondrial entre outros mecanismos revisto por ${ }^{83}$. A oxidação dos ácidos graxos gera acetil-CoA, que entra no ciclo de Krebs e produz NADH e $\mathrm{FADH}_{2}$, que transferem elétrons principalmente para o complexo II mitocondrial. O aumento excessivo no potencial de membrana mitocondrial pode prejudicar o fluxo normal de elétrons e provocar um fluxo reverso e eventualmente aumentar a produção de EROs. Assim sendo, com o aumento na oxidação dos ácidos graxos a mitocôndria aumenta a respiração, o potencial de membrana e geração de EROs revisto em ${ }^{84}$. No entanto, esse aumento de EROs parece ter função sinalizadora. O ácido oléico, por exemplo, em músculo liso vascular estimula o aumento de EROs via PKC após 5 minutos de estímulo e esse aumento parece estar associado a proliferação e remodelamento vascular ${ }^{85}$.

Apesar da relevante importância da mitocôndria na produção de EROs na maioria das células, em neutrófilos a produção de EROs é dependente da NAD(P)H oxidase. Em células Jurkat e Raiji (linhagens de linfócitos T e B, respectivamente), o aumento de EROs induzido por ácidos graxos de 18 carbonos é mediado pela enzima NAD(P)H oxidase ${ }^{86}$. Similarmente, em células vasculares, o aumento de EROs por altas concentrações de glicose e ácidos graxos ocorre através da ativação da $\mathrm{NAD}(\mathrm{P}) \mathrm{H}$ oxidase ${ }^{87}$.

\subsection{A Enzima NAD(P)H oxidase}

Além da reconhecida importância da mitocôndria como sítio gerador de EROs a $\mathrm{NAD}(\mathrm{P}) \mathrm{H}$ oxidase também apresenta representatividade em diversos tecidos inclusive na célula $\beta$ pancreática ${ }^{88-92}$. Está presente em grande concentração em células de defesa como neutrófilos e linfócitos $\mathrm{B}$ catalisando a redução do oxigênio a superóxido através da doação de um elétron do $\mathrm{NAD}(\mathrm{P}) \mathrm{H}$ como representado no esquema abaixo.

$$
2 \mathrm{O}_{2}+\mathrm{NAD}(\mathrm{P}) \mathrm{H} \rightarrow 2 \mathrm{O}_{2}^{\bullet-}+\mathrm{NAD}(\mathrm{P})^{+}+\mathrm{H}^{+}
$$

Essa enzima é formada por 5 subunidades principais: p40 ${ }^{\text {PHOX }}$, p4 $7^{\text {PHOX }}$, p6 $7^{\text {PHOX }}$, p22 $2^{\text {PHOX }}$ e gp91 ${ }^{\text {PHOX }}$ (ou Nox2). Os três primeiros são citosólicos e os outros dois componentes ( $\mathrm{p} 22^{\text {PHOX }}$ e Nox2) encontram-se na membrana formando o citocromo b558. 
Essas subunidades e seus homólogos já foram caracterizados em ilhotas pancreáticas ${ }^{93} \mathrm{e}$ parecem ter grande importância no diabetes e em condições fisiológicas. A p22 ${ }^{\text {PHOX }}$, por exemplo, tem sua expressão aumentada no diabetes induzido por estreptozotocina ${ }^{87,94}$.

Quando há exposição a um estímulo, o componente citosólico ( $47^{\text {PHOX }}$ ) é fosforilado e o complexo todo migra para a membrana onde se associa ao citocromo b558 ativando enzima (Figura 3). Evidências do conceito de que a p4 $7^{\text {PHOX }}$ deve estar associada à p67 $7^{\text {PHOX }}$ para que migre para a membrana vêm de neutrófilos deficientes em $\mathrm{p} 47^{\text {PHOX }}$, onde a p $67^{\text {PHOX }}$ não pode ser translocada para a membrana após estímulo. A enzima ativada está apta para transferir elétrons do substrato (NADPH) para o oxigênio e reduzi-lo para formação de superóxido $\left(\mathrm{O}_{2}{ }^{\bullet-}\right)$ via Nox2. A ativação requer a participação também das proteínas de baixo peso molecular Rac2 (citoplamática) e Rap1A, localizada na membrana. Durante a ativação a Rac2 se liga ao GTP e junto com todo complexo citoplasmático migra para a membrana para sua associação ao citocromo b558 (Figura 3) ${ }^{90}$.

A Nox2 apresenta dois homólogos recentemente caracterizados na ilhota pancreática, o Nox1 e Nox $4{ }^{95}$. Nox 1 foi o primeiro homólogo de Nox2 caracterizado e os dois apresentam estrutura semelhante. A subunidade Nox4 apresenta menor semelhança com outras Nox e possui apenas 39\% de homologia com a Nox2, o que torna sua ativação diferente de outras Nox. A Nox4 não necessita de subunidades citosólicas, mas só produz de EROs de forma dependente de $\mathrm{p} 22^{\text {PHOX }}$. Alguns estudos demonstraram atividade constitutiva da Nox4 dependente de seu RNA mensageiro (RNAm) e, diferentemente das outras Nox, gera principalmente peróxido de hidrogênio ao invés de superóxido ${ }^{96-98}$.

Os homólogos de $\mathrm{p} 47^{\text {PHOX }}$ e p $67^{\text {PHOX }}$ são, respectivamente Noxo1 e Noxa1. Tanto Noxo1 quanto $\mathrm{p} 47^{\text {PHOX }}$ apresentam domínios SH3, que proporcionam interação com p22 $2^{\text {PHOX }}$. Os domínios $\mathrm{SH} 3$ da $47^{P H O X}$ possuem 2 funções principais: mantêm a conformação em repouso por interações intramoleculares impedindo o contato prematuro desses sítios com o flavocitocromo b558; e contribuem diretamente para interação de sua porção aminoterminal com o p $22^{P H O X}$ e carboxiterminal com o p $67^{P H O X} 97$. O domínio auto-inibitório está ausente na Noxo1, o que implica em ativação constitutiva dessa subunidade. A interação de Nox1 pode ocorrer com $\mathrm{p} 47^{P H O X}$ ou Noxol sugerindo que subunidades citosólicas não são específicas para uma determinada Nox. No entanto, a interação entre Nox1, Noxo1 e Noxa1 ainda não está totalmente esclarecida, pois ainda não foi comprovada atividade constitutiva ou dependência de ativação via $\mathrm{PKC}{ }^{99}$. 


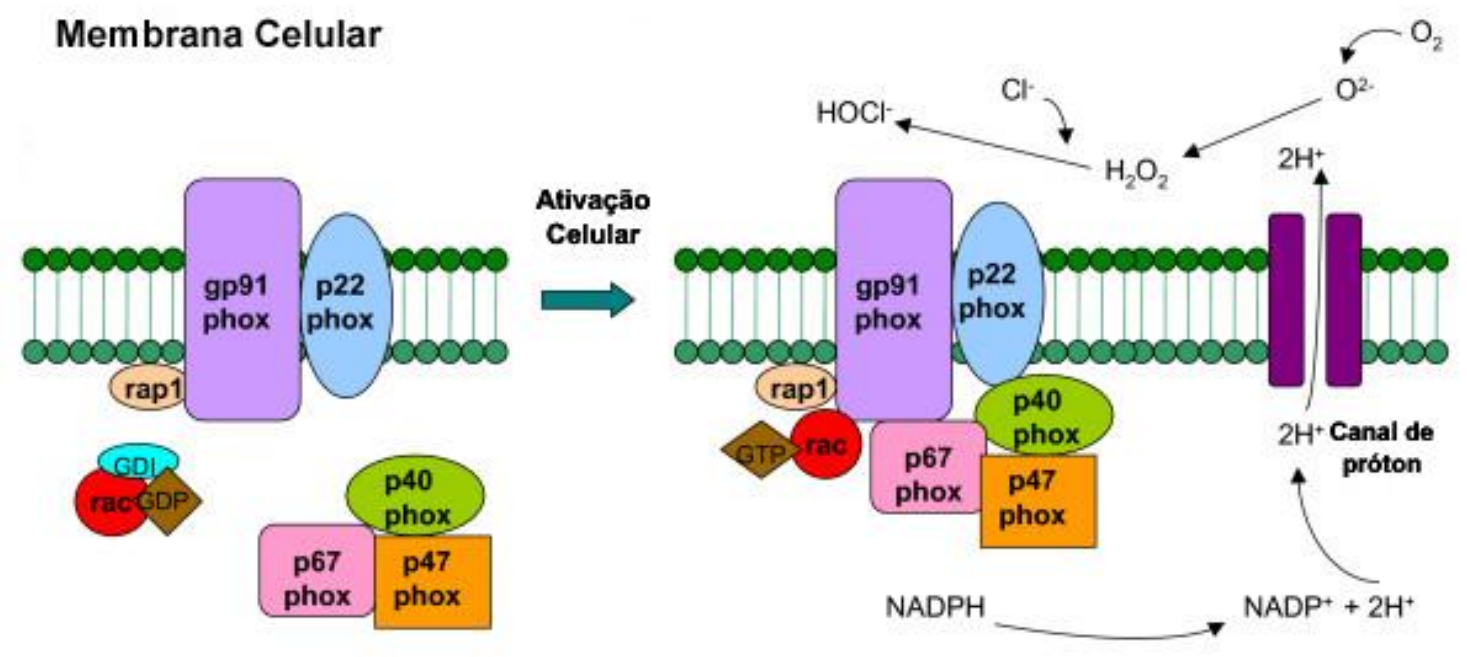

Citosol

Figura 3. Representação da ativação da enzima NAD(P)H oxidase em neutrófilos.

Durante o processo de ativação da enzima $\mathrm{NAD}(\mathrm{P}) \mathrm{H}$ oxidase a subunidade $\mathrm{p} 47^{\text {PHOX }}$ é ativada via fosforilação e migra junto com a p67 $7^{\text {PHOX }}$ e p $40^{P H O X}$ para a membrana, onde se acoplam ao citocromo b558 e promovem a produção do radical ânion superóxido após oxidação do $\mathrm{NAD}(\mathrm{P}) \mathrm{H}$.

A inibição farmacológica da $\mathrm{NAD}(\mathrm{P}) \mathrm{H}$ oxidase reduz a produção de superóxido em macrófagos, que expressam em grande quantidade a enzima ${ }^{91}$. Em ilhotas pancreáticas, tanto a inibição farmacológica quanto a induzida pelo oligonucleotídeo antisense específico para a subunidade $\mathrm{p} 47^{\text {PHOX }}$ da NAD(P)H oxidase diminuíram a produção de superóxido induzida por alta concentração de glicose ${ }^{90-92,100}$. A inibição da NAD(P)H oxidase em ilhotas pancreáticas reduz a secreção de insulina comprovando a participação dessa enzima no processo de secreção de insulina induzido pela glicose ${ }^{86,91,101,102}$. O aumento de glicose e ácidos graxos estimula a produção de EROs através da ativação da NAD(P)H oxidase dependente de PKC e PI3K em células endoteliais, musculares lisas e pancreáticas ${ }^{103}$. Por outro lado, o aumento na atividade da $\mathrm{NAD}(\mathrm{P}) \mathrm{H}$ oxidase e a redução na atividade de algumas enzimas antioxidantes possibilitam aumento de $\mathrm{O}_{2}{ }^{\bullet-}$ e os possíveis efeitos danosos dos EROs ${ }^{104}$.

Em ilhotas pancreáticas a ação do ácido oléico na regulação da produção de EROs e da função celular via NAD(P)H oxidase ainda não foi caracterizada. Porém, o ácido palmítico aumenta a produção de EROs via atividade da $\mathrm{NAD}(\mathrm{P}) \mathrm{H}$ oxidase e dessa forma regula a secreção de insulina em ilhotas pancreáticas ${ }^{105}$. O ácido oléico modula a atividade da PKC em hepatócitos ${ }^{106}$. Em neutrófilos o ácido oléico induz aumento da produção de EROs mediado pela NAD(P)H oxidase ${ }^{107}$. 
O objetivo desse estudo foi avaliar os efeitos das espécies reativas produzidas pela NAD(P)H oxidase na regulação do metabolismo e secreção de insulina após tratamento de ilhotas pancreáticas com ácido oléico. Para tal os objetivos específicos são:

- Avaliar os efeitos do ácido oléico no processo de secreção de insulina após inibição de seu metabolismo em ilhotas pancreáticas isoladas.

- Avaliar os efeitos do ácido oléico na produção de EROs. Em ilhotas pancreáticas isoladas e na linhagem de célula $\beta$ INS-1E.

- Avaliar os efeitos do ácido oléico na produção de EROs, metabolismo da glicose e secreção de insulina após inibição da $\mathrm{NAD}(\mathrm{P}) \mathrm{H}$ oxidase em ilhotas pancreáticas isoladas. 
3 MATERIAIS $\mathcal{E}$ MIÉTODOS 


\subsection{Animais}

O protocolo experimental utilizado no presente estudo foi aprovado pela Comissão de Ética em Experimentação Animal (CEEA) do Instituto de Ciências Biomédicas. Foram utilizadas ratas adultas Wistar com cerca de três meses e $200 \mathrm{~g} \pm 5 \%$ de peso corporal. Foram utilizadas também camundongas CB57L/ 6 "knockout" para a subunidade Nox2 da NAD(P)H oxidase e seus respectivos background. Os animais permaneceram em gaiolas coletivas com temperatura constante de $23 \pm 2{ }^{\circ} \mathrm{C}$ e sob ciclo de iluminação (claro/escuro) de 12/12 horas (acendimento das luzes artificiais às $7 \mathrm{~h}$ ) com livre acesso a água e alimento. Os animais foram fornecidos pelo Biotério do Instituto de Ciências Biomédicas I da Universidade de São Paulo.

\subsection{Isolamento das Ilhotas de Langerhans}

Para obter as ilhotas os animais foram decapitados, esanguinados e submetidos a um banho de álcool a 70\% na região abdominal para a assepsia. Foi realizada uma laparotomia mediana e a exposição do ducto biliar que foi clampeado junto ao duodeno, e dissecado próximo ao pedículo hepático, por onde foi introduzida uma cânula de polietileno e injetada retrogradamente cerca de $15 \mathrm{~mL}$ de solução de Hanks $\left(\mathrm{NaCl} 137 \mathrm{mM}, \mathrm{KCl} 5 \mathrm{mM}, \mathrm{CaCl}_{2}\right.$ $1 \mathrm{mM}, \mathrm{MgSO}_{4} 1 \mathrm{mM}, \mathrm{Na}_{2} \mathrm{HPO}_{4}$ 0,3 mM, $\mathrm{KH}_{2} \mathrm{PO}_{4}$ 0,4 mM, $\mathrm{NaHCO}_{3} 4 \mathrm{mM}$ ), equilibrada com carbogênio - mistura de $\mathrm{O}_{2} / \mathrm{CO}_{2}$ 95:5 V/V), com 5,6 mM de glicose e colagenase $0,7 \mathrm{mg} / \mathrm{mL}$ (Collagenase Type V - Sigma Chemical Co).

A solução flui através dos ductos pancreáticos, provocando a distensão do tecido acinar possibilitado a retirada do pâncreas, que foi colocado em placa de Petri para dissecção de gânglios linfáticos, tecido adiposo e vasos sanguíneos. Posteriormente, o pâncreas foi colocado em tubo FALCON em banho-maria a $37{ }^{\circ} \mathrm{C}$ durante 25 minutos. A seguir foi adicionado $30 \mathrm{~mL}$ de Hancks gelado e o tubo foi agitado durante 30 segundos para auxiliar na digestão da porção exócrina do pâncreas. O produto da digestão foi transferido para um becker contendo solução de Hanks gelada. Após a homogeneização, a mistura foi deixada em repouso por 4 minutos e após este período o sobrenadante foi aspirado. Foram adicionados cerca de $60 \mathrm{~mL}$ de Hanks gelado e novamente a mistura (produto de digestão + solução de Hanks) foi homogeneizada. Este procedimento de lavagem foi repetido de 3 a 4 vezes. Em placa de Petri foi feita a coleta das ilhotas com emprego de lupa e micropipeta. 


\subsection{Tratamento com Ácido Oléico}

Após o isolamento das ilhotas pancreáticas estas foram pré-incubadas em Krebs Hanseleit (KH) ( $\left.\mathrm{NaCl} 115 \mathrm{mM}, \mathrm{KCl} 5 \mathrm{mM}, \mathrm{MgCl}_{2} \cdot 6 \mathrm{H}_{2} \mathrm{O} 1 \mathrm{mM}, \mathrm{CaCl}_{2} .2 \mathrm{H}_{2} \mathrm{O} \mathrm{mM}\right)$ em 0,1\% de albumina (BSA) em concentração basal $(5,6 \mathrm{mM})$ ou alta $(16,7 \mathrm{mM})$ de glicose na presença ou ausência de $100 \mu \mathrm{M}$ de ácido oléico (AO) (Sigma Chemical Co.) O ácido oléico foi diluído em $100 \mu \mathrm{L}$ de etanol e adicionado solução de KH para completar $1000 \mu \mathrm{L}$ (solução estoque de $10 \mathrm{mM}$ ) a fim de se obter no máximo $0,01 \%$ de etanol nas amostras. Para realização dos experimentos foi realizada diluição até $100 \mu \mathrm{M}$ para incubação das ilhotas. $\mathrm{O}$ $\mathrm{KH}$ utilizado para as diluições sempre apresentou $0,1 \%$ de BSA. Em todos os experimentos foram utilizadas as concentrações de 5,6 e 16,7 mM de glicose na presença ou não de ácido oléico.

\subsection{Secreção Estática de Insulina}

Para investigar o efeito do ácido oléico em 5,6 ou 16,7 mM de glicose sobre a secreção de insulina foram utilizados grupos de 5 ilhotas em $500 \mu \mathrm{L}$ de solução de KH para préincubação, durante 30 minutos em $5,6 \mathrm{mM}$ de glicose. Em seguida a solução foi retirada e substituída pelas concentrações de glicose e ácido oléico como descrito no item 3.3. Para investigação do possível envolvimento da oxidação dos ácidos graxos na secreção de insulina mediada pelo ácido oléico as ilhotas foram incubadas na presença do inibidor farmacológico da CPT-1 (enzima responsável pelo transporte dos ácidos graxos para a mitocôndria), o etomoxir $(50 \mu \mathrm{M})$ e o análogo não-metabolizável do oleato (metil-oleato -MAO) (Sigma Aldrich). Para investigar a função da $\mathrm{NAD}(\mathrm{P}) \mathrm{H}$ oxidase foi utilizado o oligonucleotídeo antisense (AS) (IDT) e o RNA de interferência do GPR40 (RNAi-GPR40) (Invitrogen).

Após o período de incubação $400 \mu \mathrm{L}$ do sobrenadante de cada eppendorf foi removido e estocado a $-20{ }^{\circ} \mathrm{C}$ para posterior dosagem de insulina por radioimunoensaio. O conteúdo total de insulina das ilhotas foi obtido após rompimento em sonicador das mesmas 5 ilhotas em $500 \mu \mathrm{L}$ de solução de Álcool/Água/Ácido Clorídrico v: v: v (52: $17: 1)$.

\subsubsection{Dosagem de Insulina}

A determinação da quantidade de insulina secretada foi determinada por radioimunoensaio. Uma solução reagente inclui uma quantidade conhecida de anticorpo, uma 
quantidade conhecida do hormônio marcado radioativamente (insulina marcada com iodo -

${ }^{125}$ I, PerkinElmer, Turku, Finlândia) e uma quantidade desconhecida de hormônio não radioativo (amostra). Como as duas formas do hormônio, radioativos e não-radioativos, competem por um mesmo número de locais de ligação no anticorpo quanto mais hormônio não-radioativo estiver presente, menos o hormônio radioativo irá se ligar. O complexo insulina-anticorpo marcado formado é precipitado com polietilenoglicol (PM 6000) e dosado em contador tipo gama (PerkinElmer, Turku, Finlândia). Uma curva padrão é preparada, na qual a relação ligado/livre para o hormônio radioativo é dada em função da concentração do hormônio não-radioativo. A relação ligado/livre do hormônio radioativo é maior quando menor número de não-radioativo estiver presente. Em seguida, a curva padrão é utilizada para determinar a concentração do hormônio em uma amostra.

\subsection{Avaliação da Expressão Protéica por Western Blotting}

Para avaliar o efeito do ácido oléico em $16,7 \mathrm{mM}$ de glicose no conteúdo protéico foi utilizada a metodologia de Western Blotting, as ilhotas (cerca de 250 - 350 por condição) foram incubadas na presença ou não de ácido oléico como descrito no item 3.3. Foram analisadas as proteínas PKC, GPR40, Nox2 e a $\alpha$-tubulina, que foi utilizada como controle interno.

\subsubsection{Western Blotting}

Nos experimentos de Western Blotting, após a incubação de 1 hora, as ilhotas foram transferidas para um eppendorf e homogeneizadas com sonicador em 70-90uL de tampão de extração para imunoprecipitado, que fornece maior rendimento $(100 \mathrm{mM}$ de Tris $\mathrm{pH} 7,4,100$ $\mathrm{mM}$ de pirofosfato de sódio, $100 \mathrm{mM}$ de fluoreto de sódio, $10 \mathrm{mM}$ de EDTA, $10 \mathrm{mM}$ de ortovanadato de sódio, $2 \mathrm{mM}$ de PMSF, aprotinina $(200 \mu \mathrm{L} / 25 \mathrm{~mL})$ e água deionizada. As amostras foram sonicadas durante 1 minuto a $40 \mathrm{~mA}$. Posteriormente foi adicionado Triton $10 \%$ às amostras, que permaneceram 30 minutos em gelo. As amostras foram centrifugadas a $12000 \mathrm{rpm} \mathrm{a} 4{ }^{\circ} \mathrm{C}$ por $20 \mathrm{~min}$. O sobrenadante foi transferido para outro tubo eppendorf e o precipitado desprezado. A concentração de proteína foi determinada segundo Bradford (1976), utilizando albumina bovina como padrão em espectrofotômetro a $595 \mathrm{~nm}$. Foi adicionado à amostra uma mistura de tampão Laemmli com $200 \mathrm{nM}$ de ditiotreitol (DTT) e 
posteriormente ferveu-se a amostra 5 minutos. Em seguida uma quantidade padronizada de proteína total $(10 \mathrm{a} 60 \mu \mathrm{g})$ foi submetida à eletroforese em gel de poliacrilamida (SDS-PAGE) no aparelho para minigel (Mini-Protean, Bio-Rad), juntamente com marcador de peso molecular.

\subsubsection{Transferência para Membrana de PDVF}

A transferência das proteínas separadas no gel foi realizada eletricamente para uma membrana de PDVF (Millipore), que anteriormente à transferência passou por metanol (15 segundos) e água deionizada (2 minutos). Para transferência foi utilizada uma cuba de transferência (Bio-Rad) contendo tampão de transferência (Tris-base 25 nM, glicina 192 nM, $200 \mathrm{~mL}$ de metanol e água destilada q.s.p. $1000 \mathrm{~mL}$ ) durante 90 minutos a $120 \mathrm{~V}$.

\subsubsection{Ligação aos Anticorpos}

Após a transferência, as membranas foram tratadas com solução bloqueadora contendo $5 \%$ de leite desnatado Molico® diluído em solução basal $(10 \mathrm{~mL}$ de Tris $1 \mathrm{M}, 30 \mathrm{~mL}$ de $\mathrm{NaCl}$ $50 \mathrm{mM}, 500 \mu \mathrm{L}$ de Tween 20 e água destilada q.s.p $1000 \mathrm{~mL}$ ) por 2 horas a temperatura ambiente ou overnight a $4^{\circ} \mathrm{C}$. Após o período de bloqueio as membranas foram lavadas 3 vezes com solução basal e incubadas overnight a $4{ }^{\circ} \mathrm{C}$ com os anticorpos. Os anticorpos utilizados foram anti-GPR40 (Santa Cruz Biotechnology, Santa Cruz, Ca), anti-PKC total (Santa Cruz Biotechnology, Santa Cruz, Ca), anti-gp91 ${ }^{\text {PHOX }}$ (Upstate Biotechnology, CA) e anti- $\alpha$-tubulina (Upstate Biotechnology, CA). As concentrações dos anticorpos utilizadas para western blotting foram 1:500 para anti-GPR40, 1:500 para anti-PKC, 1:1000 para anti-Nox2 e 1:1000 para anti- $\alpha$-tubulina.

Após incubação com o anticorpo específico as membranas foram novamente lavadas com solução basal e incubadas, a temperatura ambiente, com anticorpo secundário anti-IgG marcado com peroxidase. As membranas foram então lavadas com solução basal e reveladas. Para revelação das membranas foi utilizado o kit ECL (Amershan Biosciense) (diluição 1:1 dos reagentes 1 e 2). Após 1 minuto o líquido excedente foi desprezado e as membranas secas e expostas (protegidas da luz) ao filme de raio-X. 


\subsection{Avaliação da Expressão Gênica por PCR em Tempo Real}

Para investigar o efeito do ácido oléico em 5,6 e 16,7 mM de glicose na expressão de genes cerca de 250-350 ilhotas foram incubadas na presença ou não do ácido oléico como descrito no item 3.3. Após 1 hora de incubação foi realizada a extração de RNA pelo método de TRIZOL (Invitrogen).

\subsubsection{Extração do RNA}

O sobrenadante da incubação das ilhotas isoladas foi retirado e desprezado, a seguir foi adicionado $1 \mathrm{~mL}$ do reagente de TRIZOL com posterior homogeneização para romper as células e incubação por 5 minutos a temperatura ambiente, para permitir a completa dissociação dos complexos nucleoprotéicos. Após a incubação foi adicionado $0,2 \mathrm{~mL}$ de clorofórmio para desproteinização. A amostra foi agitada vigorosamente (por aproximadamente 15 segundos) e incubada a temperatura ambiente por 3 minutos. Para a separação de fases, a amostra foi centrifugada a $12000 \mathrm{~g}$ por 15 minutos a $2-8{ }^{\circ} \mathrm{C}$.

Após a centrifugação formaram-se três fases: a superior, aquosa e incolor e que contém o RNA; uma intermediária esbranquiçada que contém DNA e proteína; e uma inferior vermelha e orgânica. A fase aquosa contendo o RNA foi cuidadosamente transferida para outro eppendorf, onde foi adicionado $10 \mu \mathrm{g}$ de glicogênio de ostra tipo II (livre de RNase) para aumentar o rendimento de RNA na preparação. $\mathrm{O}$ isopropanol gelado foi adicionado no mesmo volume retirado de solução de RNA. A amostra foi incubada por 10 minutos a temperatura ambiente e centrifugada a 12000 g por 10 minutos a $4{ }^{\circ} \mathrm{C}$, para promover a sedimentação do RNA precipitado.

Após a precipitação e sedimentação, o sobrenadante foi removido e o sedimento foi lavado com etanol 75\% preparado com água tratada com DEPC (dietilpirocarbonato). Após a adição e a mistura suave do etanol, a amostra foi centrifugada a 7000 g por 5 minutos a $4{ }^{\circ} \mathrm{C}$. Após lavagem e centrifugação, o sobrenadante foi retirado e o sedimento de RNA foi seco a temperatura ambiente. Após secagem o RNA foi dissolvido em água deionizada previamente tratada com DEPC. 


\subsubsection{Quantificação do RNA}

O RNA foi quantificado por leitura espectrofotométrica no comprimento de onda de $260 \mathrm{~nm}$ (diluição 1:125). O grau de pureza do RNA foi determinado pela relação dos valores de leitura da absorbância a 260 e $280 \mathrm{~nm}$ (valores entre 1,5 e 2,0 indicam alto grau de pureza).

\subsubsection{Eletroforese do RNA}

Para determinar a integridade do RNA e provável contaminação com DNA genômico realizamos a eletroforese em gel de agarose (1\%). A agarose foi fundida em água deionizada previamente tratada com DEPC e autoclavada. A seguir, foram adicionadas ao gel 1/10 do volume final de tampão MOPS (MOPS 200mM, NaCl 50 mM, pH 7,0, EDTA 10 mM solução $10 \mathrm{X}$ concentrada), 4\% de formaldeído e brometo de etídio (concentração estoque 10 $\mathrm{mg} / \mathrm{mL}$ ). O gel foi vertido em cuba de eletroforese, e após o resfriamento foi adicionado tampão de corrida contendo MOPS $20 \mathrm{mM}$ (1X) e formaldeído 8\%. As amostras foram preparadas com tampão de amostra $(63 \mu \mathrm{L}$ de água deionizada previamente tratada com DEPC , $81 \mu \mathrm{L}$ de formaldeído, $48 \mu \mathrm{L}$ de glicerol + azul de bromofenol, $48 \mu \mathrm{L}$ de MOPS 10x, $0,5 \mu \mathrm{L}$ de brometo de etídio $10 \mathrm{mg} / \mathrm{mL}$ ). Após este tratamento, as amostras foram aplicadas no gel e realizada a eletroforese (100 V por 60 minutos). Após a separação por eletroforese, a visualização das bandas foi realizada por exposição do gel à luz ultravioleta.

Após a corrida foi avaliado:

- Aparecimento dos RNAs ribossômicos (RNAr) 18S e 28S;

- Degradação do material;

- Contaminação com DNA genômico.

As amostras foram armazenadas em deep freezer $\left(-70{ }^{0} \mathrm{C}\right)$.

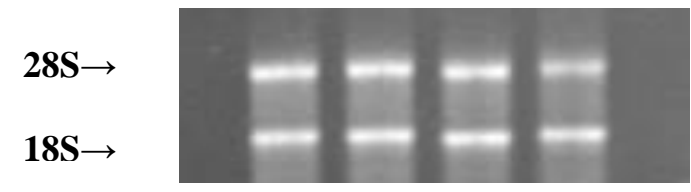

Figura 4. Avaliação da integridade do RNA e contaminação com DNA genômico.

Gel de agarose 1\% mostrando a ausência de contaminação com DNA genômico e degradação do RNA. As bandas são referentes ao RNAr $28 \mathrm{~S}$ e $18 \mathrm{~S}$, aos incubação das ilhotas em (da esquerda para a direita) 5,6 mM, 5,6 mão, 16,7 mM e 16,7 $\mathrm{mM}+\mathrm{AO}$. 


\subsubsection{RT-PCR (“Reverse Transcriptase Polymerase Chain Reaction")}

Para reação de transcrição reversa o cDNA foi obtido a partir do RNA total extraído das amostras de ilhota. A cada tubo foram adicionados: $3 \mu \mathrm{g}$ do RNA total, tampão DNAse 10x e DNAse $(1 \mathrm{U} / \mu \mathrm{L})$. Após incubação de 15 minutos a $25^{\circ} \mathrm{C}$ a DNAse foi inibida com EDTA $(25 \mathrm{mM})$ durante 10 minutos a $65{ }^{\circ} \mathrm{C}$, em seguida foram adicionados primers randômicos $(146 \mathrm{ng} / \mu \mathrm{L})$ e incubados a $70{ }^{\circ} \mathrm{C}$ por 10 minutos. Os reagentes tampão $\mathrm{RT} 5 \mathrm{x}$, DTT (100 mM) e dNTP mix (10 mM) e a enzima Tanscriptase Reversa SuperScript III foram adicionados e as amostras foram incubadas por 10 minutos a $25{ }^{\circ} \mathrm{C}, 52$ minutos a $42^{\circ} \mathrm{C}$ e 15 minutos a $70{ }^{\circ} \mathrm{C}$. A amostras de cDNA foram armazenadas a $-20{ }^{\circ} \mathrm{C}$. A reação foi realizada utilizando termociclador Multicycler PTC-0200 (Mj Research, Inc, Walhan, MA, USA).

\subsubsection{Sequência dos Primers}

A sequência dos primers foi obtida a partir do RNAm obtidos no Genbank dos genes estudados: GPR40 (NM_153304.1), pró-insulina (NM_019129.2), p47 ${ }^{\text {PHOX }}$ (NM_053734.2), Noxo1 (NM_001106986.1), p67 ${ }^{\text {PHOX }}$ (NM_010877.4), Noxa1 (NM_001100171.1), Nox2 (NM_023965.1), Nox1 (NM_053683.1), Nox4 (NM_053524.1), p22 ${ }^{\text {PHOX }}$ (NM_024160.1) e HPRT (hipoxantina fosforibosiltransferase) (NM_012583.2). Após obtenção da sequência de RNAm estas foram colocadas e analisadas pelo programa GeneRunner 3.5C . Em seguida foi utilizado a ferramenta Blast do sítio http://blast.ncbi.nlm.nih.gov/Blast.cgi para verificação da especificidade do primer para o gene em questão. 
Tabela 1 - Sequência dos primers utilizados para reação de PCR em tempo real

\begin{tabular}{|c|c|}
\hline Gene & Sequência dos primers $\left(5^{\prime}-3^{\prime}\right)$ \\
\hline \multirow[t]{2}{*}{ GPR40 } & Sense: TCCTTTGCCACCTGGGACTG \\
\hline & Antisense: CATTCACGGGTATGTTGATGCC \\
\hline \multirow[t]{2}{*}{ Pró-Insulina } & Sense: CAGGTCATTGTTCCAACATGGC \\
\hline & Antisense: ACTTCACGACGGGACTTGGG \\
\hline \multirow[t]{2}{*}{$\mathrm{p} 47^{\text {PHOX }}$} & Sense: CACCTTCATTCGCCACATCGC \\
\hline & Antisense: ACGCTGCCCATCATACCACCTG \\
\hline \multirow[t]{2}{*}{ Noxo1 } & Sense: TGGCAAGTCCAAGACACCCAG \\
\hline & Antisense: CCAGCACACAGAGAAGGCAAAC \\
\hline \multirow[t]{2}{*}{ p67 $7^{\text {PHOX }}$} & Sense: TACACCATCCTGGACAACCTGC \\
\hline & Antisense: TCCTCGCTGGAAGTAAGCCAC \\
\hline \multirow[t]{2}{*}{ Noxa1 } & Sense: GTACTTCAACATGGGCTGCGTG \\
\hline & Antisense: TGGTCACTGCTTGGTCAAATGC \\
\hline \multirow[t]{2}{*}{ Nox2 ou gp91 ${ }^{\text {PHOX }}$} & Sense: GAAGGGATTCAGGATGGAGGTG \\
\hline & Antisense: CTTCACTGGCTGTACCAAAGGG \\
\hline \multirow[t]{2}{*}{ Nox1 } & Sense: CTTCCTCACTGGCTGGGATA \\
\hline & Antisense: CGACAGCATTTGCGCAGGCT \\
\hline \multirow[t]{2}{*}{ Nox4 } & Sense: CCTCTGTCTGCTTGTTTGGCTG \\
\hline & Antisense: GCTAGGGACCTTCTGTGATCCG \\
\hline \multirow[t]{2}{*}{ p22 $2^{\text {PHOX }}$} & Sense: GAGGTCCGCAAGAAGCCAAG \\
\hline & Antisense: GAAACTCAAGCAGGAGCCACTG \\
\hline \multirow[t]{2}{*}{ HPRT } & Sense: GCTGAAGATTTGGAAAAGGTGT \\
\hline & Antisense: ACAGAGGGCCACAATGTGAT \\
\hline
\end{tabular}




\subsubsection{PCR em Tempo Real}

Os ensaios de real-time PCR foram realizados utilizando o cDNA obtido como descrito no item 5.6.4 para genes correspondentes a GPR40, pró-insulina, p47 ${ }^{\text {PHOX }}$, Noxo1, p67 $7^{\text {PHOX }}$, Noxa1, Nox1, Nox2, Nox4 e p22 $2^{\text {PHOX }}$. O HPRT foi utilizado como gene constitutivo e em paralelo aos outros genes, pois não alterou sua expressão nos tratamentos realizados. A expressão dos genes correspondentes foi avaliada por PCR em tempo real utilizando o equipamento ROTOR GENE 6000 (Corbett Research, Mortlake, Australia) e o SYBR GREEN (Invitrogen, Carlsbad, CA, EUA) para quantificação fluométrica. Para tal foi utilizado $1 \mu \mathrm{L}$ de cDNA ao qual foi adicionado $0,5 \mu \mathrm{L}$ de primer sense e $0,5 \mu \mathrm{L}$ de primer anti-sense, $10,5 \mu \mathrm{L}$ de $\mathrm{H}_{2} \mathrm{O}$ deionizada tratada com DEPC e 12,5 $\mu \mathrm{L}$ de SYBR GREEN (Invitrogen $\left.{ }^{\circledR}\right)$.

A quantificação relativa do valor de cada gene alvo foi analisada utilizando o método do CT comparativo ${ }^{108}$. O valor do CT é o número de ciclos calculado onde o sinal de fluorescência emitido está significativamente acima dos níveis basais. Quanto menor o CT significa que foi necessário menor número de ciclos para realizar a amplificação e por isso indica maior expressão do gene (cDNA), que pode variar de acordo com o tratamento realizado. Para tal avaliação quantitativa relativa foi utilizada a seguinte a formula $2^{-\Delta \Delta C T} \mathrm{e}$ quanto maior o valor obtido maior a expressão do gene avaliado em cada tratamento.

Para avaliação da eficácia do HPRT como gene constitutivo foi observado se não havia diferença superior a uma unidade de CT entre cada tratamento e em todos os experimentos realizados essa diferença foi inferior a 1, demonstrando assim a eficiência desse gene para ser utilizado como normalizador.

\subsection{Avaliação do Conteúdo de Superóxido}

O conteúdo de superóxido) foi determinado utilizando o método de fluorescência com diidroetídeo ${ }^{109}$. O Diidroetídeo (DHE) é uma sonda redox-sensível, extensamente usada para detectar a produção intracelular de ânion superóxido. Em estudo por HPLC foi demonstrado que a reação entre o superóxido e o DHE resulta na formação de um produto oxidado e este se intercala às bases de DNA, corando o núcleo com uma fluorescência vermelha ${ }^{24,67}$.

Grupos de 20 ilhotas foram pré-incubadas durante 30 minutos em 5,6 mM glicose e incubadas durante 40 minutos na presença de 5,6 $\mathrm{mM}$ ou $16,7 \mathrm{mM}$ glicose e sob a adição de $100 \mu \mathrm{M}$ de ácido oleíco a $37^{\circ} \mathrm{C}$ em banho-maria sob agitação. Em seguida, as ilhotas foram 
retiradas do banho e adicionou-se a hidroetidina $(1 \mu \mathrm{L} / 100 \mu \mathrm{L})$ numa concentração final de $100 \mu \mathrm{M}$ e incubou-se por 20 minutos a temperatura ambiente. Após a incubação, a solução de incubação foi retirada, as ilhotas foram lavadas em Krebs Henseleit e transferidas para lâminas para cultura (chamber slide system).

A produção da fluorescência foi analisada em microscópio confocal (LSM 510 Aaxiovert 100M - Carl Zeiss; Jena - Germany). Para tanto, as ilhotas foram submetidas à excitação com laser de argônio no comprimento de onda $488 \mathrm{~nm}$, sendo o máximo de emissão capturado no comprimento de $575 \mathrm{~nm}$. A obtenção das imagens foi realizada com uma objetiva de 20x, sendo utilizados parâmetros idênticos entre as amostra de uma mesma sequência experimental. Para a quantificação da fluorescência é feita a projeção das secções e utilizado o programa "Image J. 1.33u" (Wayne Rasband, National Institutes of Health, USA). Os dados são expressos em unidades arbitrárias.

Para os experimentos com a superóxido dismutase permeável à membrana (PEGSOD) as ilhotas foram pré-incubadas durante 1 hora em solução de $\mathrm{KH}$ com 5,6 mM de glicose na presença ou não da PEG-SOD, em seguida as soluções foram trocadas para os estímulos utilizados nos outros experimentos ainda na presença da PEG-SOD por mais 40 minutos (Figura 5). A hidroetidina foi adicionada como já citado anteriormente. 

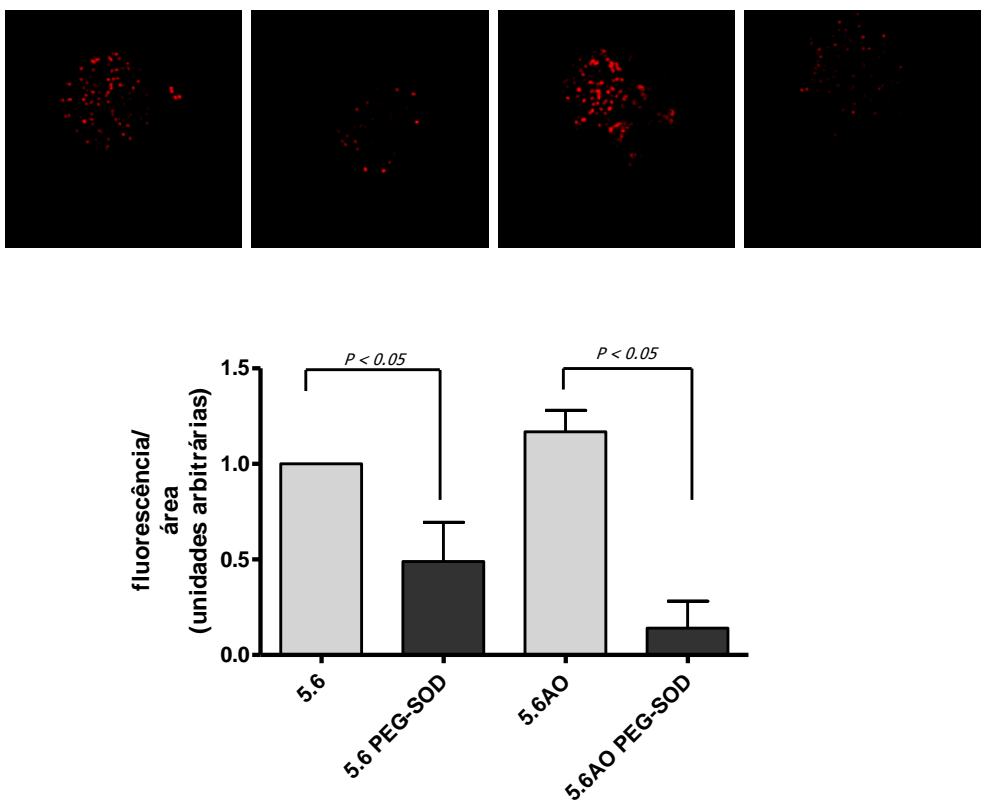

B
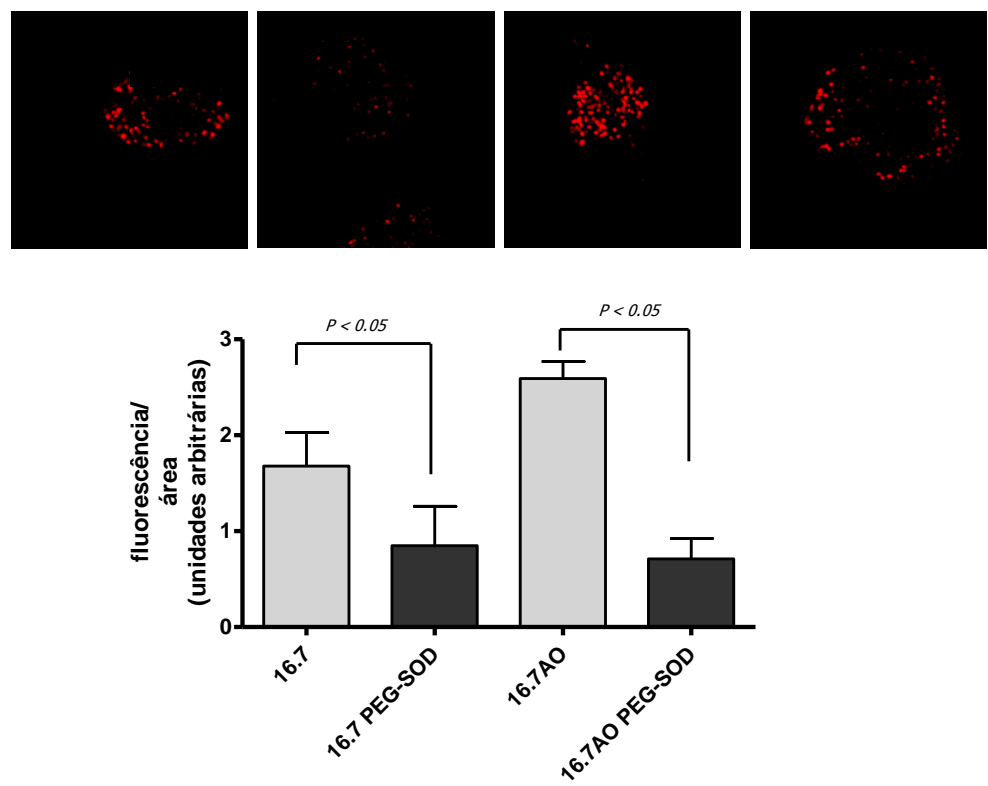

Figura 5. Representação do conteúdo de superóxido após incubação com a PEG-SOD

Avaliação do conteúdo de superóxido de ilhotas pancreáticas isoladas após incubação com SOD permeável à membrana (PEG-SOD). Exposição das ilhotas durante 1 hora a $37^{\circ} \mathrm{C}$ às concentrações de 5,6 mM de glicose na presença ou não de PEG-SOD $(50 \mathrm{U} / \mathrm{mL})$. Em seguida as ilhotas foram incubadas durante 40 minutos na presença de $5,6 \mathrm{mM}$ de glicose (5,6mM), 5,6 mM de glicose e ácido oléico (5,6 mM+AO), 16,7 $\mathrm{mM}$ de glicose $(16,7 \mathrm{mM})$, $16,7 \mathrm{mM}$ de glicose e ácido oléico $(16,7 \mathrm{mM}+\mathrm{AO})$. (A) Avaliação do conteúdo de superóxido na presença de concentração de $5,6 \mathrm{mM}$ de glicose; (B) Avaliação do conteúdo de superóxido na presença de concentração de $16,7 \mathrm{mM}$ de glicose. Os resultados estão expressos como média \pm erro padrão da média $(n=6-8))$. One-way ANOVA, Tukey’s mutiple comparison test. 


\subsection{Metabolismo}

\subsubsection{Metabolismo da Glicose}

A avaliação do metabolismo da glicose em ilhotas expostas ao oleato por $1 \mathrm{~h}$ a $37^{\circ} \mathrm{C}$ foram realizadas pelo método da descarboxilação da glicose. Esse método consiste em administrar no meio de incubação das ilhotas $0,3 \mu \mathrm{Ci} / \mathrm{mL}$ de glicose marcada (U- ${ }^{14} \mathrm{C}$ Glicose) para dosar quanto de ${ }^{14} \mathrm{CO}_{2}$ foi produzido.

Aproximadamente 120 ilhotas foram incubadas em 1,2 mL de solução de $\mathrm{KH}$ nas condições já citadas anteriormente na presença ou não de oleato. Em cada um dos "vials" fechados com tampas de borracha utilizados para incubação das ilhotas foi inserido um eppendorf com papel filtro embebido em $400 \mu \mathrm{L}$ de feniletilamina:metanol (1:1) e permaneceram em banho a $37{ }^{\circ} \mathrm{C}$ durante 1 hora. Para interromper a reação e liberar o $\mathrm{CO}_{2}$ para que esse seja captado pelo papel filtro foi utilizado $400 \mu \mathrm{L}$ de ácido clorídrico sem abrir os "vials". Foram mantidos mais 1 hora em banho a $37^{\circ} \mathrm{C}$ para total liberação do $\mathrm{CO}_{2}$ e foram retirados os papéis de filtro e embebidos em líquido de cintilação. Os dados são obtidos em $\left[{ }^{14} \mathrm{C} \mathrm{CO}_{2}\right]$ pmol/ilhota/hora.

\subsubsection{Metabolismo do Ácido Oléico}

A avaliação do metabolismo do ácido oléico foi realizada da mesma forma que ao da glicose, porém foi utilizado $0,2 \mu \mathrm{Ci}$ de oleato marcado ( $\mathrm{U}_{-}{ }^{14} \mathrm{C}$ Ácido Oléico).

Os grupos analisados foram os expostos às duas concentrações de glicose na presença do ácido oléico. Os dados são obtidos em $\left[{ }^{14} \mathrm{C} \mathrm{CO}_{2}\right]$ pmol/ilhota/hora.

\subsection{Oligonucleotídeo Antisense (AS) para o Componente p47 ${ }^{\text {PHOX }}$ da NAD(P)H oxidase}

O desenho do oligonucleotídeo antisense foi realizado utilizando o programa da empresa Integrated DNA Technologies (IDT). Para isso foi utilizada a sequência do RNA do gene da $47^{\text {PHOX }}$ (GeneID: 114553) e foi obtida uma seqüência de 18 bases específica para a proteína de interesse, pois sequências muito maiores são destruídas ao entrarem na célula. $\mathrm{O}$ antisense utilizado só apresenta homologia com o p $47^{P H O X}$ e a sequência controle negativo ("scrambled" ou sense) não apresenta homologia a qualquer gene conhecido. 
As ilhotas foram isoladas e mantidas durante $4 \mathrm{~h}$ em estufa de $\mathrm{O}_{2} / \mathrm{CO}_{2}(95 / 5 \%)$ a $37{ }^{\circ} \mathrm{C}$ em meio OPTI-MEM com Lipofectamina 2000 e $10 \mathrm{mM}$ de glicose na presença ou ausência do oligonucleotídeo antisense e do "scrambled" ou sense (200 nM para ambos) para o p47 $7^{\text {PHOX }}$. Após $4 \mathrm{~h}$ de transfecção foi adicionado meio RPMI-1640 com $5 \mathrm{mM}$ de glicose e $10 \%$ de soro fetal inativado e as ilhotas foram mantidas durante 20 horas em estufa de $\mathrm{O}_{2} / \mathrm{CO}_{2}$ $(95 / 5 \%)$ a $37{ }^{\circ} \mathrm{C}$.

Tabela 2 - Sequência de oligonucleotídeos antisense e "scrambled" para inibição da subunidade p47 ${ }^{\text {PHOX }}$ da NAD(P)H oxidase

Sequência

$\begin{array}{ll}\text { "Scrambled" ou sense } & 5 \text { ' }- \text { TTT TCC CCC AGG CCC AAT - 3' } \\ \text { Antisense } & 5 \text { ' - CTT CAT TCG CCA CAT CGC - 3' }\end{array}$

Para verificar a efetividade da inibição do $\mathrm{p} 47^{P H O X}$ pelo antisense após o período de incubação as ilhotas foram lavadas em KH e homogeneizadas em tampão de extração de proteínas e as membranas foram incubadas com anticorpo anti-p47 ${ }^{\text {PHOX }}$. Em seguida foi quantificado o conteúdo total da $\mathrm{p} 47^{P H O X}$ e da $\alpha$-tubulina para verificar a alteração de seu conteúdo em relação ao controle (sem oligo) e ao "scrambled" (ou sense).

Todas as avaliações realizadas após incubação com antisense foram realizadas após estímulo com alta concentração de glicose, na presença ou não do ácido oléico, pois os efeitos desse ácido graxo foram observados somente nessa concentração de glicose. Posteriormente à validação do bloqueio da $\mathrm{NAD}(\mathrm{P}) \mathrm{H}$ oxidase pelo antisense foram realizados experimentos para avaliar: conteúdo de superóxido, secreção de insulina e oxidação da glicose como já descritos anteriormente.

\subsection{RNA de Interferência (RNAi) para o Receptor de Ácidos Graxos GPR40}

Para inibição da expressão do receptor de ácidos graxos (GPR40) foi utilizada a metodologia do RNA de interferência (RNAi). O RNAi, o qual só é complementar ao GPR40, e a correspondente sequência "scrambled", a qual não é complemetar a qualquer outra sequência de RNA foram obtidos da Invitrogen, onde já foram pré-validados. O fornecedor 
forneceu 3 sequencias diferentes de RNAi para serem testadas a fim de obter qual a mais efetiva para inibição da expressao do GPR40.

Tabela 3 - Sequência de RNAi testadas para inibição do GPR40

Sequência 1 5'-3':UACAUAGAGAGCGAAGGAGAGCUGU

5'-3’: ACAGCUCUCCUUCGCUCUCUAUCUA

Sequência 2 5'-3': AUUCACGGGUAUGUUGAUGCCCAGG

5'-3’: CCUGGGCAUCAACAUACCCGUGAAU

Sequência 3 5'-3': AAGAGCAGAAUCGAGAAACUGAGUC

5'-3’: GACUCAGUUUCUCGAUUCUGCUCUU

Para a realização da inibição as células B INS-1E foram pré-incubadas durante 7 horas em meio Optimen sem soro com $11 \mathrm{mM}$ de glicose. Após esse período o Optimen foi retirado e as células lavadas com meio RPMI 1640 suplementado com soro fetal bovino (10\%), piruvato de sódio $(1 \mathrm{mM})$, 2-mercaptoetanol $(50 \mu \mathrm{M})$, glutamina $(2 \mathrm{mM})$, HEPES $(10 \mathrm{mM})$, penicillina $(100 \mathrm{U} / \mathrm{mL}) \mathrm{e}$, and estreptomicina $(100 \mu \mathrm{g} / \mathrm{mL})$. Em seguida as células ficaram 48 horas em meio de cultivo completo até a realização de experimentos posteriores. Ao fim das 48h de inibição foi quantificada a porcentagem de inibição obtida em cada sequência testada e a maior redução na expressão do GPR40 foi observada na sequência 2. A partir desse ponto todos os experimentos foram realizados com a sequência "scrambled" e com a sequência 2 do RNAi.

Todas as avaliações realizadas após incubação com RNAi foram realizadas após estímulo com alta concentração de glicose, na presença ou não do ácido oléico, pois os efeitos desse ácido graxo foram observados somente nessa concentração de glicose. Para verificar a efetividade da inibição do GPR40 será utilizada a mesma metodologia para o antisense da p47 $7^{\text {PHOX }}$ descrito no item 3.9. Posteriormente à validação do bloqueio do GPR40 pelo RNAi foram realizados experimentos para avaliar: conteúdo de superóxido e secreção de insulina como já descritos anteriormente na presença de $16,7 \mathrm{mM}$ de glicose. 


\subsection{Análise Estatística}

Os resultados foram apresentados como média \pm erro padrão da média. O intervalo mínimo de significância considerado foi de $95 \%(\mathrm{p}<0,05)$. Para cada sequência experimental as diferenças entre as condições foram determinadas por análise de variância (ANOVA), de uma ou duas vias, seguido de comparações entre as condições pelo pós-teste de Tukeyi, como especificado na legenda da figura. Para sequências experimentais com apenas duas condições, a diferença foi determinada por teste " $\mathrm{t}$ " de student. O programa utilizado para análise estatística foi o Graphpad Prism data analysis and package (v4.03, GraphPad Software, Inc., San Diego, Califórnia, EUA). 
4 RESULTADOS 


\subsection{Avaliação da Ação do Ácido Oléico em Ilhotas Isoladas}

\subsubsection{Secreção Estática de Insulina}

O tratamento das ilhotas pancreáticas durante 1 hora em $\mathrm{KH}(0,1 \%$ de BSA) com 100 $\mu \mathrm{M}$ de ácido oléico (AO) provocou aumento de 50\% na secreção de insulina em 16,7 mM de glicose. $\mathrm{O}$ aumento da secreção de insulina induzido pela alta concentração de glicose foi de três vezes. A fim de investigar se o metabolismo dos ácidos graxos estava mediando o aumento na secreção de insulina foi realizada a inibição da de algumas vias de metabolismo do ácido oléico. A inibição da enzima CPT-1, responsável pelo transporte de ácidos graxos para o interior da mitocôndria para que sejam oxidados, com etomoxir, impediu o aumento da secreção de insulina induzida pelo ácido oléico. O análogo não-metabolizável do ácido oléico (metil-oleato, MAO) também inibiu a resposta de aumento de secreção induzida pelo AO (Figura 6).

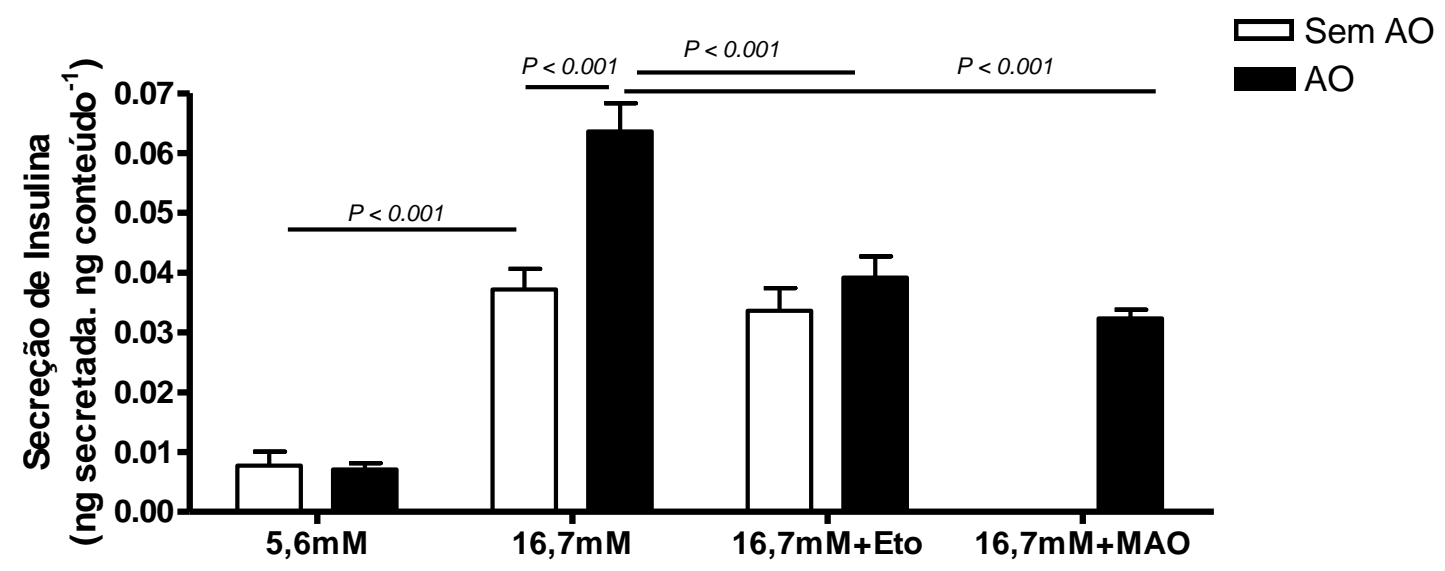

Figura 6. Efeito da glicose e do ácido oléico na secreção de insulina de ilhotas pancreáticas isoladas.

As ilhotas foram mantidas por 1 hora a $37{ }^{\circ} \mathrm{C}$ em $\mathrm{KH}(0,1 \%$ de BSA) na presença de 5,6 $\mathrm{mM}$ ou $16,7 \mathrm{mM}$ de glicose na presença ou não de $\mathrm{AO}(100 \mu \mathrm{M})$. As ilhotas foram préincubadas durante $30 \mathrm{~min} \mathrm{em} \mathrm{5,6} \mathrm{mM} \mathrm{de} \mathrm{glicose} \mathrm{na} \mathrm{presença} \mathrm{ou} \mathrm{não} \mathrm{do} \mathrm{inibidor} \mathrm{de} \mathrm{oxidação}$ de ácidos graxos, etomoxir ( $50 \mu \mathrm{M}$ - Eto), ou do análogo do AO não-metabolizável (metiloleato - MAO). Os resultados estão expressos como média \pm erro padrão da média $(n=6-$ 8). One-way ANOVA, Tukey's mutiple comparison test. 


\subsubsection{Metabolismo da Glicose}

A alta concentração de glicose promoveu aumento em seu metabolismo de aproxiamdamten quatro vezes. A presença do ácido oléico não alterou a oxidação da glicose em 5,6 mM de glicose, porém a reduziu em 50\% em 16,7 mM (Figura 7).

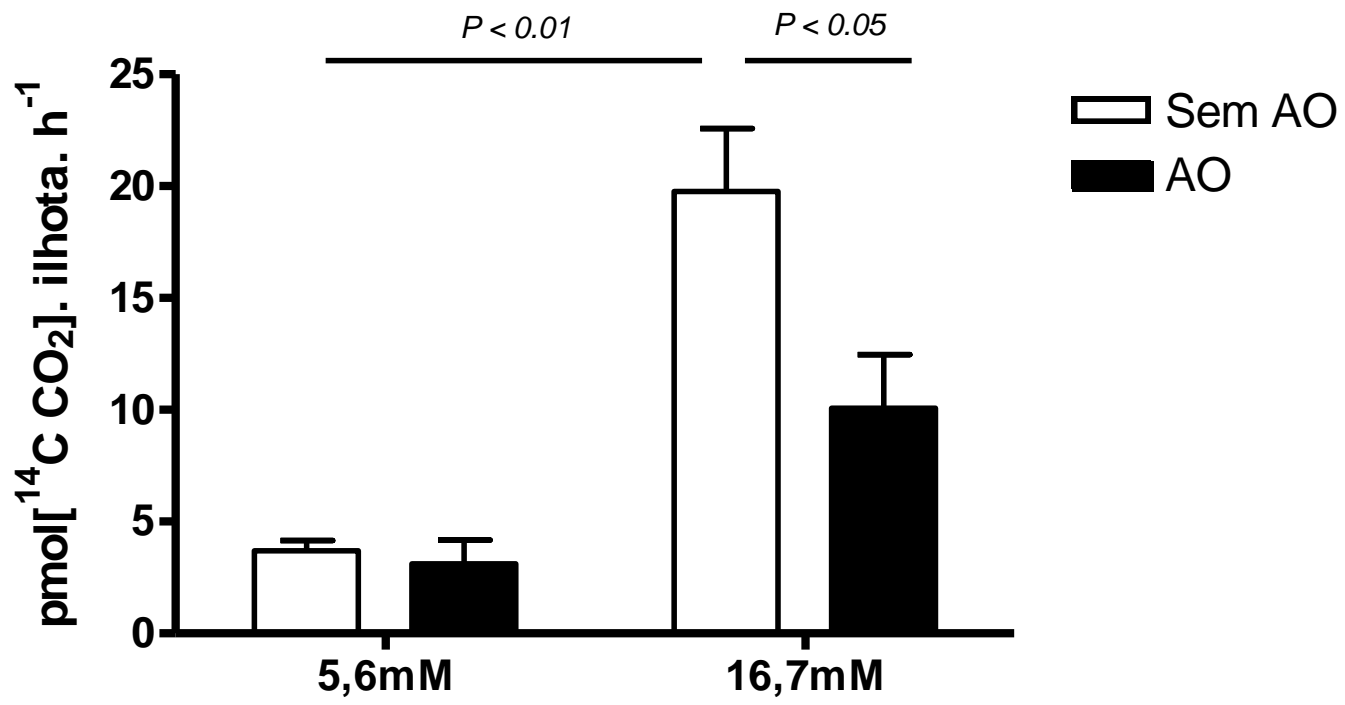

Figura 7. Efeito da presença do ácido oléico na oxidação da glicose em ilhotas pancreáticas isoladas

As ilhotas foram mantidas por $1 \mathrm{~h}$ a $37{ }^{\circ} \mathrm{C}$ em KH $(0,1 \%$ de BSA) na presença de $5,6 \mathrm{mM}$ ou $16,7 \mathrm{mM}$ de glicose na presença ou não de $\mathrm{AO}(100 \mu \mathrm{M})$. Os resultados estão expressos como média \pm erro padrão da média $(n=4-6)$. One-way ANOVA, Tukey's mutiple comparison test. 


\subsubsection{Metabolismo do Ácido Oléico}

Sabendo da importância da oxidação dos ácidos graxos na secreção de insulina induzida pelo AO foi observado aumento do metabolismo do ácido oléico de aproximadamente 3,5 vezes na presença de alta concentração de glicose (Figura 8).

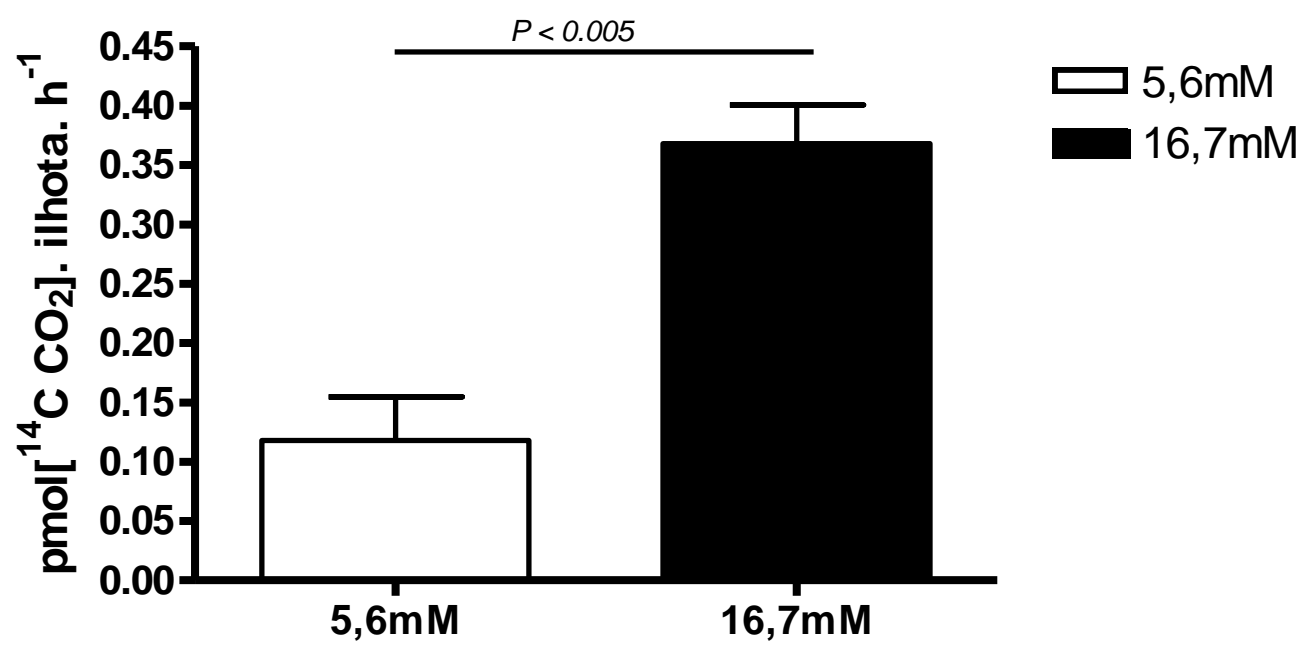

Figura 8. Efeito da alta concentração de glicose na oxidação do ácido oleíco

As ilhotas foram mantidas por $1 \mathrm{~h}$ a $37{ }^{\circ} \mathrm{C}$ em $\mathrm{KH}(0,1 \%$ de BSA) na presença de $5,6 \mathrm{mM}$ ou $16,7 \mathrm{mM}$ de glicose na presença ou não de AO $(100 \mu \mathrm{M})$. Os resultados estão expressos como média \pm erro padrão da média $(n=5)$. Student $t$ test, paired $t$ test. 


\subsubsection{Avaliação do conteúdo de Superóxido}

A presença de ácido oléico induziu aumento no conteúdo de superóxido quando em $16,7 \mathrm{mM}$ de glicose tanto em ilhotas pancreáticas isoladas quanto na linhagem de células B INS-1E (Figura 9).

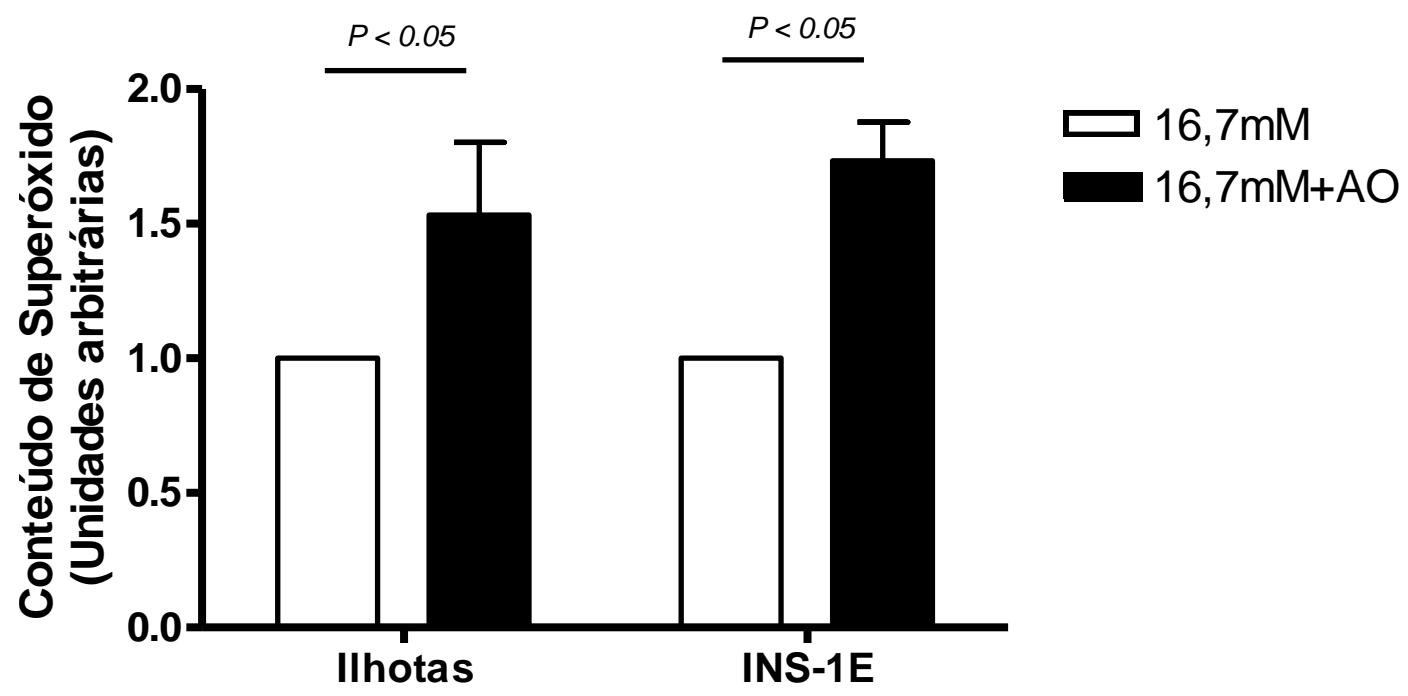

Figura 9. Efeito do ácido oléico no conteúdo de superóxido de ilhotas isoladas e na linhagem de células $\beta$ (INS-1E)

As ilhotas ou células INS-1E foram mantidas por $1 \mathrm{~h}$ a $37{ }^{\circ} \mathrm{C}$ em $\mathrm{KH}(0,1 \%$ de BSA) na presença de $16,7 \mathrm{mM}$ de glicose na presença ou não de $\mathrm{AO}(100 \mu \mathrm{M})$. Os resultados estão expressos como média \pm erro padrão da média $(n=6-8)$. Student $T$ test, paired $t$ test. 
Em células INS-1E, a inibição do metabolismo de ácidos graxos e a utilização do análogo do oleato não-metabolizável (MAO) aboliram o aumento no conteúdo de superóxido induzido pelo AO assim como já observado no item 4.1.1 para secreção de insulina em ilhotas pancreáticas isoladas. A inibição da PKC após incubação com calphostin C novamente aboliu o efeito do ácido oléico em produzir aumento no conteúdo de superóxido em células INS-1E (Figura 10).

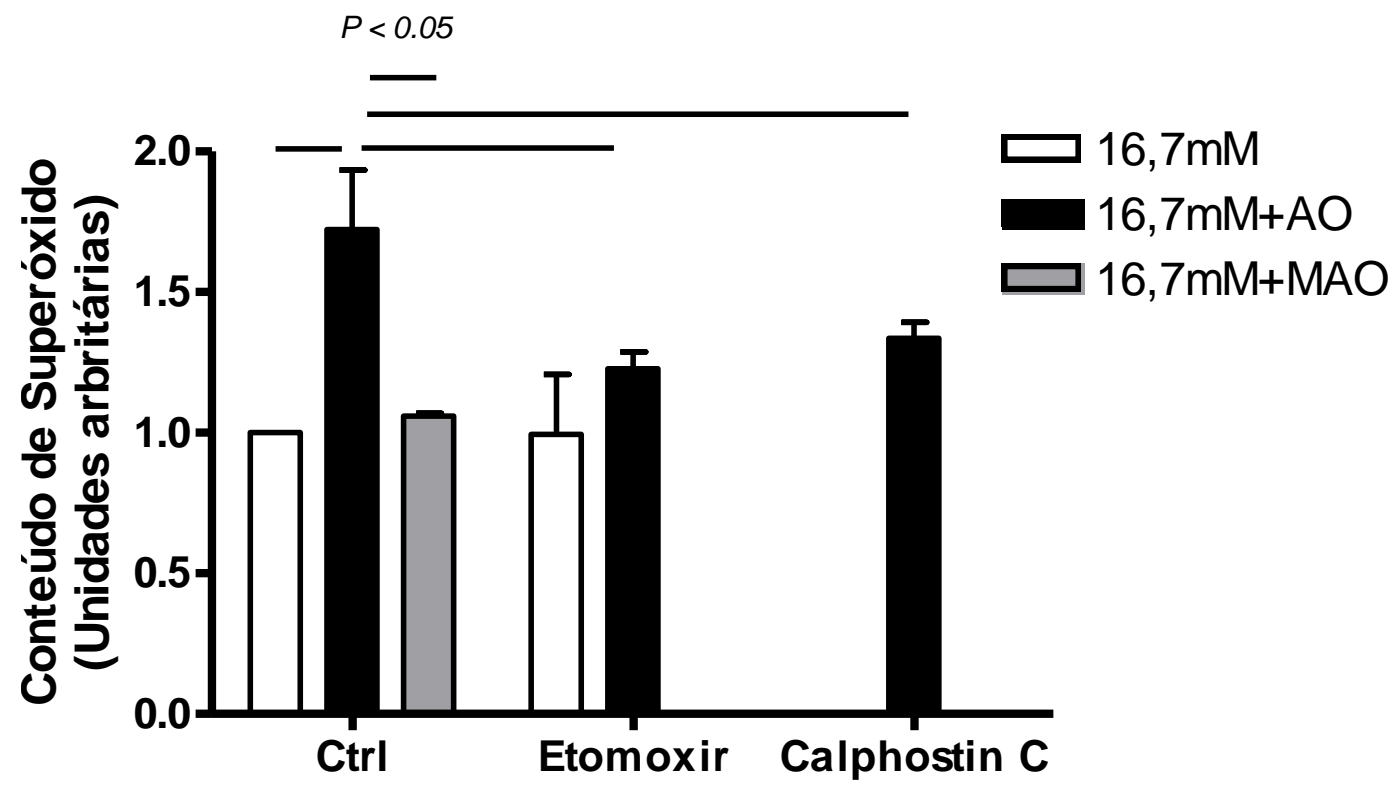

Figura 10. Efeito da inibição da oxidação do ácido oléico e da inibição da PKC no conteúdo de superóxido de células INS-1E

As células INS-1E forma mantidas por 1 hora a $37^{\circ} \mathrm{C}$ em $\mathrm{KH}(0,1 \%$ de BSA) na presença de $16,7 \mathrm{mM}$ de glicose na presença ou não de ácido oleíco $(100 \mu \mathrm{M})$. As céluals INS-1E forma pré-incubadas durante $30 \mathrm{~min}$ em $5,6 \mathrm{mM}$ de glicose na presença ou não do inibidor de oxidação de ácidos graxos, etomoxir (50 $\mu \mathrm{M}$ - Eto), ou do inidor da PKC, calphostin C $(5 \mu \mathrm{M}$ - Calphostin $\mathrm{C})$. Os resultados estão expressos como média \pm erro padrão da média $(\mathrm{n}=4-5)$. One-way ANOVA, Tukey's mutiple comparison test. 


\subsubsection{Avaliação do Conteúdo Protéico}

Como a inibição da PKC aboliu o efeito do ácido oléico em aumentar o conteúdo de superóxido e PKC é uma potente ativadora da $\mathrm{NAD}(\mathrm{P}) \mathrm{H}$ oxidase foi avaliado o conteúdo protéico da PKC e da subunidade Nox 2 da NAD(P)H oxidase. A proteína $\alpha$-tubulina foi utilizada como controle interno e não apresentou alteração em seu conteúdo em qualquer dos experimentos. Para todas as proteínas avaliadas foi realizada uma razão em relação à $\alpha$ tubulina. O conteúdo protéico de GPR40 apresentou-se aumentado na presença de ácido oléico quando comparado a $16,7 \mathrm{mM}$ de glicose. O conteúdo protéico total de PKC e Nox2 também apresentou-se aumentado quando na presença de ácido oléico (Figura 11).

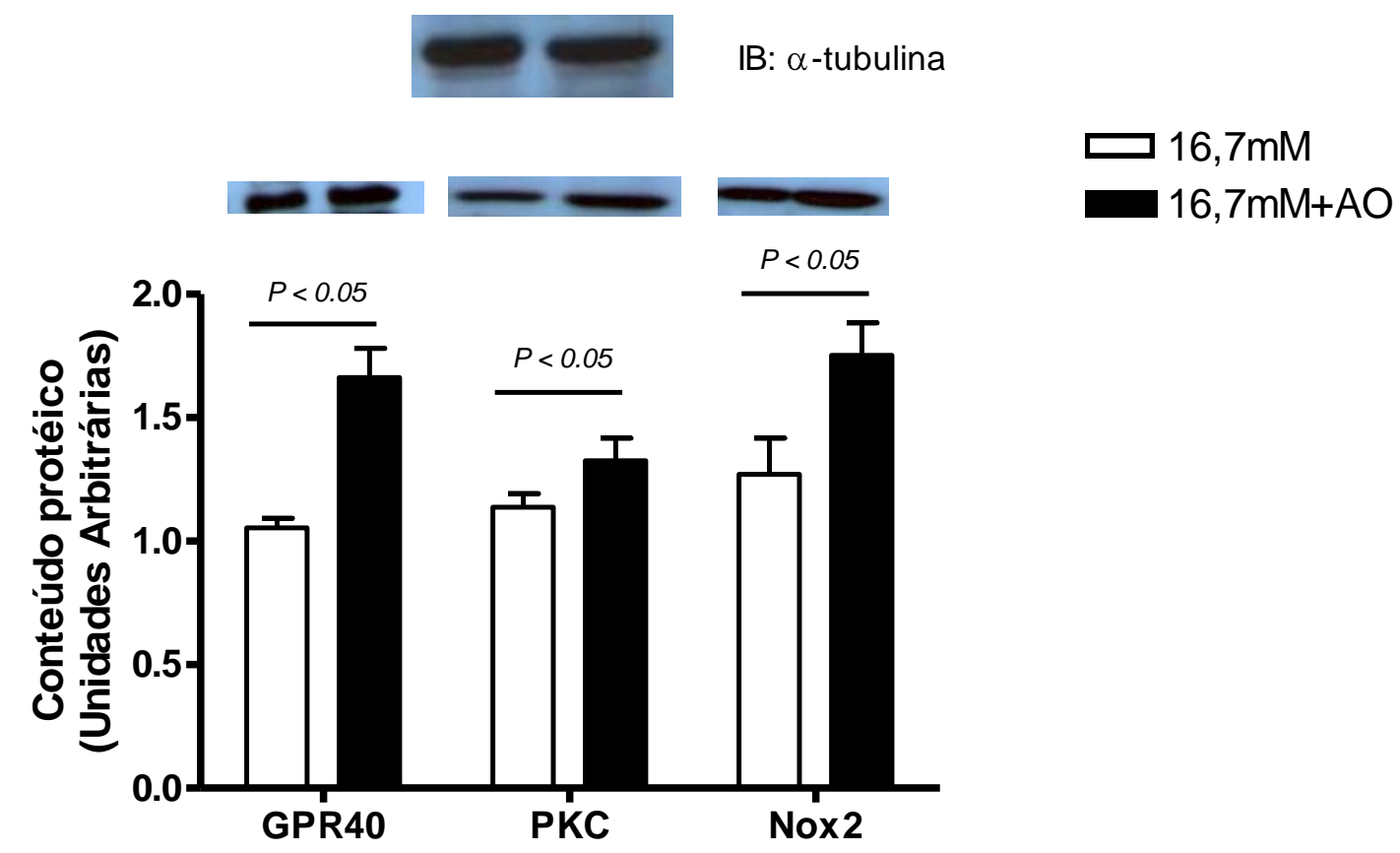

Figura 11. Efeito do ácido oléico no conteúdo protéico de GPR40, PKC e Nox2 de ilhotas pancreáticas isoladas

As ilhotas isoladas foram mantidas por $1 \mathrm{~h}$ a $37{ }^{\circ} \mathrm{C}$ em KH $(0,1 \%$ de BSA) na presença de $16,7 \mathrm{mM}$ de glicose na presença ou não de $\mathrm{AO}(100 \mu \mathrm{M})$. Representação gráfica das proteínas GPR40, PKC, Nox2 após uma hora de exposição a $16,7 \mathrm{mM}$ de glicose na presença ou ausência de $\mathrm{AO}$. Os resultados estão expressos como média \pm erro padrão da média $(\mathrm{n}=3-5)$. One-way ANOVA, Tukey's mutiple comparison test. 


\subsubsection{Avaliação da Expressão Gênica}

O tratamento com $16,7 \mathrm{mM}$ de glicose na presença de AO por $1 \mathrm{~h}$ provocou diminuição na expressão gênica dos genes pró-insulina (60 - 70 \%) e do GPR40 (45 - 55 \%). As subunidades da $\mathrm{NAD}(\mathrm{P}) \mathrm{H}$ oxidase avaliadas não se apresentaram modificadas após tratamento com ácido oléico em ambas concentrações de glicose, com exceção da Nox1 (homólogo da Nox2). A expressão gênica da Nox1 apresentou-se aumentada após tratamento com ácido oléico em ambas as concentrações de glicose (Tabela 1).

Tabela 4 - Quantificação relativa da expressão gênica após exposição ao ácido oléico

\begin{tabular}{|c|c|c|c|c|c|c|c|c|c|c|c|c|}
\hline \multirow{2}{*}{$\mathrm{p47}^{\text {PHOX }}$} & \multicolumn{3}{|c|}{$5,6 \mathrm{mM}$} & \multicolumn{3}{|c|}{$5,6 \mathrm{mM}+\mathrm{AO}$} & \multicolumn{3}{|c|}{$16,7 \mathrm{mM}$} & \multicolumn{3}{|c|}{$16,7 \mathrm{mM}+\mathrm{AO}$} \\
\hline & 1,31 & \pm & 0,34 & 1,65 & \pm & 0,34 & 1,31 & \pm & 0,44 & 1,37 & \pm & 0,39 \\
\hline Noxo1 & 0,95 & \pm & 0,38 & 0,55 & \pm & 0,14 & 0,75 & \pm & 0,09 & 0,39 & \pm & 0,08 \\
\hline $\mathrm{p} 67^{\text {PHOX }}$ & 1,49 & \pm & 0,59 & 1,57 & \pm & 0,39 & 1,27 & \pm & 0,21 & 1,48 & \pm & 0,24 \\
\hline Noxa1 & 0,84 & \pm & 0,13 & 0,83 & \pm & 0,16 & 0,39 & \pm & 0,05 & 0,55 & \pm & 0,09 \\
\hline Nox2 & 0,93 & \pm & 0,36 & 1,42 & \pm & 0,30 & 1,15 & \pm & 0,43 & 0,52 & \pm & 0,25 \\
\hline Nox1 & 0,60 & \pm & 0,15 & 1,45 & \pm & $0,35 * *$ & 0,49 & \pm & 0,22 & 5,82 & \pm & $2,01 * *$ \\
\hline Nox4 & 0,92 & \pm & 0,39 & 1,41 & \pm & $0,08^{*}$ & 1,65 & \pm & 0,53 & 2,99 & \pm & $0,38^{*}$ \\
\hline P22 $2^{\text {PHOX }}$ & 0,96 & \pm & 0,38 & 1,05 & \pm & 0,27 & 0,87 & \pm & 0,16 & 1,24 & \pm & 0,13 \\
\hline $\begin{array}{l}\text { Quan } \\
\text { Nox1 } \\
\text { Expo } \\
\text { glicos } \\
(16,7\end{array}$ & $\begin{array}{l}\text { relat } \\
\text { p22 } \\
\text { ilho } \\
\text { ilo ol } \\
\text { ). Os }\end{array}$ & . & $\begin{array}{l}\text { de ger } \\
\text { HPR } \\
\text { lurant }\end{array}$ & $\begin{array}{l}\text { ón-in } \\
\text { otas } \\
\text { a } 37\end{array}$ & , & $\begin{array}{l}\mathrm{a}, \mathrm{GPR} \\
\text { ceáticas } \\
\text { às conc }\end{array}$ & $\begin{array}{l}7^{\text {PHO }} \\
\text { as p } \\
\text { oes } \\
16 \\
\text { erro }\end{array}$ & 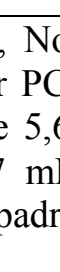 & $\begin{array}{l}\mathrm{xo1} \\
\mathrm{R} \text { en } \\
\mathrm{mM}\end{array}$ & $\begin{array}{l}\text { Nox } \\
\text { real } \\
\text { ose, } 5 \\
\text { e ác } \\
n=5\end{array}$ & $\begin{array}{l}11, \mathrm{~N} \\
=5 \\
6 \mathrm{ml}\end{array}$ & $\begin{array}{l}\text { Jox2, } \\
-9) . \\
\text { M de } \\
\text { léico } \\
\text { One- }\end{array}$ \\
\hline
\end{tabular}




\subsection{Avaliação da Ação do Ácido Oléico via GPR40}

A avaliação da função do GPR40 no processo de secreção de insulina foi realizada utilizando o método do RNA de interferência (RNAi - GPR40) para reduzir a expressão do receptor. Após incubação das células INS-1E durante 48h na presença do RNAi foi observada redução na expressão do receptor GPR40 em 45 - 50\%, o que comprova a eficácia do RNAi em inibir a expressão da proteína (dados não apresentados). A inibição do receptor GPR40 por RNAi não alterou a secreção de insulina induzida pelo ácido oléico. Foi observado aumento na secreção de insulina induzido pelo ácido oléico tanto no grupo "scrambled" quanto no exposto ao RNAi efetivo para o GPR40 (RNAi - GPR40) (Figura 12). Dessa forma, o receptor GPR40 parece não estar envolvido no processo de secreção de insulina induzido pelo ácido oléico.

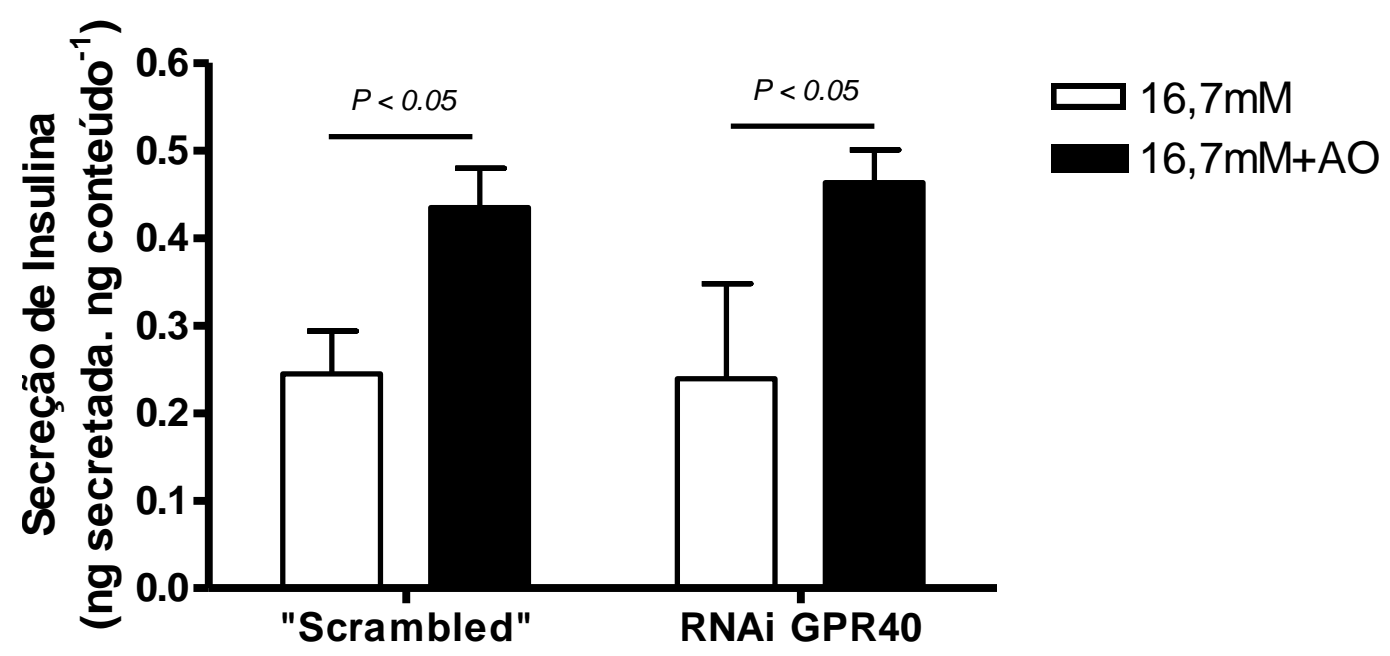

Figura 12. Efeito da inibição do receptor de ácidos graxos GPR40 na secreção de insulina induzida pelo ácido oléico em células $\beta$ INS-1E

Avaliação da secreção de insulina de células INS-1E mantidas durante $48 \mathrm{~h}$ em meio de cultura RPMI- 1640 em estufa de $\mathrm{O}_{2} / \mathrm{CO}_{2}(95 / 5 \%)$ a $37^{\circ} \mathrm{C}$. Exposição das células INS-1E por 1 hora a $37{ }^{\circ} \mathrm{C}$ em $\mathrm{KH}(0,1 \%$ de BSA) à concentração de $16,7 \mathrm{mM}$ de glicose na presença $(16,7 \mathrm{mM}+\mathrm{AO})$ ou ausência $(16,7 \mathrm{mM})$ de ácido oléico $(100 \mu \mathrm{M})$. Previamente as ilhotas foram tratadas com sequência "scrambled" ou RNAi contra GPR40 (RNAiGPR40) durante $48 \mathrm{~h}$. Os resultados estão expressos como média \pm erro padrão da média $(n=5)$. One-way ANOVA, Tukey's mutiple comparison test. 
Devido à possível interação entre a via do GPR40 e a da NAD $(\mathrm{P}) \mathrm{H}$ oxidase através da ação da PKC, que está aumentada em ilhotas pancreáticas expostas ao ácido oléico (Figura 11), investigou-se a possbilidade de indução de aumento do conteúdo de superóxido pelo GPR40. O aumento no conteúdo de superóxido obervado anteriormente em ilhotas e células INS-1E foi mantido no grupo tratado com a sequência "scrambled" do RNAi, comprovando que essa sequência não é capaz de alterar as respostas celulares. Na presença do RNAi (RNAi - GPR40) as céluals INS-1E mantiveram a mesma resposta de aumento no conteúdo de superóxid induzido pelo AO (Figura 13), sugerindo novamente ausência de ativação do receptor por essa concentração de $\mathrm{AO}$.

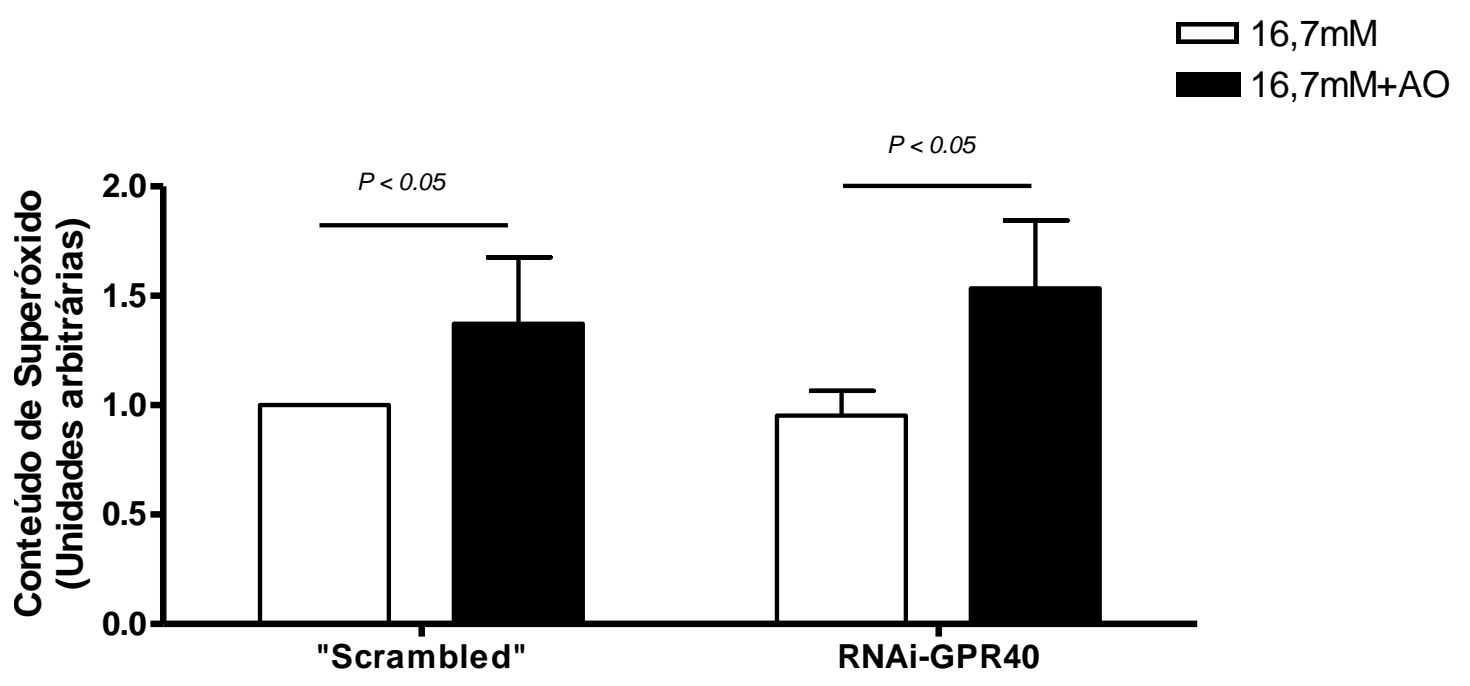

Figura 13. Efeito da inibição do receptor GPRro no conteúdo de superóxido após incubação com ácido oláeico em células $\beta$ INS-1E

Avaliação do conteúdo de superóxido de células INS-1E mantidas durante $48 \mathrm{~h}$ em meio de cultura RPMI-1640 em estufa de $\mathrm{O}_{2} / \mathrm{CO}_{2}(95 / 5 \%)$ a $37{ }^{\circ} \mathrm{C}$. Exposição das células INS$1 \mathrm{E}$ por 1 hora a $37^{\circ} \mathrm{C}$ em $\mathrm{KH}(0,1 \%$ de BSA) à concentração de $16,7 \mathrm{mM}$ de glicose na presença $(16,7 \mathrm{mM}+\mathrm{AO})$ ou ausência $(16,7 \mathrm{mM})$ de ácido oléico $(100 \mu \mathrm{M})$. Previamente as ilhotas foram tratadas com sequência "scrambled" ou RNAi contra GPR40 (RNAiGPR40) durante $48 \mathrm{~h}$. Os resultados estão expressos como média \pm erro padrão da média $(\mathrm{n}=5)$. One-way ANOVA, Tukey's mutiple comparison test. 


\subsection{Avaliação da Ação do Ácido Oléico via NAD(P)H oxidase}

\subsection{1 “Knockdown” da subunidade p47 $7^{P H O X}$ da NAD(P)H oxidase (Oligonucleotídeo antisense $-A S-p 47^{\text {PHOX }}$ )}

Para avaliarmos a ação do ácido oléico na NAD(P)H oxidase foi utilizado o método do oligonucleotídeo antisense, que inibe a tradução das proteínas, para reduzir a expressão da subunidade $\mathrm{p} 47^{P H O X}$ da NAD(P)H oxidase. Após incubação das ilhotas por $24 \mathrm{~h}$ na presença do oligo antisense foi observado redução da expressão da proteína p47 $7^{\text {PHOX }}$ em $60 \%$, o que comprova a eficácia do oligonucleotídeo em inibir a expressão da proteína. Não foi observada diferença entre o grupo incubado sem oligonucleotídeo e com o "scrambled", comprovando que o efeito observado no grupo AS foi gerado pela especificidade de sua seqüência em ligarse ao RNAm da $\mathrm{p} 47^{\text {PHOX }}$ da célula (Figura 14).
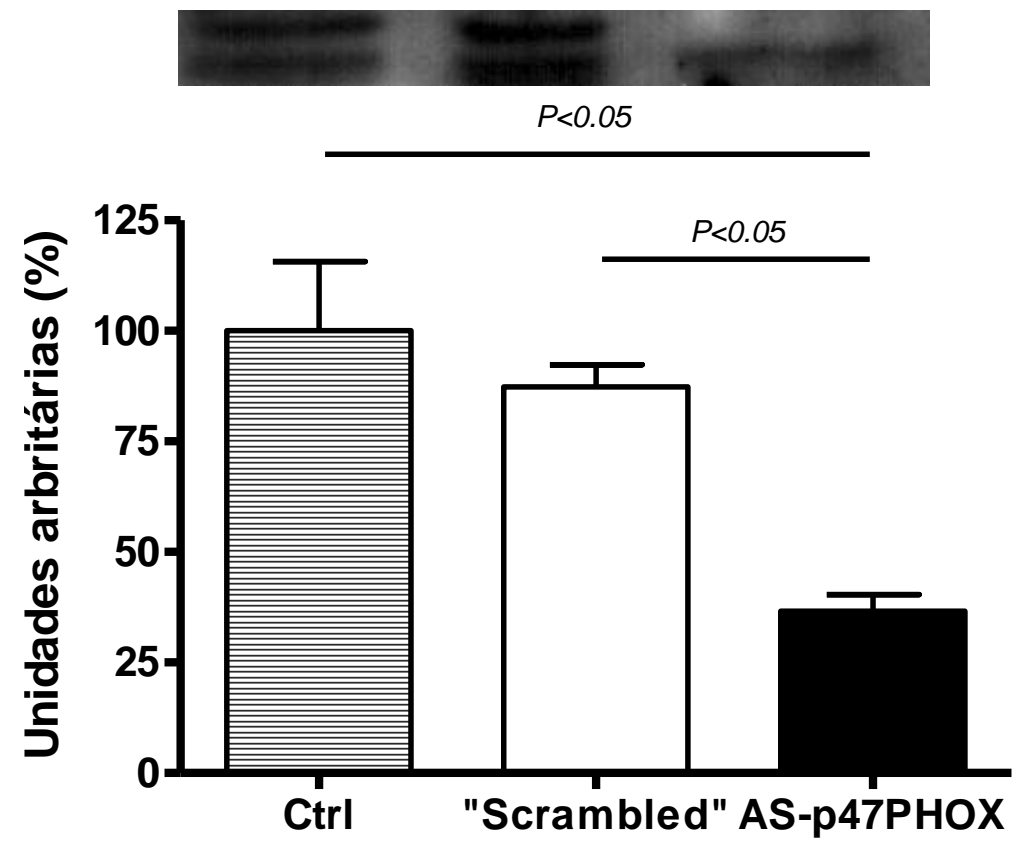

Figura 14. Efeito da transfecção de ilhotas pancreáticas isoladas com oligonucleotídeo antisense

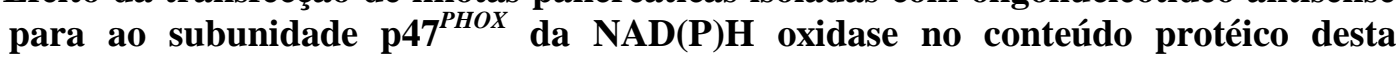
subunidade

Avaliação do conteúdo protéico de $\mathrm{p} 47^{\mathrm{PHOX}}$ de ilhotas pancreáticas isoladas mantidas em meio de cultura RPMI-1640 em estufa de $\mathrm{O}_{2} / \mathrm{CO}_{2}(95 / 5 \%)$ a $37{ }^{\circ} \mathrm{C}$. Os grupos foram previamente mantidos por $24 \mathrm{~h}$ na ausência do oligonucleotídeo (Crtl), na presença do "scrambled" ("Scrambled") e na presença do oligonucleotídeo antisense para a subunidade $\mathrm{p} 47^{\text {PHOX }}$ da NAD(P)H oxidase (AS $-\mathrm{p} 47^{\text {PHOX }}$ ). Os resultados estão expressos como média \pm erro padrão da média $(n=3)$. One-way ANOVA, Tukey's mutiple comparison test. 


\subsubsection{Conteúdo de Superóxido}

O grupo "scrambled" manteve a resposta de aumento no contéudo de superóxido induzida pelo $\mathrm{AO}$. A inibição da enzima $\mathrm{NAD}(\mathrm{P}) \mathrm{H}$ oxidase pelo $\mathrm{AS}$ para a subunidade $\mathrm{p} 47^{\text {PHOX }}$ promoveu redução no conteúdo de superóxido induzido pela alta concentração de glicose superior a $50 \%$. O AS-p $47^{P H O X}$ impediu o aumento no conteúdo de superóxido induzido pelo $\mathrm{AO}$ em $75 \%$, indicando uma possível função da $\mathrm{NAD}(\mathrm{P}) \mathrm{H}$ oxidase na produção de EROs induzida pelo AO (Figura 15).

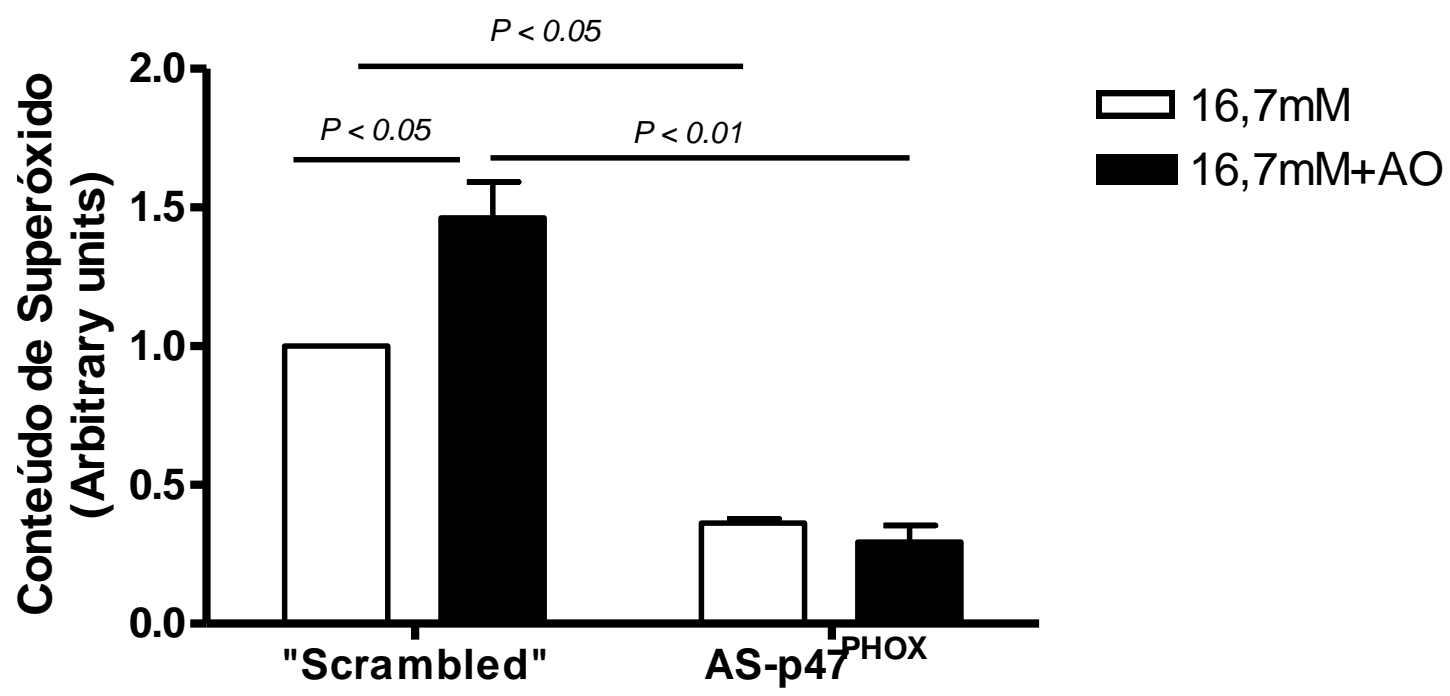

Figura 15. Efeito do ácido oléico no conteúdo de superóxido de ilhotas pancreáticas isoladas após inibição da $\mathrm{p}^{\mathrm{PHOX}}$

Avaliação do conteúdo de superóxido de ilhotas pancreáticas isoladas mantidas em meio de cultura RPMI-1640 em estufa de $\mathrm{O}_{2} / \mathrm{CO}_{2}(95 / 5 \%)$ a $37{ }^{\circ} \mathrm{C}$. Exposição das ilhotas por 1 hora a $37{ }^{\circ} \mathrm{C}$ em $\mathrm{KH}(0,1 \%$ de BSA) à concentração de $16,7 \mathrm{mM}$ de glicose na presença $(16,7 \mathrm{mM}+\mathrm{AO})$ ou ausência $(16,7 \mathrm{mM})$ de ácido oléico $(100 \mu \mathrm{M})$. Os grupos foram previamente mantidos por $24 \mathrm{~h}$ na ausência do oligonucleotídeo (Crtl), na presença do "scrambled" ("Scrambled") e na presença do oligonucleotídeo antisense para a subunidade $\mathrm{p} 47^{\text {PHOX }}$ da NAD(P)H oxidase (AS $-\mathrm{p} 47^{\text {PHOX }}$ ). Os resultados estão expressos como média \pm erro padrão da média $(n=5-8)$. Student $t$ test, paired $t$ test. 


\subsubsection{Secrecão de Insulina}

A inibição da subunidade $\mathrm{p} 47^{P H O X}$ da $\mathrm{NAD}(\mathrm{P}) \mathrm{H}$ oxidase diminuiu a secreção de insulina induzida pela alta concentração de glicose. No entanto, o aumento na secreção de insulina induzido pleo AO foi mantido após inibição da enzima (Figura 16).

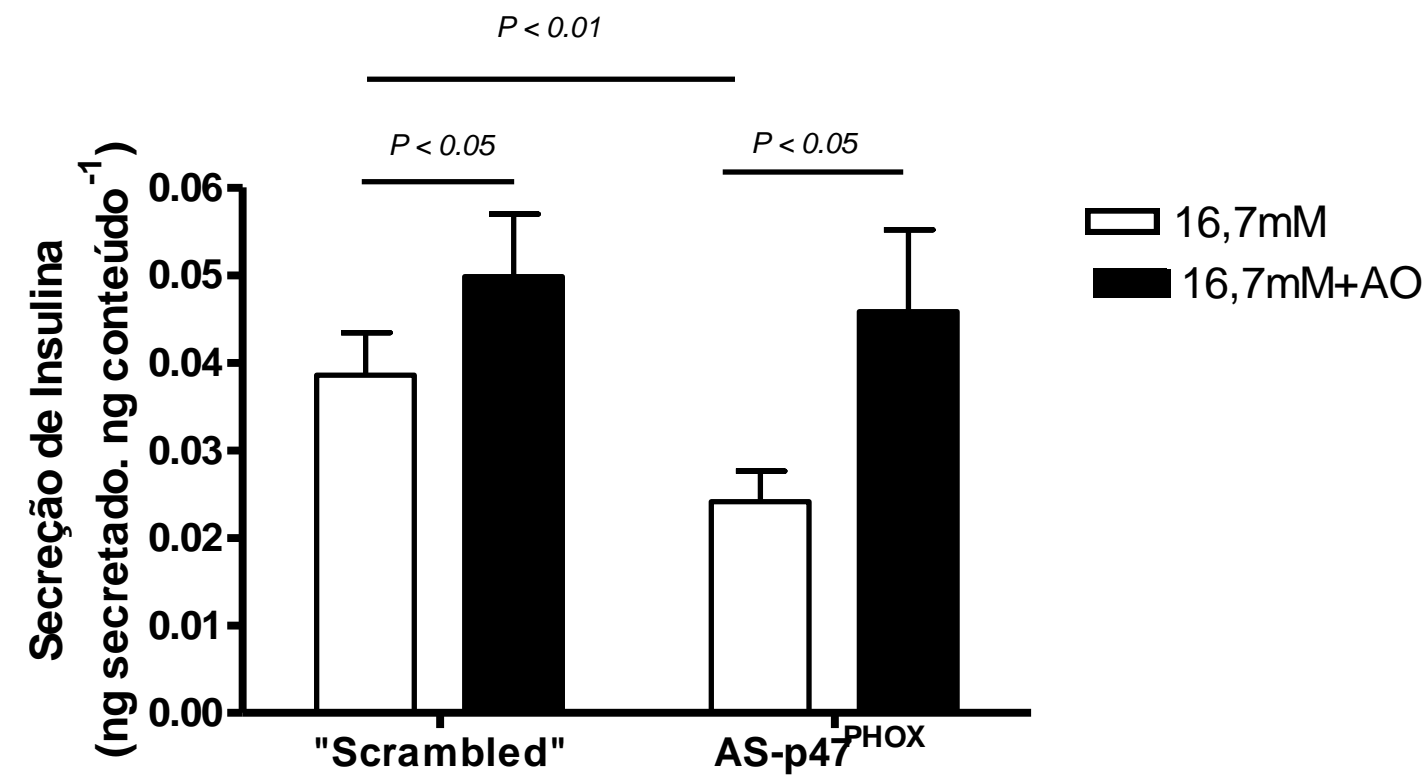

Figura 16. Efeito do ácido oléico na secreção de insulina de ilhotas pancreáticas isoladas após inibição da $\mathrm{p}^{\mathrm{PHOX}}$

Avaliação da secreção de insulina de ilhotas pancreáticas isoladas mantidas em meio de cultura RPMI-1640 em estufa de $\mathrm{O}_{2} / \mathrm{CO}_{2}(95 / 5 \%)$ a $37{ }^{\circ} \mathrm{C}(\mathrm{n}=7-10)$. Exposição das ilhotas por 1 hora a $37{ }^{\circ} \mathrm{C}$ em $\mathrm{KH}(0,1 \%$ de BSA) à concentração de $16,7 \mathrm{mM}$ de glicose na presença $(16,7 \mathrm{mM}+\mathrm{AO})$ ou ausência $(16,7 \mathrm{mM})$ de ácido oléico $(100 \mu \mathrm{M})$. Os grupos foram previamente mantidos por $24 \mathrm{~h}$ na ausência do oligonucleotídeo (Crtl), na presença do "scrambled" ("Scrambled") e na presença do oligonucleotídeo antisense para a subunidade $\mathrm{p} 47^{\text {PHOX }}$ da NAD(P)H oxidase ( $\mathrm{AS}-\mathrm{p} 47^{\text {PHOX }}$ ). Os resultados estão expressos como média \pm erro padrão da média $(n=7-10)$. One-way ANOVA, Tukey's mutiple comparison test. 
Contudo, pode ser observada uma diferença na secreção de insulina entre as ilhotas expostas somente à glicose nos grupos “scrambled" e AS-p 47 ${ }^{\text {PHOX }}$ (Figura 16). Foi calculada a razão (\%) da secreção de insulina dos grupos expostos ao ácido oléico (16,7mM+AO) em relação ao grupos expostos somente à glicose $(16,7 \mathrm{mM})$. Pontanto, se as ilhotas expostas a $16,7 \mathrm{mM}$ de glicose secretassem a mesma quantidade de insulina independentemente da inibição da $\mathrm{NAD}(\mathrm{P}) \mathrm{H}$ oxidase seria observado um aumento na secreção de insulina no grupo 16,7mM+AO em relação ao 16,7 mM após inibição da enzima (Figura 17).

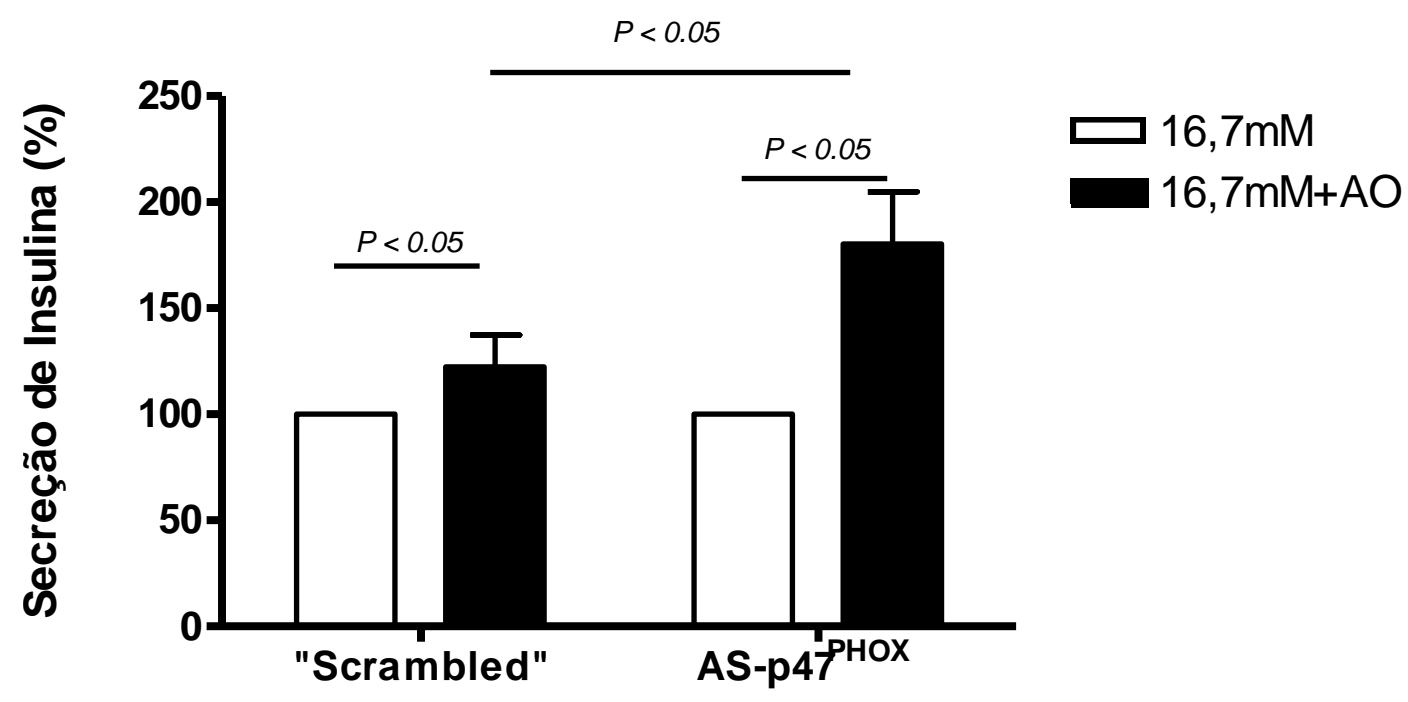

Figura 17. Efeito do ácido oléico na razão de secreção de insulina em ilhotas pancreáticas isoladas após inibição da $\mathbf{p 4}^{7 P H O X}$

Avaliação da razão de secreção de insulina (\%) entre os grupos expostos ao ácido oléico $(16,7 \mathrm{mM}+\mathrm{AO})$ e os grupos expostos somente à glicose $(16,7 \mathrm{mM})$ de ilhotas pancreáticas isoladas mantidas em meio de cultura RPMI-1640 em estufa de $\mathrm{O}_{2} / \mathrm{CO}_{2}(95 / 5 \%)$ a $37^{\circ} \mathrm{C}$ $\left(\mathrm{n}=7\right.$ - 10). Exposição das ilhotas por 1 hora a $37{ }^{\circ} \mathrm{C}$ em KH $(0,1 \%$ de BSA $)$ à concentração de $16,7 \mathrm{mM}$ de glicose na presença $(16,7 \mathrm{mM}+\mathrm{AO})$ ou ausência $(16,7 \mathrm{mM})$ de ácido oléico $(100 \mu \mathrm{M})$. Os grupos foram previamente mantidos por $24 \mathrm{~h}$ na ausência do oligonucleotídeo (Crtl), na presença do "scrambled" ("Scrambled") e na presença do oligonucleotídeo antisense para a subunidade $\mathrm{p} 47^{P H O X}$ da NAD(P)H oxidase (AS $\left.\mathrm{p} 47^{P H O X}\right)$. Os resultados estão expressos como média \pm erro padrão da média $(\mathrm{n}=7-10)$. Student $t$ test, paired $t$ test. 


\subsubsection{Metabolismo da Glicose}

As ilhotas expostas à sequência "scrambled" apresentaram o mesmo padrão de redução na oxidação da glicose já observado em ilhotas frescas (Figura 7). No entanto, o AS $\mathrm{p} 47^{\text {PHOX }}$ da NAD(P)H oxidase promoveu um aumento na oxidação da glicose para níveis semelhantes aos observados em 16,7 mM de glicose nos grupos "scrambled" (Figura 7), assim como observado na secreção de insulina (Figura 18).

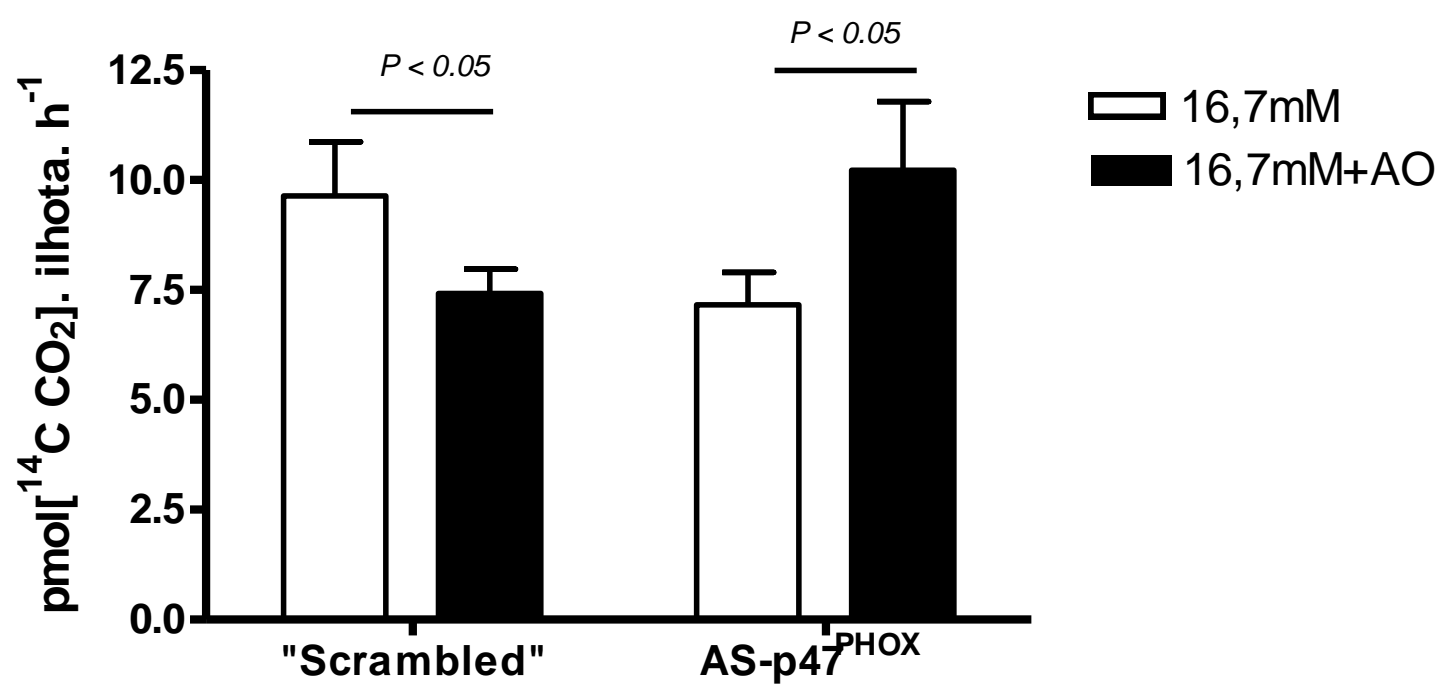

Figura 18. Efeito do ácido oléico na oxidação da glicose em ilhotas pancreáticas isoladas após inibição da $\mathrm{p} 47^{\mathrm{PHOX}}$

Avaliação da oxidação da glicose de ilhotas pancreáticas isoladas mantidas em meio de cultura RPMI-1640 em estufa de $\mathrm{O}_{2} / \mathrm{CO}_{2}(95 / 5 \%)$ a $37{ }^{\circ} \mathrm{C}$. Exposição das ilhotas por 1 hora a $37^{\circ} \mathrm{C}$ em $\mathrm{KH}(0,1 \%$ de $\mathrm{BSA})$ à concentração de $16,7 \mathrm{mM}$ de glicose na presença $(16,7 \mathrm{mM}+\mathrm{AO})$ ou ausência $(16,7 \mathrm{mM})$ de ácido oléico $(100 \mu \mathrm{M})$. Os grupos foram previamente mantidos por $24 \mathrm{~h}$ na ausência do oligonucleotídeo (Crtl), na presença do "scrambled" ("Scrambled") e na presença do oligonucleotídeo antisense para a subunidade $\mathrm{p} 47^{\text {PHOX }}$ da NAD $(\mathrm{P}) \mathrm{H}$ oxidase $\left(\mathrm{AS}-\mathrm{p} 47^{\text {PHOX }}\right.$ ). Os resultados estão expressos como média \pm erro padrão da média $(n=4-5)$. One-way ANOVA, Tukey's mutiple comparison test. 
Assim como observado no item anterior para a secreção de insulina, a oxidação da glicose no grupo exposto ao AS e estimulado com 16,7 mM de glicose apresentou-se reduzida em relação ao grupo "scrambled”. Dessa forma, a relação entre os grupos expostos ao ácido oléico $(16,7 \mathrm{mM}+\mathrm{AO})$ e os grupos expostos somente à glicose $(16,7 \mathrm{mM})$ é maior nas ilhotas que tiveram a NAD(P)H oxidase inibida (Figura 19).

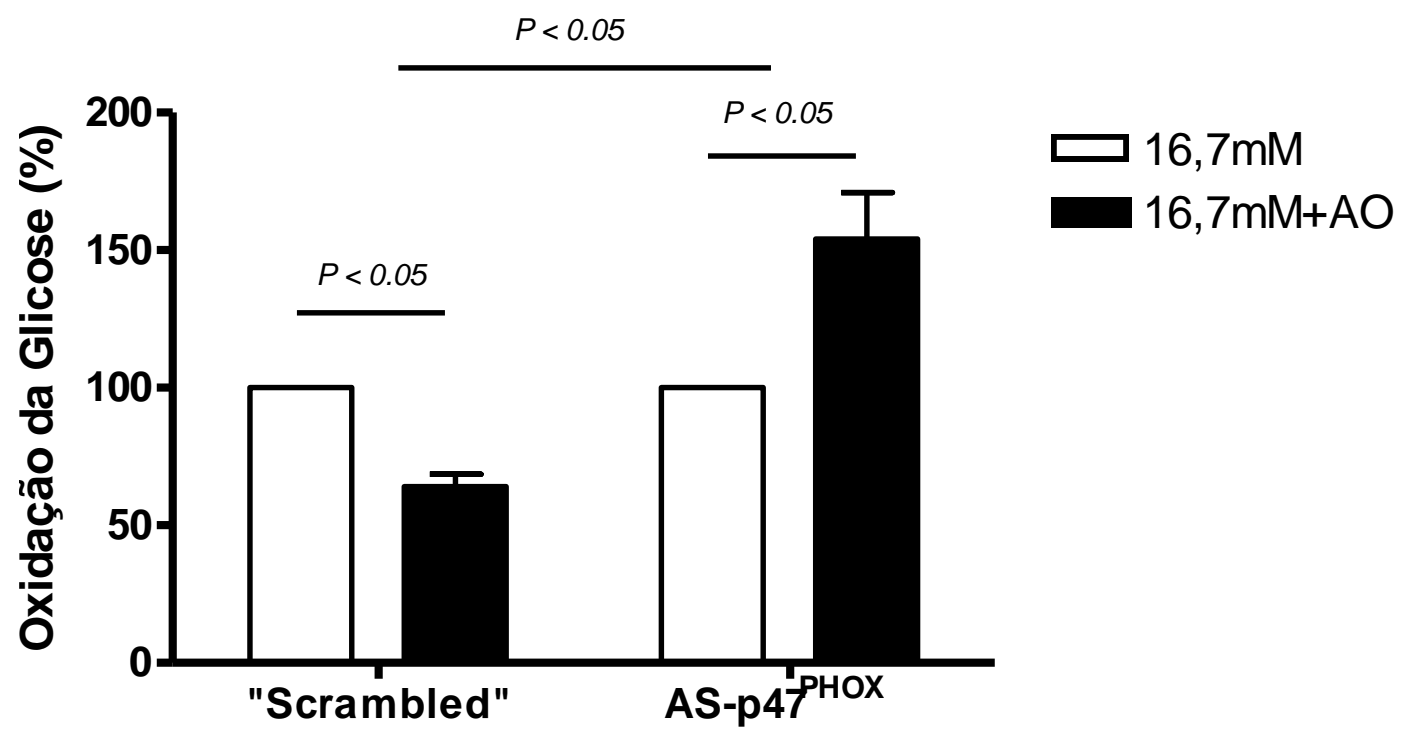

\section{Figura 19. Efeito do ácido oléico na oxidação da glicose em ilhotas pancreáticas isoladas após inibição da $\mathbf{p 4 7} 7^{\mathrm{PHOX}}$}

Avaliação da razão de oxidação da glicose (\%) entre os grupos expostos ao ácido oléico $(16,7 \mathrm{mM}+\mathrm{AO})$ e os grupos expostos somente à glicose $(16,7 \mathrm{mM})$ de ilhotas pancreáticas isoladas mantidas em meio de cultura RPMI-1640 em estufa de $\mathrm{O}_{2} / \mathrm{CO}_{2}(95 / 5 \%)$ a $37^{\circ} \mathrm{C}$. Exposição das ilhotas por 1 hora a $37{ }^{\circ} \mathrm{C}$ em $\mathrm{KH}(0,1 \%$ de BSA) à concentração de 16,7 $\mathrm{mM}$ de glicose na presença $(16,7 \mathrm{mM}+\mathrm{AO})$ ou ausência $(16,7 \mathrm{mM})$ de ácido oléico $(100$ $\mu \mathrm{M})$. Os grupos foram previamente mantidos por $24 \mathrm{~h}$ na ausência do oligonucleotídeo (Crtl), na presença do "scrambled" ("Scrambled") e na presença do oligonucleotídeo antisense para a subunidade $\mathrm{p} 47^{\text {PHOX }}$ da NAD(P)H oxidase (AS $\left.-\mathrm{p} 47^{P H O X}\right)$. Os resultados estão expressos como média \pm erro padrão da média $(n=7-10)$. Student $t$ test, paired $t$ test. 


\subsection{2 “Knockout” da Subunidade Nox2 NAD $(P) H$ oxidase (Nox2 - KO)}

A fim de comprovar a função da $\mathrm{NAD}(\mathrm{P}) \mathrm{H}$ oxidase na função da ilhota pancreática após estímulo com ácido oléico foi utilizada uma linhagem de camundongos $\mathrm{KO}$ para o gene da subunidade Nox2 da NAD(P)H oxidase. Nos camundongos KO para a subunidade Nox2 da $\operatorname{NAD}(\mathrm{P}) \mathrm{H}$ oxidase o ácido oléico não induziu o aumento no conteúdo de superóxido, que foi observado nos animais controle (Ctrl), bem como obervado na figura 15 do item $4.3 .2 \mathrm{em}$ ilhotas com reduzida expressão da subunidade $\mathrm{p} 47^{\text {PHOX }}$ da NAD(P)H oxidase (Figura 20).

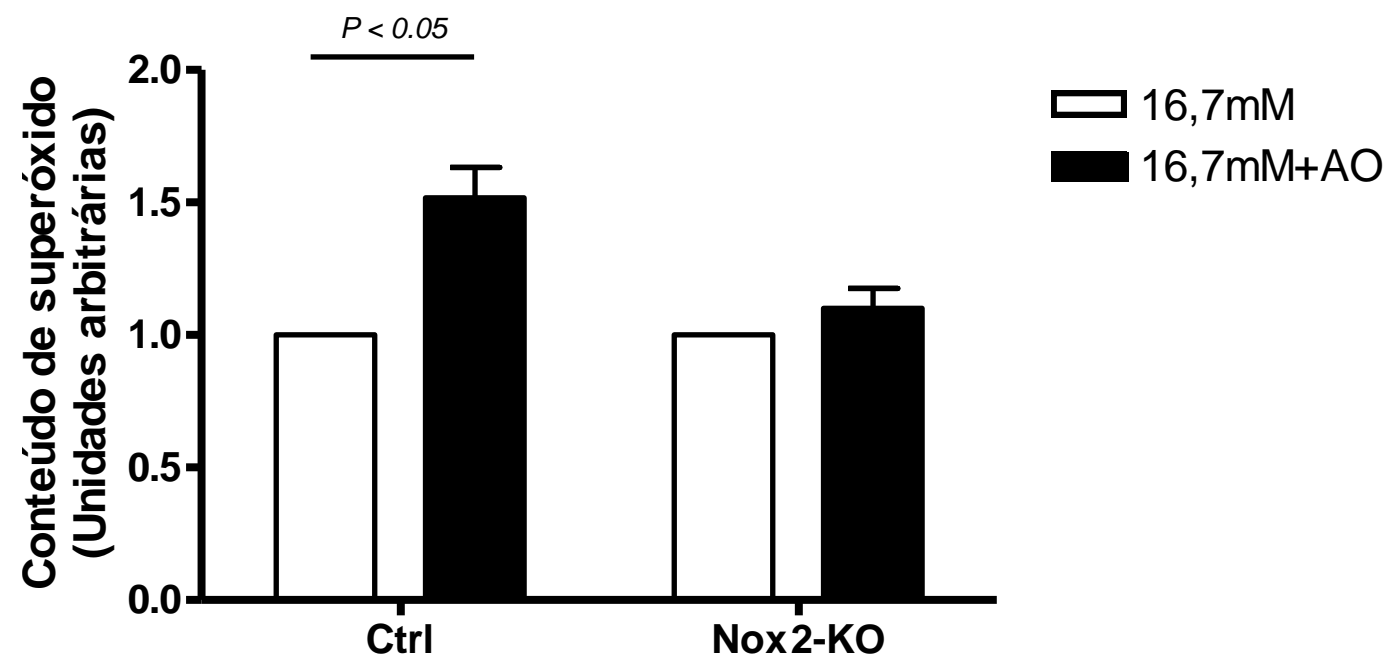

Figura 20. Efeito do ácido oléico no conteúdo de superóxido de ilhotas pancreáticas isoladas de camundongos Nox2-KO

Avaliação do conteúdo de superóxido de ilhotas pancreáticas isoladas de camundongos controle (Ctrl) e "knockout" para a subunidade Nox2 da NAD(P)H oxidase. Exposição das ilhotas por 1 hora a $37{ }^{\circ} \mathrm{C}$ em $\mathrm{KH}(0,1 \%$ de BSA) à concentração de $16,7 \mathrm{mM}$ de glicose na presença $(16,7 \mathrm{mM}+\mathrm{AO})$ ou ausência $(16,7 \mathrm{mM})$ de ácido oléico $(100 \mu \mathrm{M})$. Os resultados estão expressos como média \pm erro padrão da média $(n=3)$. Student $t$ test, paired t test.

A secreção de insulina em $16,7 \mathrm{mM}$ de glicose foi inibida nos animais $\mathrm{KO}$ para a subunidade Nox2 da NAD(P)H oxidase. A secreção de insulina de ilhotas pancreáticas isoladas de camundongos controle apresentou o mesmo padrão de aumento de secreção 
induzido pelo ácido oléico já observado anteriormente em ilhotas de ratas (Figuras 6 e 16). E, corroborando os dados das ilhotas AS-p47 $7^{\text {PHOX }}$, as ilhotas dos camundongos Nox2-KO apresentaram manutenção da secreção de insulina em resposta ao ácido oléico (Figura 21).

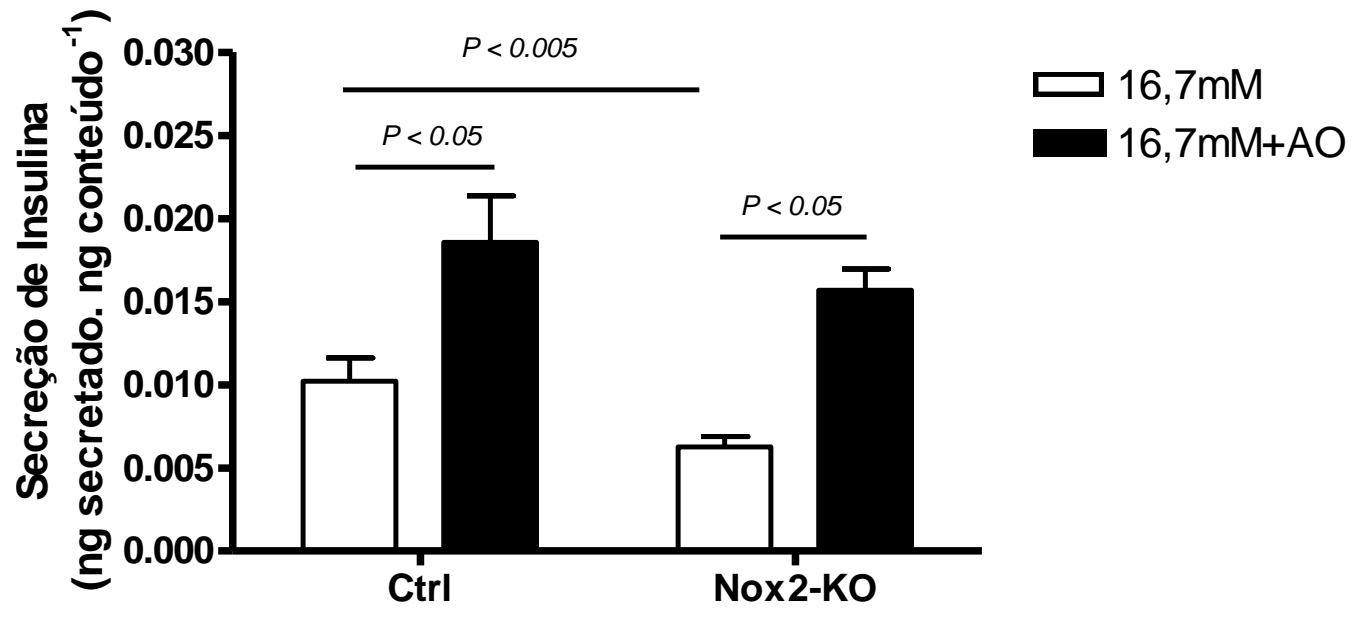

Figura 21. Efeito do ácido oléico na secreção de insulina de ilhotas pancreáticas isoladas de camundongos Nox2-KO

Avaliação da secreção de insulina de ilhotas pancreáticas isoladas de camundongos controle (Ctrl) e "knockout" para a subunidade Nox2 da NAD(P)H oxidase. Exposição das ilhotas por 1 hora a $37{ }^{\circ} \mathrm{C}$ em $\mathrm{KH}(0,1 \%$ de BSA) à concentração de $16,7 \mathrm{mM}$ de glicose na presença $(16,7 \mathrm{mM}+\mathrm{AO})$ ou ausência $(16,7 \mathrm{mM})$ de ácido oléico $(100 \mu \mathrm{M})$. Os resultados estão expressos como média \pm erro padrão da média $(n=4)$. One-way ANOVA, Tukey's mutiple comparison test. 
Da mesma forma ao observado no item 4.3.3, após inibição da $\mathrm{NAD}(\mathrm{P}) \mathrm{H}$ oxidase pelo antisense, os animais Nox2-KO apresentaram redução da secreção de insulina após estímulo somente com glicose. Se todos os animais expostos a $16,7 \mathrm{mM}$ de glicose (ctrl ou KO) apresentassem mesma secreção de insulina, os animais Nox2-KO apresentariam aumento na secreção após exposição ao ácido oléico quando comparados ao grupos controle (ctrl) (Figura 22).

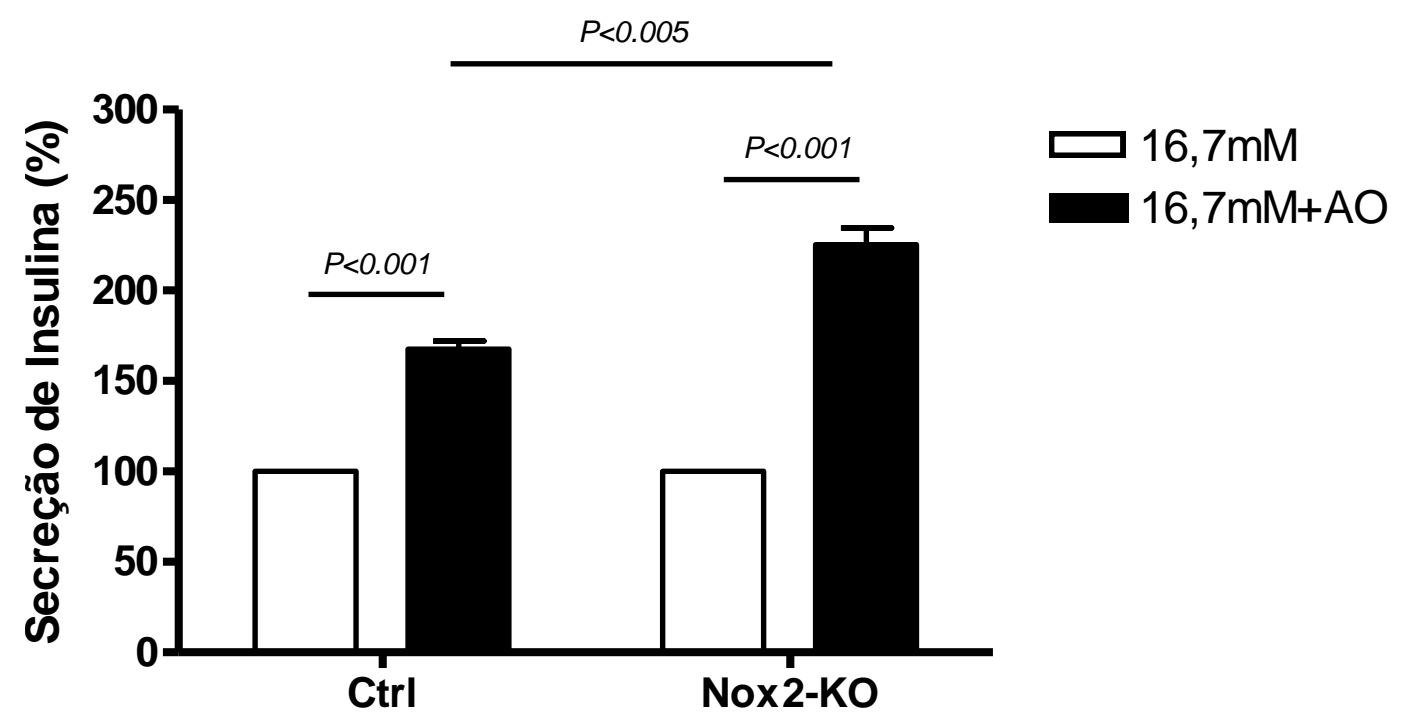

Figura 22. Efeito do ácido oléico na razão de secreção de insulina em ilhotas pancreáticas isoladas de camundongos Nox2-KO

Avaliação da razão de secreção de insulina (\%) entre os grupos expostos ao ácido oléico $(16,7 \mathrm{mM}+\mathrm{AO})$ e os grupos expostos somente à glicose $(16,7 \mathrm{mM})$ de ilhotas pancreáticas isoladas de camundongos controle (Ctrl) e "knockout" para a subunidade Nox2 da $\mathrm{NAD}(\mathrm{P}) \mathrm{H}$ oxidase. Exposição das ilhotas por 1 hora a $37^{\circ} \mathrm{C}$ em $\mathrm{KH}(0,1 \%$ de $\mathrm{BSA})$ à concentração de $16,7 \mathrm{mM}$ de glicose na presença $(16,7 \mathrm{mM}+\mathrm{AO})$ ou ausência $(16,7 \mathrm{mM})$ de ácido oléico $(100 \mu \mathrm{M})$. Os resultados estão expressos como média \pm erro padrão da média $(n=4)$. Student $t$ test, paired $t$ test. 
5 DISCUSS ̃̃O 
O principal nutriente estimulador da secreção de insulina em ilhotas pancreáticas é a glicose. O estímulo de secreção de insulina induzido pela glicose é gerado após o metabolismo da mesma e geração de ATP, que promove o fechamento de canais $\mathrm{K}_{\mathrm{ATP}}$ e a abertura de canais de cálcio. Os canais de cálcio permitem a entrada desses íons, que induzem a secreção por ativação de diversas proteínas intracelulares e ligação a moléculas responsáveis pelo atracamento dos grânulos de insulina à membrana. Além da glicose, outros nutrientes como aminoácidos e ácidos graxos também são capazes de modular a secreção de insulina. Sabe-se que ácidos graxos podem induzir efeitos estimulatórios ou inbitórios na secreção de insulina de forma dependente da concentração e do tempo de exposição. Entretanto, os mecanismos pelo quais AGs exercem seus efeitos na célula B ainda não estão totalmente esclarecidos. Dois dos mecanismos envolvidos podem ser a regulação do metabolismo após a entrada dos AGs na célula ou a ligação a receptores acoplados a proteínas $\mathrm{G}$ específicos para AGs, como o GPR40, que é estimulado por ácidos graxos de cadeia média e longa.

A ação aguda do ácido oleico foi pouco investigada e os estudos já realizados utilizam concentrações mais elevadas de ácido oléico que as encontradas no plasma de ratos e humanos ${ }^{110}$. O aumento na secreção de insulina induzido pelo ácido oléico somente na presença de alta concentração de glicose (Figura 6) demonstra a importância de concentrações fisiológicas $(0,07 \mathrm{mM}-0,4 \mathrm{mM})^{111-113}$ de ácido oléico no processo de secreção de insulina induzido pela glicose. Esse efeito já foi bem caratcterizado para outros ácidos graxos, como o palmitíco, que é saturado ${ }^{25,114}$.

Alterações nas vias metabólicas envolvidas na geração de ATP podem alterar a secreção de insulina. A administração crônica de AGs, que pode induzir acúmulo de LC-CoA, promove regulação do metabolismo da glicose em diversos tecidos ${ }^{115}$. Em geral, cronicamente a alta concentração de glicose pode inibir a oxidação de ácidos graxos como palmitato ${ }^{63}$. A utilização do etomoxir, inibidor da CPT-1, enzima responsável pelo transporte de LC-CoA para o interiror da mitocôndria para sua posterior $\beta$-oxidação ${ }^{116}$, e do análogo do AO não-metabolizável (metil-oleato) (Figura 6), comprovaram a participação da oxidação de ácidos graxos no aumento na secreção de insulina induzido por uma concentração fisiológica de ácido oléico. É possível que o oleato, através de seu metabolismo esteja regulando a oxidação da glicose de uma forma compensatória em ilhotas pancreáticas. Conget e colaboradores também observaram aumento da oxidação do AGs após 30 minutos de incubação com palmitato e oleato ${ }^{117}$. A redução do metabolismo da glicose observada em 
16,7 mM de glicose na presença de AO (Figura 7) corrobora a hipótese de que a oxidação do AO pode estar gerando níveis elevados de substratos inibidores do metabolismo da glicose.

O aumento do metabolismo do AO pode ter aumentado a formação de ATP, que além de promover a secreção de insulina induzido por esse ácido graxo, é também um inibidor da PFK, enzima essencial para a via glicolítica. O aumento na oxidação de ácidos graxos também aumenta formação de acetil-CoA, que é inibidor da PFK-1. Em músculo esquelético de camundongos e humanos a administração de baixas concentrações de oleioil-CoA, forma na qual o AO entra na mitocôndria, aumenta, enquanto doses muito elevadas, reduzem a formação ATP ${ }^{4,118-120}$, o que pode explicar os efeitos controversos de ácidos graxos na ilhota pancreática.

Após a entrada da glicose na célula $\beta$ é formado piruvato, através da glicólise, que posteriormente é transportado para mitocôndria onde sofrerá metabolização. Na mitocôndria o piruvato pode seguir duas vias diferentes, uma em que sofre descarboxilação para formar acetil-CoA e passa a ser metabolizado no ciclo de Krebs e a outra na qual é carboxilado a oxalacetato, formando intermediários como malato, e posteriormente sendo exportado da mitocôndria para o citosol. A produção de malato, citrato e outros intermediários anapleróticos está altamente relacionada com a secreção de insulina ${ }^{3}$. A alta concentração de piruvato carboxilase (PC) na ilhota pancreática em níveis semelhantes aos de tecidos de importância gliconeogênica como fígado e rins sugere uma grande importância da via de anaplerose nesse tecido ${ }^{121}$. O tratamento crônico com palmitato reduz o conteúdo protéico de PC e promove menor secreção de insulina em linhagem de célula $\beta$, atribuindo à PC função relevante no processo de secreção de insulina induzido por ácidos graxos ${ }^{13}$. Nesse mesmo estudo supõe-se como mecanismo compensatório da célula um aumento na oxidação da glicose a fim de manter o aporte necessário de ATP. A elevação da concentração de acetilCoA, que normalmente ocorre durante o metabolismo de ácidos graxos, inibe a atividade da PDH e ativa alostericamente a PC ${ }^{47,122-124}$. Dessa forma, é possível que, além da inibição da PDH, ocorra ativação da PC induzida por altas concentrações de acetil-CoA geradas pela oxidação do AO. O possível aumento na $\mathrm{PC}$ induz maior formação de oxalacetato $\mathrm{e}$ intermediários anapleróticos com consequente diminuição da oxidação da glicose .

Além da via de oxidação, os ácidos graxos podem exercer sua função por ação do receptor de ácidos graxos de cadeia média e longa denominado GPR40. A ativação desse receptor por diversos ácidos graxos de cadeia longa, dentre eles o ácido oléico, induz ativação da fosfolipase C ativando a PKC, que, por sua vez está envolvida no processo de secreção de 
insulina induzido por ácidos graxos. O GPR40 é um receptor com ação comprovada na secreção de insulina induzida por ácidos graxos de cadeia média e longa e a ação do oleato por essa via já foi demonstrada em células $\beta$ isoladas ou em linhagens secretoras de insulina 55 . Foi comprovado que a ausência do GPR40 pode impedir a inibição da secreção de insulina observada após 48 horas de exposição ao palmitato ${ }^{125}$. A inibição do GPR40 reduz a ativação do canal de $\mathrm{K}_{\mathrm{ATP}}$, sugerindo que a inibição da secreção de insulina observada após exposição crônica a ácidos graxos poderia ser gerada pela ativação de canais de $\mathrm{K}_{\mathrm{ATP}}$ mediada pelo GPR40. O metabolismo dos ácidos graxos também apresenta importância nesse processo, pois a administração de um agonista do GPR40 não-metabolizável reduziu a ativação de canais de $\mathrm{K}^{+126}$. No entanto, Feng e colaboradores (2006) observaram redução nas correntes em canais de $\mathrm{K}^{+}$voltagem dependente em células $\beta$ após estímulo com o mesmo ácido graxo. Os resultados ainda controversos a respeito da função do GPR40 no processo de secreção de insulina podem ter sido gerados pela diferença no tempo e via de administração, na concentração e na presença ou ausência de BSA no meio de incubação.

Não observamos efeito do GPR40 na secreção de insulina induzida pelo AO (Figura 12), como observado anteriormente. O tratamento com ácido oléico por 1 hora aumentou a expressão protéica (Figura 11) do receptor, mas como não foi observado efeito do mesmo na secreção de insulina, é possível que o aumento do conteúdo protéico tenha sido gerado por uma diminuição de degradação da proteína. Dessa forma, é possível que, ao menos em ilhotas normais submetidas a concentrações fisiológicas de ácido oléico por 1 hora, o GPR40 não apresente função importante ou significativa. Muitos trabalhos têm demonstrado a importância desse receptor em condições de diabetes, ou em animais submetidos a condições de lipotoxicidade, ou em ilhotas tratadas cronicamente com altas concentrações de ácidos graxos. No entanto, o aumento de $\mathrm{Ca}^{2+}$ induzido pelo AO é inibido na ausência do GPR40, mas não observam o mesmo efeito na secreção de insulina ${ }^{47}$.

Os efeitos deletérios da administração crônica de acidos graxos vêm sendo associados a produção aumentada de EROs. Ilhotas humanas expostas ao oleato durante 48 horas apresentam diminuição da oxidação da glicose, aumento da oxidação do próprio oleato e indução da geração de EROs ${ }^{127}$. A produção excessiva desses radicais e seu acúmulo pode ser danoso, induzindo apoptose da célula $\beta$ e aumento de peroxidação lipídica no plasma de indivíduos diabéticos ${ }^{128}$. Apesar da importância dessas moléculas na instalação de diversas doenças, as EROs parecem ser importantes sinalizadores de diversos processos, dentre eles a secreção de insulina. Camundongos com super-expressão de enzimas antioxidantes como 
catalase (CAT) e superóxido dismutase (MnSOD) e da proteína metalotioneína são mais propensos a desenvolverem diabetes ${ }^{100}$. Foi demonstrado em ilhotas isoladas expostas a baixas concentrações de $\mathrm{H}_{2} \mathrm{O}_{2}(1-4 \mu \mathrm{M})$, na presença de $3 \mathrm{mM}$ de glicose, um aumento na secreção de insulina ${ }^{129}$. Rebelato e colaboradores, porém, demonstraram em altas concentrações de glicose (16,7 mM de glicose) diminuição na secreção de insulina após exposição a concentrações semelhantes de $\mathrm{H}_{2} \mathrm{O}_{2}(5 \mu \mathrm{M}){ }^{91,92,130}$. Esses trabalhos reforçam a importância das espécies reativas de oxigênio na função da célula $\beta$, corroborando os dados recentemente publicados pelo nosso grupo de pesquisa ${ }^{65,86}$. É necessário, portanto, cautela na avaliação dos efeitos dessas moléculas, pois a determinação de uma concentração ótima de EROs no meio intracelular é difícil e pode ser alterada dependendo do tecido e do estado redox da célula.

Ácidos graxos aumentam a produção de EROs em diversos tecidos sob condições de alta concentração de glicose ${ }^{131}$ ao interferir em vários de seus sítios de formação. $\mathrm{Na}$ mitocôndria, por exemplo, o catabolismo dos ácidos graxos pode aumentar o fluxo de elétrons, que está associado ao aumento de $\mathrm{H}_{2} \mathrm{O}_{2}{ }^{132}$. Concentrações baixas de ácidos graxos são capazes de amentar EROs de uma forma dependente de substratos geradores de NADH em músculo ${ }^{133}$.

Os dados de aumento no metabolismo do ácido oléico (Figura 8) indicam aumento na atividade mitocondrial, já que AGs são metabolizados nesta organela. $\mathrm{O}$ aumento no conteúdo de superóxido induzido pelo AO (Figura 9) indica importância desse ácido graxo no processo de produção de EROs na ilhota pancreática. A inibição da oxidação do AO inibe o aumento de EROs induzido pelo AG em células $\beta$ (INS-1E) (Figura 10), que pode sugrerir envolvimento da atividade mitocondrial na geração de EROs na ilhota pancreática, mas ainda não comprovamos essa hipótese com a utilização de inibidores mitocondriais. A inibição da CPT-1 em células hepáticas reduz efeitos mediados por EROs após 16 horas de tratamento com ácido palmítico, sugerindo também uma relação entre o aumento do metabolismo dos ácidos graxos e a geração de EROs via mitocôndria ${ }^{134}$.

Além da reconhecida importância da mitocôndria como geradora de EROs em diversos tecidos, a $\mathrm{NAD}(\mathrm{P}) \mathrm{H}$ oxidase é uma importante geradora de EROs em células

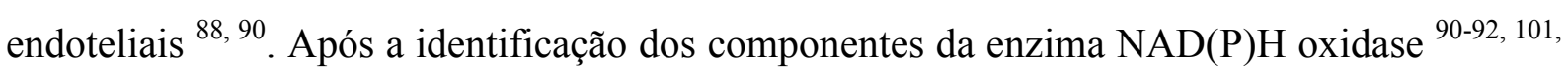
135-137 em ilhotas pancreáticas sua importância na produção de EROs foi comprovada por diversos estudos 138, 139. Mais recentemente, demonstraram relação entre a atividade da enzima NAD(P)H oxidase e a secreção de insulina induzida pela glicose ${ }^{92}$. O aumento na 
ativação da PKC por EROs mitocondriais podem sugerir uma interação entre o aumento de EROs,via metabolismo do $\mathrm{AO}$ e atividade da enzima NAD(P)H oxidase em ilhotas pancreáticas e células $\beta$ como observado em outro tecido ${ }^{102,140}$.

Algumas proteínas cinase como PKC e PI3K são importantes para ativação da subunidade $\mathrm{p} 47^{\text {PHOX }}$ e Noxo1 e sua posterior migração para membrana ${ }^{84,141}$. O oleato é um ativador de PI3K em músculo liso e de PKC em células vasculares ${ }^{5}$. A PKC pode ser ativada pela formação de LC-CoA e aumentar a secreção de insulina induzida ${ }^{106}$. Sabendo da sua capacidade em ativar a enzima $\mathrm{NAD}(\mathrm{P}) \mathrm{H}$ oxidase e que em neutrófilos medeia a ativação dessa enzima pelo $\mathrm{AO}{ }^{138,142,143}$ é possível supor uma relação entre a atividade ou expressão da $\mathrm{PKC}$ e a $\mathrm{NAD}(\mathrm{P}) \mathrm{H}$ oxidase em ilhotas pancreáticas após exposição ao mesmo AG. Foi observado aumento no conteúdo protéico de PKC e Nox2 (Figura 11) em ilhotas pancreáticas isoladas tratadas com ácido oléico, sugerindo uma possível ativação da NAD(P)H oxidase, apesar da ausência de alteração na expressão gênica da maioria das subunidades da NAD(P)H oxidase (Tabela 4). Além do aumento da expressão dessas proteínas, a inibição da atividade da PKC diminuiu o conteúdo de EROs após o tratamento com ácido oléico em células INS-1E (Figura 10), corroborando com a possível geração de EROs através da ativação da enzima $\mathrm{NAD}(\mathrm{P}) \mathrm{H}$ oxidase pela PKC. Graciano et al. (in press) observaram aumento na translocação da subunidade $\mathrm{p} 47^{\text {PHOX }}$ e da PKC para a membrana na presença de palmitato em ilhotas pancreáticas. Portanto, pode-se inferir também ao ácido oléico capacidade de ativação da $\mathrm{NAD}(\mathrm{P}) \mathrm{H}$ oxidase e geração de EROs com a participação da PKC assim como induzido pelo ácido palmítico.

Foi demonstrado que o aumento na produção de EROs induzido pelo aumento na atividade do TCA pode induzir maior atividade da PKC em adipócitos e células endoteliais aórticas ${ }^{89}$. Assim sendo, o aumento no metabolismo do ácido oléico pode ter aumentado o influxo de substratos para a mitocôndria, elevando sua atividade, que aumentaria a produção de EROs. Com o aumento de EROs produzido pelo metabolismo do ácido oléico (Figura 10) ocorreria aumento na atividade e/ou expressão da PKC (Figuras 10 e 11) e da NAD(P)H oxidase.

A maioria das subunidades da $\mathrm{NAD}(\mathrm{P}) \mathrm{H}$ oxidase não teve a expressão gênica alterada pela ação do ácido oléico, apesar de ter sido observado aumento na expressão protéica da subunidade Nox2 da NAD(P)H oxidase (Figura 11 e Tabela 4). Assim sendo, a ausência de alteração da expressão gênica do componente $\mathrm{p} 47^{P H O X}$ e seu homólogo não exclui a possibilidade de ativação dessas subunidades por ação da PKC ou PI3K. Dentre todas as 
subunidades da NAD(P)H oxidase avaliadas somente a Nox1 sofreu alteração na expressão gênica após tratamento com ácido oléico, bem como observado anteriormente em modelos animais de diabetes tipo II ${ }^{144}$. Lee e colaboradoresobservaram íntima relação entre a produção de EROs pela mitocôndria e a posterior ativação da Nox $1^{145}$. Os autores supra citados observaram uma escala temporal de ativação na produção de EROs pela mitocôndria e Nox1, nessa respectiva ordem, mediada pela ativação da PI3K e da Rac1. Há evidências de interdependência entre a produção de EROs via mitocôndria e $\mathrm{NAD}(\mathrm{P}) \mathrm{H}$ oxidase, pois foi observada diminuição na indução do RNAm da Nox1 quando há redução do DNA mitocondrial de células vasculares e menor produção de EROs ${ }^{146}$. Na presença do ácido oléico a expressão gênica da Nox1 aumentou em ambas concentrações de glicose sugerindo um efeito do ácido oléico em subunidades importantes para geração de superóxido e uma possível aumento no RNAm dessa subunidade após elevação no conteúdo de EROs gerados pela mitocôndria.

A inibição da $\mathrm{NAD}(\mathrm{P}) \mathrm{H}$ oxidase com $\mathrm{AS}-\mathrm{p} 47^{P H O X}$ e a ausência de Nox2 em camundongos KO promoveram inibição do aumento do conteúdo de superóxido em 16,7 mM de glicose na presença ou ausência de AO, como observado após tratamento com palmitato e inibição da enzima com seu inibidor farmacológico (Graciano et al. in press). Assim sendo, fica comprovado que, além da possível geração de EROs via oxidação de AO na mitocôndria, há participação relevante da $\mathrm{NAD}(\mathrm{P}) \mathrm{H}$ oxidase na geração de EROs induzida pelo ácido oléico na ilhota pancreática.

Apesar de EROs serem essenciais a diversos processos intracelulares, a hiperglicemia induz uma produção excessiva de superóxido, que inibe a enzima gliceraldeído-3-fosfato desidrogenase (G3PDH) ${ }^{147}$. Assim sendo, parece que além da possível inibição da via glicolítica induzida pelo aumento no acetil-CoA e no ATP, o aumento de EROs pode também ter sua participação na inibição da oixdação da glicose. Foi demonstrado recentemente em uma linhagem celular de monócitos que níveis de EROs $\left(\mathrm{H}_{2} \mathrm{O}_{2}\right)$ incapazes de gerar apoptose aumentam a atividade da G3PDH e níveis mais elevados de peróxido de hidrogênio inibem a atividade da enzima ${ }^{92}$, o que demonstra uma regulação mutio fina da atividade dessa enzima. Sendo assim, é possível uma regulação do metabolismo da glicose, dimuído na presença do AO (Figura 7), através da produção de EROs via NAD(P)H oxidase.

A inibição da NAD(P)H oxidase com AS para o $\mathrm{p} 47^{P H O X}$ promoveu diminuição da oxidação da glicose na presença de $16,7 \mathrm{mM}$ do açúcar, confirmando dados anteriores do nosso grupo de pesquisa ${ }^{65}$. A redução na geração de EROs induzida pela menor expressão da 
subunidade $\mathrm{p} 47^{\text {PHOX }}$ ou pelo Nox2-KO da NAD(P)H oxidase pode ter promovido atividade normal da G3PDH, liberação da via glicolítica e, consequentemente, a reversão da inibição na oxidação da glicose na presença de ácido oléico (Figura 18). A reversão da inibição do metabolismo da glicose a taxas normais confere às EROs função importante na regulação do metabolismo da glicose via ativação da $\mathrm{NAD}(\mathrm{P}) \mathrm{H}$ oxidase. Na ausência de fatores reguladores da via glicolítica, como as EROs, seria possível a manutenção de taxas elevadas de oxidação de ambos nutrientes, porém não é possível prever o que ocorreria cronicamente na célula $\beta$.

A ausência da subunidade da $\mathrm{p} 47^{P H O X}$ ou da Nox2 manteve o aumento na secreção induzido pelo ácido oléico, o que poderia sugerir ausência de efeito da NAD(P)H oxidase no processo de secreção de insulina induzido pelo AO. A inibição da enzima por ambos os métodos (AS ou KO) promoveu diminuição na secreção de insulina na presença de $16,7 \mathrm{mM}$ de glicose. Portanto, a manutenção do estímulo à secreção induzido pelo AO implica numa maior secreção de insulina relativa. Pode-se então sugerir que a inibição da $\mathrm{NAD}(\mathrm{P}) \mathrm{H}$ oxidase, e, consequente, redução no conteúdo de EROs, aumenta a secreção de insulina induzida pelo AO através da modulação da oxidação da glicose. Assim sendo, as EROs geradas por diversas vias parecem exercer seus efeitos na secreção de forma dependente de alterações metabólicas.

A atividade da $\mathrm{NAD}(\mathrm{P}) \mathrm{H}$ oxidase parece ser essencial para geração do efeito do $\mathrm{AO}$ na produção de EROs e regulação metabólica induzidas pelo ácido oléico. Todavia, a regulação do metabolismo de AGs parece não ser susceptível à regulação por EROs. Foi demonstrado anteriormente, que o aumento no RNAm da CPT-1 induzido pela exposição crônica ao ácido oléico não é regulada por EROs ${ }^{65}$. Além da via já caracterizada por Randle, na qual níveis elevados de acetil-CoA e citrato são responsáveis pela inibição da PFK, as EROs geradas pelo AO parecem modular a oxidação da glicose ao atuarem na via glicolítica, possivelmente regulando a atividade da G3PDH. Ambos os dados a respeito do AO na regulação do metabolismo sugerem maior susceptibilidade de algumas vias, como a de oxidação da glicose, à regulação por EROs.

A tênue regulação entre o metabolismo da glicose e do AO sugerida pela variação no metabolismo de glicose em relação ao de oleato, comprovam a capacidade da ilhota pancreática em lidar com variações na concentração de nutrientes. A ausência de um fator regulador do metabolismo, como as EROs, poderia sobrecarregar a célula $\beta$ e causar danos ao processo secretório. A inibição da via glicolítica pela ação de EROs pode ser um ajuste 
fisiológico presente na célula $\beta$ a fim de manter níveis de secreção essenciais para o controle agudo do excesso de nutrientes na corrente sanguínea. 


\section{CONCLUS ̃̃O}

- Concentração fisiológica de ácido oléico $(100 \mu \mathrm{M}+0,1 \%$ BSA) induz aumento na secreção de insulina na presença de alta concentração de glicose.

- O efeito dessa concentração de ácido oléico na secreção de insulina não é mediado pelo GPR40.

- A oxidação aumentada do AO está envolvida no processo de secreção induzido pelo AO.

- O ácido oléico induz aumento na produção de EROs via NAD(P)H oxidase.

- As EROs produzidas pela atividade da $\mathrm{NAD}(\mathrm{P}) \mathrm{H}$ oxidase induzida pelo $\mathrm{AO}$ são responsáveis pela regulação do metabolismo da glicose.

- O aumento na oxidação da glicose obervado após inibição da NAD(P)H oxidase parece ter sido responsável pelo aumento na secreção de insulina. 


\section{REFER $\hat{E} \mathcal{N} C I \mathcal{A S}$}

\section{REFERÊNCIAS*}

1 Carpinelli AR, Malaisse WJ. Regulation of 86Rb outflow from pancreatic islets. IV. Effect of cyclic AMP, dibutyryl-cyclic AMP and theophylline. Acta Diabetol Lat. 1980;17:199-205.

2 Ashcroft F, Rorsman P. ATP-sensitive channels: a link between B-cell metabolism and insulin secretion. Biochem Soc Trans. 1990;18:109-11.

3 MacDonald MJ, Fahien LA, Brown LJ, Hasan NM, Buss JD, Kendrick MA. Perspective: emerging evidence for signaling roles of mitochondrial anaplerotic products in insulin secretion. Am J Physiol Endocrinol Metab. 2005;288:E1-15.

4 MacDonald PE, Joseph JW, Rorsman P. Glucose-sensing mechanisms in pancreatic beta-cells. Philos Trans R Soc Lond B Biol Sci. 2005;360:2211-25.

5 Yaney GC, Korchak HM, Corkey BE. Long-chain acyl CoA regulation of protein kinase $\mathrm{C}$ and fatty acid potentiation of glucose-stimulated insulin secretion in clonal beta-cells. Endocrinology. 2000;141:1989-98.

6 Maechler P, Wollheim CB. Mitochondrial signals in glucose-stimulated insulin secretion in the beta cell. J Physiol. 2000;529 (Pt 1):49-56.

7 Maechler P, Carobbio S, Rubi B. In beta-cells, mitochondria integrate and generate metabolic signals controlling insulin secretion. Int J Biochem Cell Biol. 2006;38:696709.

8 Maechler P, Kennedy ED, Pozzan T, Wollheim CB. Mitochondrial activation directly triggers the exocytosis of insulin in permeabilized pancreatic beta-cells. EMBO J. 1997; 16:3833-41.

9 Rutter GA, Burnett P, Rizzuto R, Brini M, Murgia M, Pozzan T, Tavare JM, Denton RM. Subcellular imaging of intramitochondrial $\mathrm{Ca} 2+$ with recombinant targeted aequorin: significance for the regulation of pyruvate dehydrogenase activity. Proc Natl Acad Sci U S A. 1996;93:5489-94. 
10 Kennedy ED, Maechler P, Wollheim CB. Effects of depletion of mitochondrial DNA in metabolism secretion coupling in INS-1 cells. Diabetes. 1998;47:374-80.

11 Sekine N, Cirulli V, Regazzi R, Brown LJ, Gine E, Tamarit-Rodriguez J, Girotti M, Marie S, MacDonald MJ, Wollheim CB, et al. Low lactate dehydrogenase and high mitochondrial glycerol phosphate dehydrogenase in pancreatic beta-cells. Potential role in nutrient sensing. J Biol Chem. 1994;269:4895-4902.

12 MacDonald MJ. Glucose enters mitochondrial metabolism via both carboxylation and decarboxylation of pyruvate in pancreatic islets. Metabolism. 1993;42:1229-31.

* de acordo com: International Committee of Medical Journal Editors. Uniform requirements for manuscripts submitted to Biomedical Journal: sample references available from: http://www.icmje.org [2007 May 22].

14 MacDonald MJ. Influence of glucose on pyruvate carboxylase expression in pancreatic islets. Arch Biochem Biophys. 1995;319:128-32.

15 Ivarsson R, Quintens R, Dejonghe S, Tsukamoto K, in 't Veld P, Renstrom E, Schuit FC. Redox control of exocytosis: regulatory role of NADPH, thioredoxin, and glutaredoxin. Diabetes. 2005;54:2132-42.

16 Jensen MV, Joseph JW, Ilkayeva O, Burgess S, Lu D, Ronnebaum SM, Odegaard M, Becker TC, Sherry AD, Newgard CB. Compensatory responses to pyruvate carboxylase suppression in islet beta-cells. Preservation of glucose-stimulated insulin secretion. J Biol Chem. 2006;281:22342-51.

17 MacDonald MJ, Tang J, Polonsky KS. Low mitochondrial glycerol phosphate dehydrogenase and pyruvate carboxylase in pancreatic islets of Zucker diabetic fatty rats. Diabetes. 1996;45:1626-30.

18 MacDonald MJ, Efendic S, Ostenson CG. Normalization by insulin treatment of low mitochondrial glycerol phosphate dehydrogenase and pyruvate carboxylase in pancreatic islets of the GK rat. Diabetes. 1996;45:886-90.

19 Xu J, Han J, Long YS, Epstein PN, Liu YQ. The role of pyruvate carboxylase in insulin secretion and proliferation in rat pancreatic beta cells. Diabetologia. 2008;51:2022-30.

20 Boucher A, Lu D, Burgess SC, Telemaque-Potts S, Jensen MV, Mulder H, Wang MY, Unger RH, Sherry AD, Newgard CB. Biochemical mechanism of lipid-induced impairment of glucose-stimulated insulin secretion and reversal with a malate analogue. J Biol Chem. 2004;279:27263-71.

21 Liu YQ, Jetton TL, Leahy JL. beta-Cell adaptation to insulin resistance. Increased pyruvate carboxylase and malate-pyruvate shuttle activity in islets of nondiabetic Zucker fatty rats. J Biol Chem. 2002;277:39163-68. 
22 Liu YQ, Tornheim K, Leahy JL. Glucose-fatty acid cycle to inhibit glucose utilization and oxidation is not operative in fatty acid-cultured islets. Diabetes. 1999;48:1747-53.

23 Kotarsky K, Nilsson NE, Flodgren E, Owman C, Olde B. A human cell surface receptor activated by free fatty acids and thiazolidinedione drugs. Biochem Biophys Res Commun. 2003;301:406-10.

24 Deeney JT, Gromada J, Hoy M, Olsen HL, Rhodes CJ, Prentki M, Berggren PO, Corkey BE. Acute stimulation with long chain acyl-CoA enhances exocytosis in insulin-secreting cells (HIT T-15 and NMRI beta-cells). J Biol Chem. 2000;275:936368.

25 Assimacopoulos-Jeannet F, Thumelin S, Roche E, Esser V, McGarry JD, Prentki M. Fatty acids rapidly induce the carnitine palmitoyltransferase I gene in the pancreatic beta-cell line INS-1. J Biol Chem. 1997;272:1659-64.

26 McGarry JD. Banting lecture 2001: dysregulation of fatty acid metabolism in the etiology of type 2 diabetes. Diabetes. 2002;51:7-18.

27 El-Assaad W, Buteau J, Peyot ML, Nolan C, Roduit R, Hardy S, Joly E, Dbaibo G, Rosenberg L, Prentki M. Saturated fatty acids synergize with elevated glucose to cause pancreatic beta-cell death. Endocrinology. 2003;144:4154-63.

28 Liang Y, Buettger C, Berner DK, Matschinsky FM. Chronic effect of fatty acids on insulin release is not through the alteration of glucose metabolism in a pancreatic betacell line (beta HC9). Diabetologia. 1997;40:1018-27.

29 Dobbins RL, Chester MW, Stevenson BE, Daniels MB, Stein DT, McGarry JD. A fatty acid- dependent step is critically important for both glucose- and non-glucosestimulated insulin secretion. J Clin Invest. 1998;101:2370-76.

30 Azevedo-Martins AK, Monteiro AP, Lima CL, Lenzen S, Curi R. Fatty acid-induced toxicity and neutral lipid accumulation in insulin-producing RINm5F cells. Toxicol In Vitro. 2006;20:1106-13.

31 Segall L, Lameloise N, Assimacopoulos-Jeannet F, Roche E, Corkey P, Thumelin S, Corkey BE, Prentki M. Lipid rather than glucose metabolism is implicated in altered insulin secretion caused by oleate in INS-1 cells. Am J Physiol. 1999;277:E521-28.

32 Gudz TI, Tserng KY, Hoppel CL. Direct inhibition of mitochondrial respiratory chain complex III by cell-permeable ceramide. J Biol Chem. 1997;272:24154-4158.

33 Lupi R, Dotta F, Marselli L, Del Guerra S, Masini M, Santangelo C, Patane G, Boggi U, Piro S, Anello M, Bergamini E, Mosca F, Di Mario U, Del Prato S, Marchetti P. Prolonged exposure to free fatty acids has cytostatic and pro-apoptotic effects on human pancreatic islets: evidence that beta-cell death is caspase mediated, partially dependent on ceramide pathway, and Bcl-2 regulated. Diabetes. 2002;51:1437-42. 
34 Maedler K, Spinas GA, Dyntar D, Moritz W, Kaiser N, Donath MY. Distinct effects of saturated and monounsaturated fatty acids on beta-cell turnover and function. Diabetes. 2001;50:69-76.

35 Picinato MC, Curi R, Machado UF, Carpinelli AR. Soybean- and olive-oils-enriched diets increase insulin secretion to glucose stimulus in isolated pancreatic rat islets. Physiol Behav. 1998;65:289-94.

36 Gravena C, Mathias PC, Ashcroft SJ. Acute effects of fatty acids on insulin secretion from rat and human islets of Langerhans. J Endocrinol. 2002;173:73-80.

37 Dixon G, Nolan J, McClenaghan NH, Flatt PR, Newsholme P. Arachidonic acid, palmitic acid and glucose are important for the modulation of clonal pancreatic betacell insulin secretion, growth and functional integrity. Clin Sci (Lond). 2004;106:19199.

38 Yaney GC, Corkey BE. Fatty acid metabolism and insulin secretion in pancreatic beta cells. Diabetologia. 2003;46:1297-12.

39 Stein DT, Esser V, Stevenson BE, Lane KE, Whiteside JH, Daniels MB, Chen S, McGarry JD. Essentiality of circulating fatty acids for glucose-stimulated insulin secretion in the fasted rat. J Clin Invest. 1996;97:2728-35.

40 McGarry JD, Brown NF. The mitochondrial carnitine palmitoyltransferase system. From concept to molecular analysis. Eur J Biochem. 1997;244:1-14.

41 Rubi B, Antinozzi PA, Herrero L, Ishihara H, Asins G, Serra D, Wollheim CB, Maechler P, Hegardt FG. Adenovirus-mediated overexpression of liver carnitine palmitoyltransferase I in INS1E cells: effects on cell metabolism and insulin secretion. Biochem J. 2002;364:219-26.

42 Randle PJ, Garland PB, Hales CN, Newsholme EA. The glucose fatty-acid cycle. Its role in insulin sensitivity and the metabolic disturbances of diabetes mellitus. Lancet. 1963;1:785-89.

43 Randle PJ. Regulatory interactions between lipids and carbohydrates: the glucose fatty acid cycle after 35 years. Diabetes Metab Rev. 1998;14:263-83.

44 Briscoe CP, Tadayyon M, Andrews JL, Benson WG, Chambers JK, Eilert MM, Ellis C, Elshourbagy NA, Goetz AS, Minnick DT, Murdock PR, Sauls HR, Jr., Shabon U, Spinage LD, Strum JC, Szekeres PG, Tan KB, Way JM, Ignar DM, Wilson S, Muir AI. The orphan G protein-coupled receptor GPR40 is activated by medium and long chain fatty acids. J Biol Chem. 2003;278:11303-11.

45 Hirasawa A, Tsumaya K, Awaji T, Katsuma S, Adachi T, Yamada M, Sugimoto Y, Miyazaki S, Tsujimoto G. Free fatty acids regulate gut incretin glucagon-like peptide1 secretion through GPR120. Nat Med. 2005;11:90-94. 
46 Shapiro H, Shachar S, Sekler I, Hershfinkel M, Walker MD. Role of GPR40 in fatty acid action on the beta cell line INS-1E. Biochem Biophys Res Commun. 2005;335:97-104.

47 Fujiwara K, Maekawa F, Yada T. Oleic acid interacts with GPR40 to induce Ca2+ signaling in rat islet beta-cells: mediation by PLC and L-type Ca2+ channel and link to insulin release. Am J Physiol Endocrinol Metab. 2005;289:E670-77.

48 Tikhonova IG, Sum CS, Neumann S, Thomas CJ, Raaka BM, Costanzi S, Gershengorn MC. Bidirectional, iterative approach to the structural delineation of the functional "chemoprint" in GPR40 for agonist recognition. J Med Chem. 2007;50:2981-89.

49 Brown AJ, Jupe S, Briscoe CP. A family of fatty acid binding receptors. DNA Cell Biol. 2005;24:54-61.

50 Sum CS, Tikhonova IG, Neumann S, Engel S, Raaka BM, Costanzi S, Gershengorn MC. Identification of residues important for agonist recognition and activation in GPR40. J Biol Chem. 2007;282:29248-55.

51 Bollheimer LC, Kemptner DM, Kagerbauer SM, Kestler TM, Wrede CE, Buettner R. Intracellular depletion of insulin: a comparative study with palmitate, oleate and elaidate in INS-1 cells. Eur J Endocrinol. 2003;148:481-86.

52 Itoh Y, Kawamata Y, Harada M, Kobayashi M, Fujii R, Fukusumi S, Ogi K, Hosoya M, Tanaka Y, Uejima H, Tanaka H, Maruyama M, Satoh R, Okubo S, Kizawa H, Komatsu H, Matsumura F, Noguchi Y, Shinohara T, Hinuma S, Fujisawa Y, Fujino M. Free fatty acids regulate insulin secretion from pancreatic beta cells through GPR40. Nature. 2003;422:173-76.

53 Poitout V. The ins and outs of fatty acids on the pancreatic beta cell. Trends Endocrinol Metab. 2003;14:201-03.

54 Gromada J. The free fatty acid receptor GPR40 generates excitement in pancreatic beta-cells. Endocrinology. 2006;147:672-73.

55 Steneberg P, Rubins N, Bartoov-Shifman R, Walker MD, Edlund H. The FFA receptor GPR40 links hyperinsulinemia, hepatic steatosis, and impaired glucose homeostasis in mouse. Cell Metab. 2005;1:245-58.

56 Latour MG, Alquier T, Oseid E, Tremblay C, Jetton TL, Luo J, Lin DC, Poitout V. GPR40 is necessary but not sufficient for fatty acid stimulation of insulin secretion in vivo. Diabetes. 2007;56:1087-94.

57 Waterman E, Lockwood B. Active components and clinical applications of olive oil. Altern Med Rev. 2007;12:331-42. 
58 Fujiwara K, Maekawa F, Yada T. Oleic acid interacts with GPR40 to induce Ca2+ signaling in rat islet beta-cells: mediation by PLC and L-type Ca2+ channel and link to insulin release. Am J Physiol Endocrinol Metab. 2005;289:E670-77.

59 Hardy S, Langelier Y, Prentki M. Oleate activates phosphatidylinositol 3-kinase and promotes proliferation and reduces apoptosis of MDA-MB-231 breast cancer cells, whereas palmitate has opposite effects. Cancer Res. 2000;60:6353-58.

60 Hardy S, St-Onge GG, Joly E, Langelier Y, Prentki M. Oleate promotes the proliferation of breast cancer cells via the G protein-coupled receptor GPR40. J Biol Chem. 2005;280:13285-91.

61 Maedler K, Oberholzer J, Bucher P, Spinas GA, Donath MY. Monounsaturated fatty acids prevent the deleterious effects of palmitate and high glucose on human pancreatic beta-cell turnover and function. Diabetes. 2003;52:726-33.

62 Welters HJ, Tadayyon M, Scarpello JH, Smith SA, Morgan NG. Mono-unsaturated fatty acids protect against beta-cell apoptosis induced by saturated fatty acids, serum withdrawal or cytokine exposure. FEBS Lett. 2004;560:103-08.

63 Miller TA, LeBrasseur NK, Cote GM, Trucillo MP, Pimentel DR, Ido Y, Ruderman NB, Sawyer DB. Oleate prevents palmitate-induced cytotoxic stress in cardiac myocytes. Biochem Biophys Res Commun. 2005;336:309-15.

64 Cury-Boaventura MF, Gorjao R, de Lima TM, Newsholme P, Curi R. Comparative toxicity of oleic and linoleic acid on human lymphocytes. Life Sci. 2006;78:1448-56.

65 Oprescu AI, Bikopoulos G, Naassan A, Allister EM, Tang C, Park E, Uchino H, Lewis GF, Fantus IG, Rozakis-Adcock M, Wheeler MB, Giacca A. Free fatty acidinduced reduction in glucose-stimulated insulin secretion: evidence for a role of oxidative stress in vitro and in vivo. Diabetes. 2007;56:2927-37.

66 Crespin SR, Greenough WB, 3rd, Steinberg D. Stimulation of insulin secretion by long-chain free fatty acids. A direct pancreatic effect. J Clin Invest. 1973;52:1979-84.

67 Stein DT, Stevenson BE, Chester MW, Basit M, Daniels MB, Turley SD, McGarry JD. The insulinotropic potency of fatty acids is influenced profoundly by their chain length and degree of saturation. J Clin Invest. 1997;100:398-403.

68 Tian Y, Corkey RF, Yaney GC, Goforth PB, Satin LS, Moitoso de Vargas L. Differential modulation of L-type calcium channel subunits by oleate. Am J Physiol Endocrinol Metab. 2008;294:E1178-86.

69 Branstrom R, Aspinwall CA, Valimaki S, Ostensson CG, Tibell A, Eckhard M, Brandhorst H, Corkey BE, Berggren PO, Larsson O. Long-chain CoA esters activate human pancreatic beta-cell KATP channels: potential role in Type 2 diabetes. Diabetologia. 2004;47:277-83. 
70 Speier S, Yang SB, Sroka K, Rose T, Rupnik M. KATP-channels in beta-cells in tissue slices are directly modulated by millimolar ATP. Mol Cell Endocrinol. 2005;230:51-58.

71 Halliwell B, Gutterridge JMC. Free radicals in biology and medicine, 3rd ed. Oxford: Clarendon Press; 1999.

72 Droge W. Free radicals in the physiological control of cell function. Physiol Rev. 2002;82:47-95.

73 Oliveira HR, Curi R, Carpinelli AR. Glucose induces an acute increase of superoxide dismutase activity in incubated rat pancreatic islets. Am J Physiol. 1999;276:C507-10.

74 Stone JR, Yang S. Hydrogen peroxide: a signaling messenger. Antioxid Redox Signal. 2006;8:243-70.

75 Sivitz WI, Yorek MA. Mitochondrial dysfunction in diabetes: from molecular mechanisms to functional significance and therapeutic opportunities. Antioxid Redox Signal. 12:537-77.

76 Robertson RP. Chronic oxidative stress as a central mechanism for glucose toxicity in pancreatic islet beta cells in diabetes. J Biol Chem. 2004;279:42351-54.

77 Robertson RP, Harmon J, Tran PO, Poitout V. Beta-cell glucose toxicity, lipotoxicity, and chronic oxidative stress in type 2 diabetes. Diabetes. 2004;53 (Suppl 1):S119-24.

78 Robertson RP, Harmon JS. Diabetes, glucose toxicity, and oxidative stress: A case of double jeopardy for the pancreatic islet beta cell. Free Radic Biol Med. 2006;41:17784.

79 Robertson RP, Harmon J, Tran PO, Tanaka Y, Takahashi H. Glucose toxicity in betacells: type 2 diabetes, good radicals gone bad, and the glutathione connection. Diabetes. 2003;52:581-87.

80 Tanaka Y, Tran PO, Harmon J, Robertson RP. A role for glutathione peroxidase in protecting pancreatic beta cells against oxidative stress in a model of glucose toxicity. Proc Natl Acad Sci U S A. 2002;99:12363-68.

81 Piro S, Anello M, Di Pietro C, Lizzio MN, Patane G, Rabuazzo AM, Vigneri R, Purrello M, Purrello F. Chronic exposure to free fatty acids or high glucose induces apoptosis in rat pancreatic islets: possible role of oxidative stress. Metabolism. 2002;51:1340-47.

82 Schonfeld P, Wojtczak L. Fatty acids as modulators of the cellular production of reactive oxygen species. Free Radic Biol Med. 2008;45:231-41. 
83 Hue L, Taegtmeyer H. The Randle cycle revisited: a new head for an old hat. Am J Physiol Endocrinol Metab. 2009;297:E578-91.

84 Lu G, Greene EL, Nagai T, Egan BM. Reactive oxygen species are critical in the oleic acid-mediated mitogenic signaling pathway in vascular smooth muscle cells. Hypertension. 1998;32:1003-10.

85 Cury-Boaventura MF, Curi R. Regulation of reactive oxygen species (ROS) production by C18 fatty acids in Jurkat and Raji cells. Clin Sci (Lond). 2005;108:24553.

86 Inoguchi T, Li P, Umeda F, Yu HY, Kakimoto M, Imamura M, Aoki T, Etoh T, Hashimoto T, Naruse M, Sano H, Utsumi H, Nawata H. High glucose level and free fatty acid stimulate reactive oxygen species production through protein kinase $\mathrm{C}$-dependent activation of $\mathrm{NAD}(\mathrm{P}) \mathrm{H}$ oxidase in cultured vascular cells. Diabetes. 2000;49:1939-45.

87 Babior BM. NADPH oxidase: an update. Blood. 1999;93:1464-76.

88 Oliveira HR, Verlengia R, Carvalho CR, Britto LR, Curi R, Carpinelli AR. Pancreatic beta-cells express phagocyte-like NAD(P)H oxidase. Diabetes. 2003;52:1457-63.

89 Nakayama M, Inoguchi T, Sonta T, Maeda Y, Sasaki S, Sawada F, Tsubouchi H, Sonoda N, Kobayashi K, Sumimoto H, Nawata H. Increased expression of NAD(P)H oxidase in islets of animal models of Type 2 diabetes and its improvement by an AT1 receptor antagonist. Biochem Biophys Res Commun. 2005;332:927-33.

90 Uchizono Y, Takeya R, Iwase M, Sasaki N, Oku M, Imoto H, Iida M, Sumimoto H. Expression of isoforms of NADPH oxidase components in rat pancreatic islets. Life Sci. 2006;80:133-39.

91 Morgan D, Oliveira-Emilio HR, Keane D, Hirata AE, Santos da Rocha M, Bordin S, Curi R, Newsholme P, Carpinelli AR. Glucose, palmitate and pro-inflammatory cytokines modulate production and activity of a phagocyte-like NADPH oxidase in rat pancreatic islets and a clonal beta cell line. Diabetologia. 2007;50:359-69.

92 Morgan D, Rebelato E, Abdulkader F, Graciano MF, Oliveira-Emilio HR, Hirata AE, Rocha MS, Bordin S, Curi R, Carpinelli AR. Association of Nad(P)H Oxidase with Glucose-Induced Insulin Secretion by Pancreatic Beta Cells. Endocrinology. 2009; 150:2197-2201.

93 Femling JK, Cherny VV, Morgan D, Rada B, Davis AP, Czirjak G, Enyedi P, England SK, Moreland JG, Ligeti E, Nauseef WM, DeCoursey TE. The antibacterial activity of human neutrophils and eosinophils requires proton channels but not BK channels. J Gen Physiol. 2006;127:659-72. 
94 Babior BM, Lambeth JD, Nauseef W. The neutrophil NADPH oxidase. Arch Biochem Biophys. 2002;397:342-44.

95 Serrander L, Cartier L, Bedard K, Banfi B, Lardy B, Plastre O, Sienkiewicz A, Forro $\mathrm{L}$, Schlegel W, Krause KH. NOX4 activity is determined by mRNA levels and reveals a unique pattern of ROS generation. Biochem J. 2007;406:105-14.

96 de Mendez I, Homayounpour N, Leto TL. Specificity of p47phox SH3 domain interactions in NADPH oxidase assembly and activation. Mol Cell Biol. 1997; 17:2177-85.

97 Bedard K, Krause KH. The NOX family of ROS-generating NADPH oxidases: physiology and pathophysiology. Physiol Rev. 2007;87:245-313.

98 Nauseef WM. Assembly of the phagocyte NADPH oxidase. Histochem Cell Biol. 2004;122:277-91.

99 O'Donnell BV, Tew DG, Jones OT, England PJ. Studies on the inhibitory mechanism of iodonium compounds with special reference to neutrophil NADPH oxidase. Biochem J. 1993;290 ( Pt 1):41-49.

100 Pi J, Bai Y, Zhang Q, Wong V, Floering LM, Daniel K, Reece JM, Deeney JT, Andersen ME, Corkey BE, Collins S. Reactive oxygen species as a signal in glucosestimulated insulin secretion. Diabetes. 2007;56:1783-91.

101 Tsubouchi H, Inoguchi T, Inuo M, Kakimoto M, Sonta T, Sonoda N, Sasaki S, Kobayashi K, Sumimoto H, Nawata H. Sulfonylurea as well as elevated glucose levels stimulate reactive oxygen species production in the pancreatic beta-cell line, MIN6-a role of NAD(P)H oxidase in beta-cells. Biochem Biophys Res Commun. 2005;326:6065 .

102 Kinoshita H, Matsuda N, Kaba H, Hatakeyama N, Azma T, Nakahata K, Kuroda Y, Tange $\mathrm{K}$, Iranami $\mathrm{H}$, Hatano $\mathrm{Y}$. Roles of phosphatidylinositol 3-kinase-Akt and NADPH oxidase in adenosine 5'-triphosphate-sensitive $\mathrm{K}+$ channel function impaired by high glucose in the human artery. Hypertension. 2008;52:507-13.

103 Roberts CK, Barnard RJ, Sindhu RK, Jurczak M, Ehdaie A, Vaziri ND. Oxidative stress and dysregulation of $\mathrm{NAD}(\mathrm{P}) \mathrm{H}$ oxidase and antioxidant enzymes in dietinduced metabolic syndrome. Metabolism. 2006;55:928-34.

104 Graciano MF, Santos LR, Curi R, Carpinelli AR. NAD(P)H oxidase participates in the palmitate-induced superoxide production and insulin secretion by rat pancreatic islets. J Cell Physiol. 2010. In press.

105 Chen S, Lam TK, Park E, Burdett E, Wang PY, Wiesenthal SR, Lam L, Tchipashvili V, Fantus IG, Giacca A. Oleate-induced decrease in hepatocyte insulin binding is mediated by PKC-delta. Biochem Biophys Res Commun. 2006;346:931-37. 
106 Padovese R, Curi R. Modulation of rat neutrophil function in vitro by cis- and transMUFA. Br J Nutr. 2009;101:1351-59.

107 Livak KJ, Schmittgen TD. Analysis of relative gene expression data using real-time quantitative PCR and the 2(-Delta Delta C(T)) Method. Methods. 2001;25:402-08.

108 Bindokas VP, Kuznetsov A, Sreenan S, Polonsky KS, Roe MW, Philipson LH. Visualizing superoxide production in normal and diabetic rat islets of Langerhans. Journal of Biological Chemistry. 2003;278:9796-01.

109 Zhao H, Kalivendi S, Zhang H, Joseph J, Nithipatikom K, Vasquez-Vivar J, Kalyanaraman B. Superoxide reacts with hydroethidine but forms a fluorescent product that is distinctly different from ethidium: potential implications in intracellular fluorescence detection of superoxide. Free Radic Biol Med. 2003;34:1359-68.

110 Tietz NW. Textbook of Clinical Chemistry. 2nd ed. Philadelphia: Sauders Company; 1994.

111 Carpentier A, Mittelman SD, Lamarche B, Bergman RN, Giacca A, Lewis GF. Acute enhancement of insulin secretion by FFA in humans is lost with prolonged FFA elevation. Am J Physiol. 1999;276:E1055-66.

112 Nogueira TC, Anhe GF, Carvalho CR, Curi R, Bordin S, Carpinelli AR. Involvement of phosphatidylinositol-3 kinase/AKT/PKCzeta/lambda pathway in the effect of palmitate on glucose-induced insulin secretion. Pancreas. 2008;37:309-15.

113 Carpinelli AR, Picinato MC, Stevanato E, Oliveira HR, Curi R. Insulin secretion induced by palmitate--a process fully dependent on glucose concentration. Diabetes Metab. 2002;28:3S37-44.

114 Hirabara SM, Curi R, Maechler P. Saturated fatty acid-induced insulin resistance is associated with mitochondrial dysfunction in skeletal muscle cells. J Cell Physiol. 2010;222:187-94.

115 Haber EP, Ximenes HM, Procopio J, Carvalho CR, Curi R, Carpinelli AR. Pleiotropic effects of fatty acids on pancreatic beta-cells. J Cell Physiol. 2003;194:1-12.

116 Conget I, Rasschaert J, Sener A, Leclercq-Meyer V, Villanueva-Penacarrillo M, Valverde I, Malaisse WJ. Secretory, biosynthetic, respiratory, cationic, and metabolic responses of pancreatic islets to palmitate and oleate. Biochem Med Metab Biol. $1994 ; 51: 175-84$.

117 Abdul-Ghani MA, Muller FL, Liu Y, Chavez AO, Balas B, Zuo P, Chang Z, Tripathy D, Jani R, Molina-Carrion M, Monroy A, Folli F, Van Remmen H, DeFronzo RA. Deleterious action of FA metabolites on ATP synthesis: possible link between lipotoxicity, mitochondrial dysfunction, and insulin resistance. Am J Physiol Endocrinol Metab. 2008;295:E678-85. 
118 Newgard CB, Lu D, Jensen MV, Schissler J, Boucher A, Burgess S, Sherry AD. Stimulus/secretion coupling factors in glucose-stimulated insulin secretion: insights gained from a multidisciplinary approach. Diabetes. 2002;51 (Suppl 3):S389-93.

119 Fransson U, Rosengren AH, Schuit FC, Renstrom E, Mulder H. Anaplerosis via pyruvate carboxylase is required for the fuel-induced rise in the ATP:ADP ratio in rat pancreatic islets. Diabetologia. 2006;49:1578-86.

120 Stark R, Pasquel F, Turcu A, Pongratz RL, Roden M, Cline GW, Shulman GI, Kibbey RG. Phosphoenolpyruvate cycling via mitochondrial pepck links anaplerosis and mitochondrial GTP with insulin secretion. J Biol Chem. 2009;284:26578-90.

121 Iizuka K, Nakajima H, Namba M, Miyagawa J, Miyazaki J, Hanafusa T, Matsuzawa Y. Metabolic consequence of long-term exposure of pancreatic beta cells to free fatty acid with special reference to glucose insensitivity. Biochim Biophys Acta. 2002;1586:23-31.

122 Itoh Y, Hinuma S. GPR40, a free fatty acid receptor on pancreatic beta cells, regulates insulin secretion. Hepatol Res. 2005;33:171-73.

123 Doshi LS, Brahma MK, Sayyed SG, Dixit AV, Chandak PG, Pamidiboina V, Motiwala HF, Sharma SD, Nemmani KV. Acute administration of GPR40 receptor agonist potentiates glucose-stimulated insulin secretion in vivo in the rat. Metabolism. 2009;58:333-43.

124 Salehi A, Flodgren E, Nilsson NE, Jimenez-Feltstrom J, Miyazaki J, Owman C, Olde B. Free fatty acid receptor $1(\mathrm{FFA}(1) \mathrm{R} / \mathrm{GPR} 40)$ and its involvement in fatty-acidstimulated insulin secretion. Cell Tissue Res. 2005;322:207-15.

125 Zhao YF, Pei J, Chen C. Activation of ATP-sensitive potassium channels in rat pancreatic beta-cells by linoleic acid through both intracellular metabolites and membrane receptor signalling pathway. J Endocrinol. 2008;198:533-40.

126 Bikopoulos G, da Silva Pimenta A, Lee SC, Lakey JR, Der SD, Chan CB, Ceddia RB, M BW, Rozakis-Adcock M. Ex vivo transcriptional profiling of human pancreatic islets following chronic exposure to monounsaturated fatty acids. J Endocrinol. 2008;196:455-64.

127 Furukawa S, Fujita T, Shimabukuro M, Iwaki M, Yamada Y, Nakajima Y, Nakayama O, Makishima M, Matsuda M, Shimomura I. Increased oxidative stress in obesity and its impact on metabolic syndrome. J Clin Invest. 2004;114:1752-61.

128 Li Y, Cao Z, Zhu H. Upregulation of endogenous antioxidants and phase 2 enzymes by the red wine polyphenol, resveratrol in cultured aortic smooth muscle cells leads to cytoprotection against oxidative and electrophilic stress. Pharmacol Res. 2006;53:615. 
129 Rebelato E, Abdulkader F, Curi R, Carpinelli AR. Low doses of hydrogen peroxide impair glucose-stimulated insulin secretion via inhibition of glucose metabolism and intracellular calcium oscillations. Metabolism. 2010;59:409-13.

130 Morgan D, Rebelato E, Abdulkader F, Graciano MF, Oliveira-Emilio HR, Hirata AE, Rocha MS, Bordin S, Curi R, Carpinelli AR. Association of NAD $(\mathrm{P}) \mathrm{H}$ oxidase with glucose-induced insulin secretion by pancreatic beta-cells. Endocrinology. 2009;150:2197-01.

131 Cocco T, Di Paola M, Papa S, Lorusso M. Arachidonic acid interaction with the mitochondrial electron transport chain promotes reactive oxygen species generation. Free Radic Biol Med. 1999;27:51-59.

132 Seifert EL, Estey C, Xuan JY, Harper ME. Electron transport chain-dependent and independent mechanisms of mitochondrial $\mathrm{H} 2 \mathrm{O} 2$ emission during long-chain fatty acid oxidation. J Biol Chem. 2010;285:5748-58.

133 Nakamura S, Takamura T, Matsuzawa-Nagata N, Takayama H, Misu H, Noda H, Nabemoto S, Kurita S, Ota T, Ando H, Miyamoto K, Kaneko S. Palmitate induces insulin resistance in H4IIEC3 hepatocytes through reactive oxygen species produced by mitochondria. J Biol Chem. 2009;284:14809-18.

134 Inoguchi T, Tsubouchi H, Etoh T, Kakimoto M, Sonta T, Utsumi H, Sumimoto H, Yu HY, Sonoda N, Inuo M, Sato N, Sekiguchi N, Kobayashi K, Nawata H. A possible target of antioxidative therapy for diabetic vascular complications-vascular NAD(P)H oxidase. Curr Med Chem. 2003;10:1759-64.

135 Newsholme P, Haber EP, Hirabara SM, Rebelato EL, Procopio J, Morgan D, OliveiraEmilio HC, Carpinelli AR, Curi R. Diabetes associated cell stress and dysfunction: role of mitochondrial and non-mitochondrial ROS production and activity. J Physiol. 2007;583:9-24.

136 Sawada F, Inoguchi T, Tsubouchi H, Sasaki S, Fujii M, Maeda Y, Morinaga H, Nomura M, Kobayashi K, Takayanagi R. Differential effect of sulfonylureas on production of reactive oxygen species and apoptosis in cultured pancreatic beta-cell line, MIN6. Metabolism. 2008;57:1038-45.

137 Guichard C, Moreau R, Pessayre D, Epperson TK, Krause KH. NOX family NADPH oxidases in liver and in pancreatic islets: a role in the metabolic syndrome and diabetes? Biochem Soc Trans. 2008;36:920-29.

138 Nishikawa T, Kukidome D, Sonoda K, Fujisawa K, Matsuhisa T, Motoshima H, Matsumura T, Araki E. Impact of mitochondrial ROS production in the pathogenesis of insulin resistance. Diabetes Res Clin Pract. 2007;77 (Suppl 1):S161-64. 
139 Lee HB, Yu MR, Song JS, Ha H. Reactive oxygen species amplify protein kinase C signaling in high glucose-induced fibronectin expression by human peritoneal mesothelial cells. Kidney Int. 2004;65:1170-79.

140 Espinosa A, Garcia A, Hartel S, Hidalgo C, Jaimovich E. NADPH Oxidase and Hydrogen Peroxide Mediate Insulin-induced Calcium Increase in Skeletal Muscle Cells. J Biol Chem. 2009;284:2568-75.

141 Yun MR, Lee JY, Park HS, Heo HJ, Park JY, Bae SS, Hong KW, Sung SM, Kim CD. Oleic acid enhances vascular smooth muscle cell proliferation via phosphatidylinositol 3-kinase/Akt signaling pathway. Pharmacol Res. 2006;54:97-102.

142 Talior I, Yarkoni M, Bashan N, Eldar-Finkelman H. Increased glucose uptake promotes oxidative stress and PKC-delta activation in adipocytes of obese, insulinresistant mice. Am J Physiol Endocrinol Metab. 2003;285:E295-302.

143 Nishikawa T, Edelstein D, Brownlee M. The missing link: a single unifying mechanism for diabetic complications. Kidney Int Suppl. 2000;77:S26-30.

144 Lee SB, Bae IH, Bae YS, Um HD. Link between mitochondria and NADPH oxidase 1 isozyme for the sustained production of reactive oxygen species and cell death. J Biol Chem. 2006;281:36228-35.

145 Wosniak J, Santos CX, Kowaltowski AJ, Laurindo FR. Cross-Talk Between Mitochondria and NADPH Oxidase: Effects of Mild Mitochondrial Dysfunction on Angiotensin II-Mediated Increase in Nox Isoform Expression and Activity in Vascular Smooth Muscle Cells. Antioxid Redox Signal. 2009;11:1265-78.

146 Du XL, Edelstein D, Rossetti L, Fantus IG, Goldberg H, Ziyadeh F, Wu J, Brownlee M. Hyperglycemia-induced mitochondrial superoxide overproduction activates the hexosamine pathway and induces plasminogen activator inhibitor-1 expression by increasing Sp1 glycosylation. Proc Natl Acad Sci U S A. 2000;97:12222-26.

147 Cerella C, D'Alessio M, Cristofanon S, De Nicola M, Radogna F, Dicato M, Diederich M, Ghibelli L. Subapoptogenic oxidative stress strongly increases the activity of the glycolytic key enzyme glyceraldehyde 3-phosphate dehydrogenase. Ann N Y Acad Sci. 2009; 1171:583-90. 


\section{$\mathcal{A N E X O S}$}

\section{ANEXO A - Artigo 1}

\section{Artigo Aceito para Publicação}

Artigo 1 Graciano, M.F.R, Santos, L.R.B., Curi, R., Carpinelli, A.R. NAD(P)H oxidase participates in the palmitate-induced superoxide production and insulin secretion by rat pancreatic islets. J Cell Physiol. 2010. 


\title{
NAD(P)H Oxidase Participates in the Palmitate-Induced Superoxide Production and Insulin Secretion by Rat Pancreatic Islets
}

\author{
MARIA FERNANDA R. GRACIANO*, LAILA R.B. SANTOS, RUI CURI \\ AND ANGELO R. CARPINELLI
}

Department of Physiology and Biophysics, Institute of Biomedical Sciences, University of São Paulo (USP), São Paulo, SP, Brazil

\begin{abstract}
Nicotinamide adenine dinucleotide phosphate $[\mathrm{NAD}(\mathrm{P}) \mathrm{H}]$ oxidase complex has been shown to be involved in the process of glucosestimulated insulin secretion (GSIS). In this study, we examined the effect of palmitic acid on superoxide production and insulin secretion by rat pancreatic islets and the mechanism involved. Rat pancreatic islets were incubated during I h with I mM palmitate, I\% fatty acid freealbumin, 5.6 or $10 \mathrm{mM}$ glucose and in the presence of inhibitors of $\mathrm{NAD}(\mathrm{P}) \mathrm{H}$ oxidase (DPI-diphenyleneiodonium), PKC (calphostin C) and carnitine palmitoyl transferase-I (CPT-I) (etomoxir). Superoxide content was determined by hydroethidine assays. Palmitate increased superoxide production in the presence of 5.6 and $10 \mathrm{mM}$ glucose. This effect was dependent on activation of PKC and NAD(P)H oxidase. Palmitic acid oxidation was demonstrated to contribute for the fatty acid induction of superoxide production in the presence of $5.6 \mathrm{mM}$ glucose. In fact, palmitate caused $\mathrm{p} 47^{\mathrm{PHOX}}$ translocation to plasma membrane, as shown by immunohistochemistry. Exposure to palmitate for I h up-regulated the protein content of $\mathrm{p}^{4} 7^{\mathrm{PHOX}}$ and the mRNA levels of $\mathrm{p} 22^{\mathrm{PHOX}}, \mathrm{gP} 9 \mathrm{I}^{\mathrm{PHOX}}, \mathrm{p} 47^{\mathrm{PHOX}}$, proinsulin and the G protein-coupled receptor 40 (GPR40). Fatty acid stimulation of insulin secretion in the presence of high glucose concentration was reduced by inhibition of $\mathrm{NAD}(\mathrm{P}) \mathrm{H}$ oxidase activity. In conclusion, $\mathrm{NAD}(\mathrm{P}) \mathrm{H}$ oxidase is an important source of superoxide in pancreatic islets and the activity of $\mathrm{NAD}(\mathrm{P}) \mathrm{H}$ oxidase is involved in the control of insulin secretion by palmitate.
\end{abstract}

J. Cell. Physiol. 226: III0-III7, 2011. (C) 2010 Wiley-Liss, Inc.

Reactive oxygen species (ROS) are involved in pathological conditions such as diabetes (Baynes, 1991), cardiovascular diseases (Griendling et al., 2000; Ceriello and Motz, 2004; Victor et al., 2009), and neurodegeneration familial amyotrophic lateral sclerosis (Harraz et al., 2008). ROS also play a role in physiological processes such as vascular smooth muscle function (Suvorava and Kojda, 2009), insulin signaling pathway (Goldstein et al., 2005), and insulin secretion (Pi et al., 2007; Imoto et al., 2008; Morgan et al., 2009), acting as second messengers. Mitochondrial production of ROS has been demonstrated to play an important role in the pancreatic beta cell secretory function ( $\mathrm{Pi}$ et al., 2007). Evidence has been accumulated that pancreatic islets produce ROS also through NADPH oxidase activity, and this process is involved in glucosestimulated insulin secretion (GSIS) (Imoto et al., 2008; Morgan et al., 2009). In fact, short-time production of ROS is associated with GSIS but excessive or sustained production of ROS is negatively correlated with the insulin secretory process ( $\mathrm{Pi}$ et al., 2007; Imoto et al., 2008). Chronic exposure to relatively high levels of ROS leads to impairment of pancreatic beta cell function and chronic complications of diabetes (Baynes, 1991; Newsholme et al., 2007).

The NADPH oxidase complex has been well characterized in phagocytic cells, where it consists of the cytosolic components $\mathrm{p}^{4} 7^{\mathrm{PHOX}}, \mathrm{p} 67^{\mathrm{PHOX}}, \mathrm{p}^{4} 0^{\mathrm{PHOX}}$, a low molecular weight $\mathrm{G}$ protein, Rac I or Rac 2, and the membrane-associated cytochrome b558, including gP9| ${ }^{\text {PHOX }}$ (the catalytic subunit, with the transmembrane redox chain) and $\mathrm{p} 22^{\mathrm{PHOX}}$. In phagocytic cells, PKC activates NADPH oxidase by a phosphorylation-dependent activation of $\mathrm{p} 47^{\mathrm{PHOX}}, \mathrm{p} 67^{\mathrm{PHOX}}$, and/or Rac (Bedard and Krause, 2007). In these cells, activation of that enzyme complex requires translocation of the cytosolic components to the plasma membrane and their association with $\mathrm{gP} 91^{\mathrm{PHOX}} / \mathrm{p} 22^{\mathrm{PHOX}}$. P47 $7^{\mathrm{PHOX}}$ phosphorylation leads to a conformational change in this molecule that allows the interaction with $\mathrm{p} 22^{\mathrm{PHOX}}$. The $\mathrm{p} 47^{\mathrm{PHOX}}$ subunit translocation to the membrane leads the $\mathrm{p} 67^{\mathrm{PHOX}}$ into contact with gP9l ${ }^{\mathrm{PHOX}}$, bringing the $\mathrm{p}^{\mathrm{PHOX}}$ subunit to the complex. Finally, the GTPase Rac interacts with gP9/ ${ }^{\text {PHOX }}$. This assembled complex is active and produces superoxide by electron transfer from NADPH to oxygen (Bedard and Krause, 2007) (Fig. I). Previous studies have demonstrated the induction of $\mathrm{p}^{47^{\mathrm{PHOX}}}$ translocation to plasma membrane by a glucose stimulus in pancreatic islets (Oliveira et al., 2003).

Expression of the components of $\mathrm{NAD}(\mathrm{P}) \mathrm{H}$ oxidase complex and its homologues (NOXI, NOX4, NOXOI, and NOXAI) has already been demonstrated in pancreatic islets (Oliveira et al., 2003; Uchizono et al., 2006). Palmitate in the presence of low glucose concentration and pro-inflammatory cytokines increases superoxide production through NAD $(P) H$ oxidase activation in insulin secreting cells and pancreatic islets (Morgan et al., 2007). However, the importance of this enzyme complex for the palmitate-dependent insulin secretion after short-time exposure remains to be established.

Contract grant sponsor: Fundação de Amparo à Pesquisa do Estado de São Paulo (FAPESP);

Contract grant number: 2005/57946-7.

Contract grant sponsor: Conselho Nacional de Desenvolvimento Científico e Tecnológico (CNPq).

Contract grant sponsor: Instituto Nacional de Obesidade e Diabetes (INCT)

*Correspondence to: Maria Fernanda R. Graciano, Department of Physiology and Biophysics, Institute of Biomedical Sciences, University of São Paulo, Av. Prof. Lineu Prestes I524, São Paulo, SP, Brazil. E-mail: mafe@icb.usp.br

Received 18 June 2010; Accepted 3 September 2010

Published online in Wiley Online Library (wileyonlinelibrary.com), 20 September 2010. DOI: 10.1002/jcp.22432 


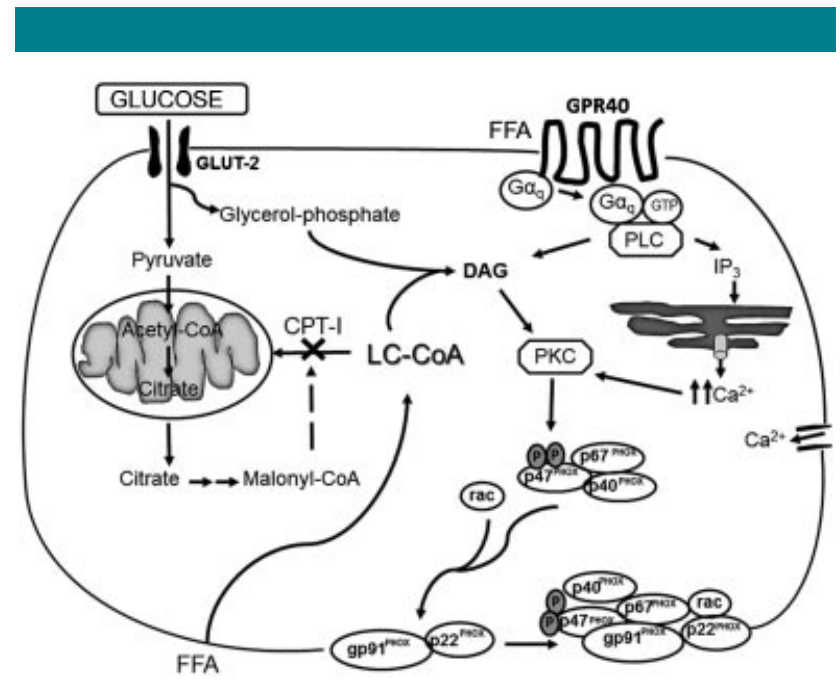

Fig. I. Proposed mechanism for free fatty acids modulation of NAD(P)H oxidase in pancreatic islets. FFA raise the insulin secretion induced by high glucose levels through the formation of malonyl-CoA that inhibits CPT-I, leading to an accumulation of LC-CoA in the cytosol. The influx of FFA into beta cells leads to an increase of acylCoA concentrations, raising the DAG content by the reaction with glycerol-phosphate. GPR40 activation by FFA stimulates the GoqPLC (phospholipase C) signaling pathway leading to calcium release from endoplasmatic reticulum stores and DAG production. DAG and calcium increases might be involved in PKC activation, which phosphorylates $\mathrm{NAD}(\mathrm{P}) \mathrm{H}$ oxidase subunits, inducing the translocation of the cytoplasmatic subunits to the membrane core. This assembled complex is active and catalyzes the superoxide production. LC-CoA: long-chain CoA; IP ${ }_{3}$ : inositol I,4,5trisphosphate; DAG: diacylglycerol; GTP: guanosine triphosphate.

Short-time exposure of pancreatic islets to free fatty acids (FFA) results in an increase of insulin secretion (Crespin et al., 1973; Warnotte et al., 1994; Carpinelli et al., 2002), whereas chronic exposure leads to a decrease (Zhou and Grill, I994; Wang et al., 2006). During short-time exposure, FFA synergistically raise the insulin secretion induced by high glucose levels through the formation of malonyl-CoA that inhibits carnitine palmitoyl transferase-I (CPT-I), leading to an accumulation of long-chain CoA (LC-CoA) in the cytosol (Chen et al., 1994). Inhibition of fatty acid oxidation increases the formation of LC-CoA and several other complex lipids that are important effectors of insulin secretion, by inducing PKC activation, protein acylation (Corkey et al., 2000), calcium influx (Warnotte et al., 1994; Olofsson et al., 2004), and stimulation of $\mathrm{Ca}^{2+}$ ATPases (Deeney et al., 1992). Pancreatic islets show high levels of GPR40, a G $\alpha$ q receptor activated by fatty acids such as oleic, linoleic, and palmitic acids (Briscoe et al., 2003; Itoh et al., 2003; Kotarsky et al., 2003; Itoh and Hinuma, 2005). GPR40 activation enhances glucose-stimulated accumulation of cytosolic calcium and consequently insulin release (Itoh et al., 2003; Fujiwara et al., 2005; Shapiro et al., 2005; Doshi et al., 2009) (Fig. I). FFA released through triglyceride/FFA cycling are partially secreted from pancreatic islets (Martins et al., 2004) and may activate the GPR40 pathway via autocrine and/or paracrine mechanisms (Nolan et al., 2006).

High plasma levels of palmitic acid are involved with abnormal islet function and type- 2 diabetes. This effect has been associated to increased lipid esterification, production of ceramides, and oxidative stress (Briaud et al., 200I). The intensified ROS production involved in the streptozotocininduced experimental diabetes leads to generation of lipid peroxides and hydroperoxides, by oxidative degradation of polyunsaturated fatty acids, that damage proteins and DNA (Palsamy and Subramanian, 20I0). The stimulating effect of FFA on ROS production has been demonstrated in several cell types (Inoguchi et al., 2000; Lambertucci et al., 2008; Muller et al., 2008). Fatty acids and their derivatives may modulate the efficiency of the mitochondrial respiratory chain by the inhibition of complexes I and III, thereby promoting generation of ROS (Schonfeld and Wojtczak, 2008).

The aim of the present study was then to investigate the effect of palmitic acid on superoxide production by rat pancreatic islets, the mechanism involved and its influence on insulin secretion. The signaling proteins directly activated by that fatty acid in pancreatic beta cell, such as PKC and GPR40, were also investigated.

\section{Materials and Methods Chemicals}

All chemicals for buffer preparation and diphenyleneiodonium (DPI) were obtained from Sigma-Aldrich Chemical (St. Louis, MO). Hydroethidine was obtained from Molecular Probes (Eugene, OR). Trizol, random primers, deoxyribonuclease I, SuperScript III, and SYBR Green were obtained from Invitrogen Life Technologies (Paisley, Scotland, UK). Reagents for sodium dodecyl sulfatepolyacrylamide gel electrophoresis (SDS-PAGE) and immunoblotting were obtained from Bio-Rad (Richmond, CA).

\section{Isolation of rat pancreatic islets}

Female Wistar albino rats weighing 250-300 g were obtained from the Institute of Biomedical Sciences, University of São Paulo, and kept under standard lighting conditions ( 12 h light/dark cycle) at a temperature of $23 \pm 1^{\circ} \mathrm{C}$, in groups of five, and were allowed free access to standard rodent chow and water until being studied. Ethics approval was granted for this study by the Animal Experimental Committee of the Institute of Biomedical Sciences, University of São Paulo. Islets of Langerhans were isolated from rats by pancreas digestion with collagenase as previously described (Lacy and Kostianovsky, 1967).

\section{Measurement of superoxide production by pancreatic islets}

Batches of 20 islets were preincubated at $37^{\circ} \mathrm{C}$ for $30 \mathrm{~min}$ in $0.5 \mathrm{ml}$ Krebs-Henseleit buffer $(\mathrm{KH})$ with $1 \%$ bovine serum albumin essentially free of fatty acids (BSA) and incubated for I $\mathrm{h}$ in $\mathrm{KH}$ with I\% BSA in the absence or presence of I mM palmitic acid and diphenyleneiodonium (DPI- $10 \mu \mathrm{M})$, calphostin C (Calp-I $\mu \mathrm{M})$, or etomoxir (Eto- $50 \mu \mathrm{M})$. Using the stepwise equilibrium method described elsewhere (Spector et al., 197I), the free concentration of I mM palmitate in the presence of $1 \%(\mathrm{w} / \mathrm{v}) \mathrm{BSA}$ corresponds to $10-100 \mu M$ (Olofsson et al., 2004). The concentration used for etomoxir, the CPT-I inhibitor (Fig. 2F,G, $50 \mu \mathrm{M}$ ), causes $70 \%$ inhibition of palmitate oxidation by pancreatic islets in low glucose concentration (Lehtihet et al., 2003). Calphostin $C$ at I $\mu M$ (Fig. 2C,D) has been shown to cause a marked reduction of the acute effect of palmitate on insulin secretion by pancreatic islets in the presence of $16.7 \mathrm{mM}$ glucose (Thams and Capito, 200I). Hydroethidine at a final concentration of $100 \mu \mathrm{M}$ was added and islets, protected from light, were incubated for additional $20 \mathrm{~min}$ at room temperature. After this period, the islets were washed twice with $\mathrm{KH}$ buffer without glucose and transferred to glass coverslips for confocal microscopy analysis (LSM 510, Axiovert 100 M, Carl Zeiss, Göttingen, Germany) using excitation wavelength set at $488 \mathrm{~nm}$ and emission wavelength between 560 and $615 \mathrm{~nm}$ (Zhao et al., 2003). Hydroethidine oxidation was quantified by the fluorescence emission intensity corrected for the islet area as previously published (Morgan et al., 2007). The same parameters were used for the analysis of all samples in each experiment. Controls for hydroethidine oxidation by superoxide were performed by pre-incubation of the islets for $\mathrm{I} \mathrm{h}$ at $5.6 \mathrm{mM}$ glucose in the absence or presence of polyethylene glycol-superoxide dismutase 
A

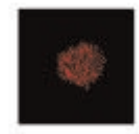

$5.6 \mathrm{mM}$ glucose
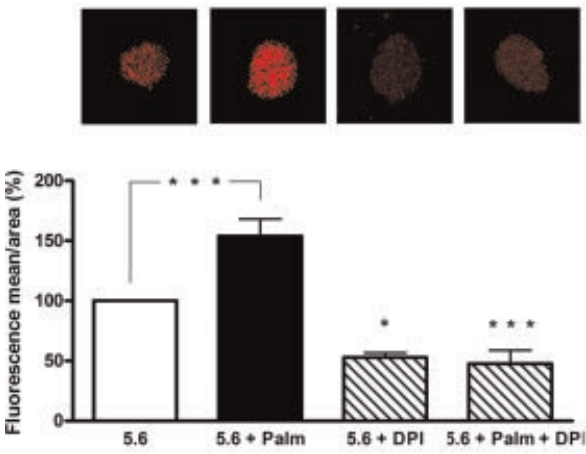

C

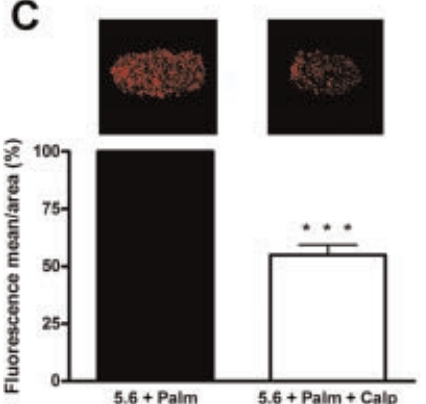

$\mathbf{F}$
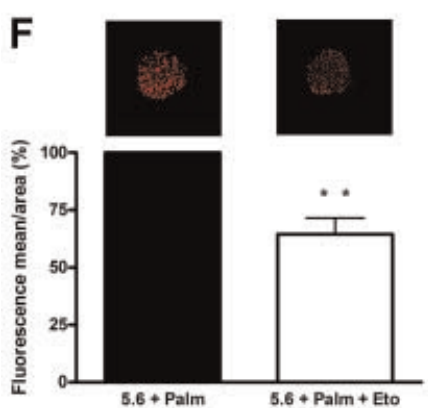

B $10 \mathrm{mM}$ glucose
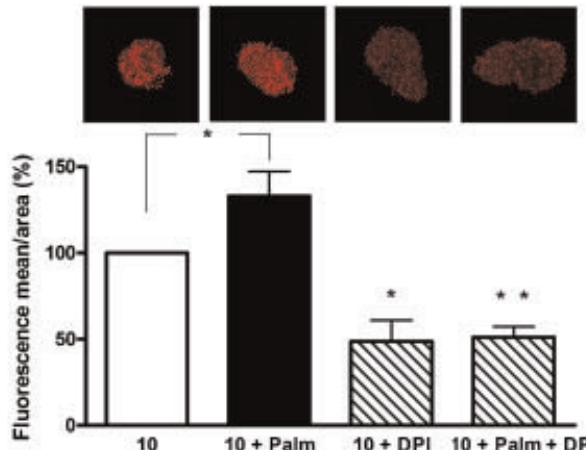

D
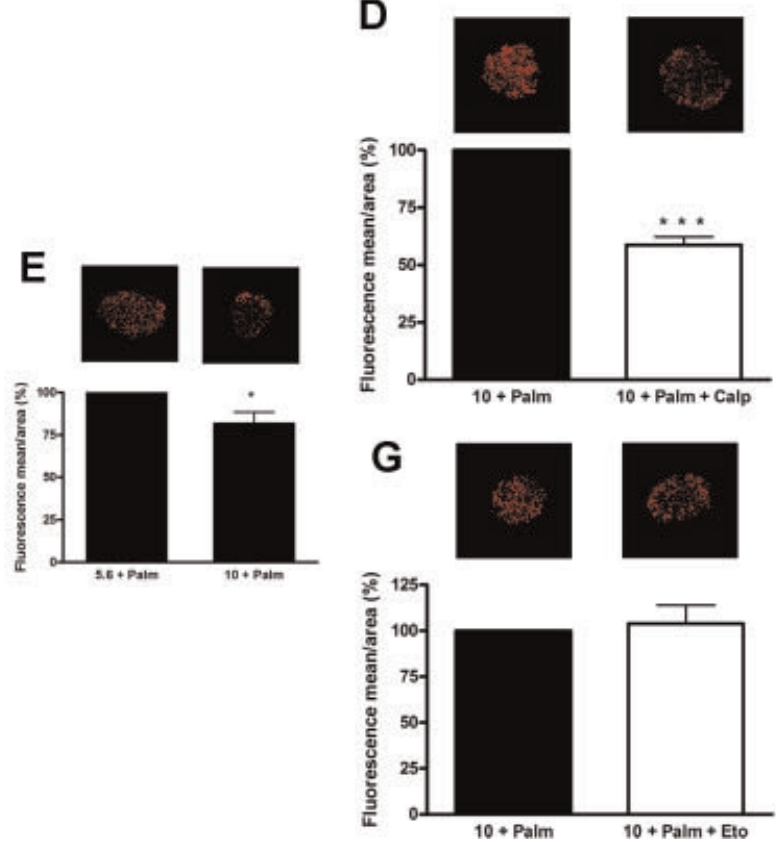

Fig. 2. Effect of palmitate on superoxide production by isolated pancreatic islets. The content of superoxide in isolated rat pancreatic islets was determined using the hydroethidine oxidation assay. The fluorescence intensity of islets was analyzed using confocal microscopy. Groups of 20 islets were preincubated in $5.6 \mathrm{mM}$ glucose for $30 \mathrm{~min}$ and incubated in $\mathrm{KH}$ with $\mathrm{I} \% \mathrm{BSA}$ in the presence of $5.6(\mathrm{~A}, \mathrm{C}, \mathrm{F})$ and I0 (B,D,G) mM glucose with I mM palmitate (Palm) for I h. A and B, Superoxide content in islets incubated with glucose, palmitate and I0 $\mu$ M DPI. The samples with DPI were compared with the respective conditions without the NAD(P)H oxidase inhibitor. C,D: Superoxide content in islets incubated with palmitate in 5.6 and $10 \mathrm{mM}$ glucose and I $\mu$ M of the PKC inhibitor calphostin C (Calp). E: Comparison of superoxide content in islets incubated with palmitate in 5.6 and $10 \mathrm{mM}$ glucose. F, G: Superoxide content in islets incubated with palmitate in 5.6 and I $0 \mathrm{mM}$ glucose and $50 \mu \mathrm{M}$ CPT-I inhibitor, etomoxir (Eto). The results are expressed as mean $\pm \mathrm{SEM}$ and normalized to controls. ${ }^{*} P<0.05,{ }^{* *} P<0.01$, and ${ }^{* * *} P<0.001$ versus the respective control conditions ( $\mathrm{n} \geq \mathbf{4}$ independent experiments).

(PEG-SOD- $100 \mathrm{U} / \mathrm{ml}$ ) and incubation for $\mathrm{l} \mathrm{h}$ at 5.6 or $10 \mathrm{mM}$ glucose with palmitate, also in the absence or presence of PEG-SOD $(100 \mathrm{U} / \mathrm{ml})$.

\section{Static insulin secretion}

Groups of five islets were preincubated at $37^{\circ} \mathrm{C}$ for $30 \mathrm{~min}$ in $0.5 \mathrm{ml}$ $\mathrm{KH}$ with $\mathrm{I} \% \mathrm{BSA}$ and incubated for $\mathrm{I} \mathrm{h}$ in $\mathrm{KH}$ with $\mathrm{I} \% \mathrm{BSA}$ in the absence or presence of I mM palmitic acid and $10 \mu \mathrm{M} \mathrm{DPI}$ and equilibrated in a mixture of $\mathrm{O}_{2}(95 \%)$ and $\mathrm{CO}_{2}(5 \%)$. The concentrations of glucose used were 5.6 and $10 \mathrm{mM}$. At the end of the experiment, the medium was collected and insulin was measured by radioimmunoassay (RIA). The islets were resuspended in $0.5 \mathrm{ml}$ alcohol acid solution (52 ethanol: 17 water: I chloridric acid) and sonicated for the measurement of the insulin content by RIA. p47 ${ }^{\text {PHOX }}$ translocation assay

Batches of 300 islets were preincubated at $37^{\circ} \mathrm{C}$ for $30 \mathrm{~min}$ in $0.5 \mathrm{ml}$ $\mathrm{KH}$ with I\% BSA and incubated for I h in $\mathrm{KH}$ with I\% BSA with 5.6 or $10 \mathrm{mM}$ glucose in the absence or presence of I mM palmitic acid, or with $10 \mathrm{mM}$ glucose plus phorbol 12-myristate 13-acetate (PMA - $20 \mathrm{nM}$ ). After incubation, pancreatic islets were fixed in $1 \%$ paraformaldehyde, $\mathrm{pH} 7.3$ and $0.1 \mathrm{M}$ phosphate buffer (PB) for $30 \mathrm{~min}$ and cryoprotected in $10 \%$ sucrose solution at $4{ }^{\circ} \mathrm{C}$. The islets were frozen in tissue freezing medium (TBS, Durham, $\mathrm{NC})$ and cut $(12 \mu \mathrm{m})$ on a cryostat. Slices were kept at $37^{\circ} \mathrm{C}$ for $30 \mathrm{~min}$ in gelatinized slides and stored at $-20^{\circ} \mathrm{C}$. For immunohistochemistry assays, the islet sections were blocked for $2 \mathrm{~h}$ in a solution containing $5 \%$ normal goat serum and $0.3 \%$ Triton $\mathrm{X}-100$ in PB. In order to determine the expression of $\mathrm{p} 47^{\mathrm{PHOX}}$, a polyclonal antibody raised against glutathione-S-transferase (GST) 
fusion protein corresponding to full-length human $\mathrm{p} 47^{\mathrm{PHOX}}$, from Upstate Biotechnology (Temecula, CA), was used in a I:50 dilution with $0.3 \%$ Triton $X-100$ in PB. The sections were incubated with the primary antibody overnight at room temperature. After several washes, sections were incubated with a secondary antibody conjugated to fluorescein isothiocyanate (FITC; I:200; Jackson Labs, West Grove, PA) in $0.3 \%$ Triton X-100 in PB. Controls for the experiments consisted of the omission of the primary antibody, which completely abolished the staining. After washing, the tissue was mounted using Vecta Shield (Vector Labs, Burlingame, CA) mounting solution. For protein migration analysis a wide-field fluorescence microscope was used (EI000, Nikon, Tokyo, Japan).

\section{Western blotting}

Groups of 300 islets were resuspended in $80 \mu$ l extraction buffer ( $100 \mathrm{mM}$ Trizma, I\% SDS, $100 \mathrm{mM}$ sodium pyrophosphate, $100 \mathrm{mM}$ sodium fluoride, $10 \mathrm{mM}$ EDTA, and $10 \mathrm{mM}$ sodium vanadate), homogenized using an ultrasonic processor (Sonics \& Materials, Newtown, PA), and boiled for $10 \mathrm{~min}$. The extracts were then centrifuged at $12,000 \mathrm{rpm}$, at $4^{\circ} \mathrm{C}$, for $20 \mathrm{~min}$ to remove insoluble material. Protein determination in the supernatants was performed by the Bradford dye method using the Bio-Rad reagent (Bradford, 1976). The samples were treated with Laemmli sample buffer (Laemmli, 1970) containing dithiothreitol and boiled for 5 min before loading onto 8-12\% SDS-PAGE in a Bio-Rad miniature slab gel apparatus. Similar-sized aliquots $(60 \mu \mathrm{g})$ were subjected to SDS-PAGE. The electrotransfer of proteins from the gel to nitrocellulose was performed for $1.5 \mathrm{~h}$ at $120 \mathrm{~V}$ in a Bio-Rad miniature transfer apparatus. Non-specific protein binding to the nitrocellulose was reduced by preincubation for $2 \mathrm{~h}$ at $22^{\circ} \mathrm{C}$ in blocking buffer ( $5 \%$ non-fat dry milk, $10 \mathrm{mM}$ Trizma, $150 \mathrm{mM} \mathrm{NaCl}$, and $0.02 \%$ Tween 20). The nitrocellulose membranes were incubated overnight at $4{ }^{\circ} \mathrm{C}$ with antibodies against PKC $(1: 1,000)$ and GPR40 (I:500) from Santa Cruz Biotechnology (Santa Cruz, CA), phospho-PKC $\alpha / \beta I I$ (Thr 638/64I) (I:I,000), gP9I ${ }^{\text {PHOX }}$ $(I: 500)$ and $p^{4} 7^{\mathrm{PHOX}}(\mathrm{I}: 500)$ from Millipore (Temecula, CA), and $\alpha$-tubulin $(1: 2,000)$ from Zymed-Invitrogen (Carlsbad, CA) diluted in blocking buffer with $3 \%$ non-fat dry milk, and then washed for $30 \mathrm{~min}$ in blocking buffer without milk. The blots were subsequently incubated with peroxidase-conjugated secondary antibodies $(\mathrm{I}: \mathrm{I} 0,000)$ for $\mathrm{I} \mathrm{h}$, and processed for enhanced chemiluminescence to visualize the immunoreactive bands. Band intensities were quantified by optical densitometry (Scion ImageRelease Beta 3b, NIH, Bethesda, MD) of the developed autoradiographs.

\section{Real-time PCR}

Total RNA was extracted from 300 islets, using the Trizol reagent as described in the manufacturer's protocol. Total RNA $(3 \mu \mathrm{g})$ was reverse transcribed to cDNA. Gene expression of $\mathrm{p} 47^{\mathrm{PHOl}}$, gP91 ${ }^{\text {PHOX }}$, P22 $2^{\text {PHOX }}$, GPR40 and proinsulin was evaluated by realtime PCR using a Rotor Gene 3000 equipment (Corbett Research, Mortlake, Australia), and SYBR Green as fluorescent dye. Gene expression was calculated by the $2^{-\Delta \Delta C_{t}}$ (cycle threshold) method (Livak and Schmittgen, 200I), using hypoxanthine-guanine phosphoribosyltransferase (HPRT) expression as internal control. The sequences of the primers used were: GPR40 (sense, TCCTTTGCCACCTGGGACTG, antisense, CATTCACGG GTATGTTGATGCC), proinsulin (sense, CAGGTCATTGTTCC AACATGGC, antisense, ACTTCACG ACGGGACTTGGG), P22 $2^{\text {PHOX }}$ (sense, GAGGTCCGCAAGAAGCCAAG, antisense, GAAACTCAA GCAGGAGCCACTG), gP9| ${ }^{\text {PHOX }}$ (sense, TGCCCAGTAC CAAAGTTTGCC, antisense, GACCCACGA TCCATTTCCAAG), p $47^{\text {PHOX }}$ (sense, CTTCATTCG CCACATCGC, antisense, TTTCTGTAGACC ACCTTCTCCG), and HPRT (sense, GCTGAAGATTTGGAAAAGGTGT, antisense ACAGAGGGCCACAATGTGAT).

\section{Statistical analysis}

Results are presented as mean \pm SEM. The statistical analysis was carried out using one-way ANOVA or Student's t-test as appropriate. The level of significance was set to $P<0.05$. The results of insulin secretion, superoxide production, and mRNA levels were expressed as arbitrary units (AU); for adjustment of the independent experimental data, control values were set to I or 100 $\mathrm{AU}$, and the relative values of the experimental conditions were then calculated.

\section{Results}

Palmitate stimulation of superoxide production involves NAD(P)H oxidase, PKC, and fatty acid oxidation

Palmitate treatment increased superoxide content in pancreatic islets by $54 \%$ in $5.6 \mathrm{mM}$ glucose (Fig. 2A) and by $36 \%$ in $10 \mathrm{mM}$ glucose after I h exposure (Fig. 2B); these effects were reduced by $61-69 \%$, respectively, by incubation with DPI (Fig. 2A,B). These observations reinforce the participation of the NAD $(P) H$ oxidase complex in the palmitate-induced increase of intracellular superoxide content. DPI also reduced the increase of superoxide content induced by glucose. The superoxide increase induced by palmitate was dependent on conventional and/or novel PKCs. Incubation with calphostin C reduced the superoxide production observed after treatment with palmitate by $45 \%$ in the presence of $5.6 \mathrm{mM}$ glucose (Fig. 2C) and by $41 \%$ in $10 \mathrm{mM}$ glucose (Fig. 2D).

The superoxide content in islets incubated with palmitate was $20 \%$ lower in $10 \mathrm{mM}$ compared with $5.6 \mathrm{mM}$ glucose (Fig. 2E). Islets incubated with etomoxir, a CPT-I irreversible inhibitor, showed a $45 \%$ reduction of the superoxide content in $5.6 \mathrm{mM}$ glucose (Fig. 2F) and did not change in $10 \mathrm{mM}$ glucose in the presence of palmitate (Fig. 2G). These findings indicate that fatty acid oxidation is involved in superoxide generation by pancreatic islets.

Hydroethidine oxidation by superoxide was confirmed by addition of PEG-SOD $(100 \mathrm{U} / \mathrm{ml})$ in islets incubated with the fatty acid in 5.6 or $10 \mathrm{mM}$ glucose. This treatment decreased hydroethidine oxidation by $60 \%$ (data not shown).

\section{Involvement of $\mathrm{NAD}(\mathrm{P}) \mathrm{H}$ oxidase in palmitate-induced insulin secretion}

The addition of DPI abrogated the stimulation of insulin secretion induced by palmitate in high glucose concentration, demonstrating the involvement of the NAD $(\mathrm{P}) \mathrm{H}$ oxidase complex in this process. The incubation with DPI also inhibited the effect of glucose on insulin release (Fig. 3A).

Palmitate induced $\mathrm{p} 47^{\mathrm{PHOX}}$ translocation to the plasma membrane of the cells in sections of pancreatic islets. This effect was more evident in the presence of $10 \mathrm{mM}$ glucose (Fig. 3B). High glucose itself and in association with PMA increased P47PHOX immunoreactivity near the plasma membrane, which demonstrates that PKC activation is a phenomenon associated to the assembling of the oxidase complex in pancreatic islets.

\section{Palmitate modulates the expression of GPR40, proinsulin, and the NAD(P)H oxidase components}

The mRNA content of GPR40, the membrane receptor activated by medium and long chain fatty acids, was upregulated (by 100\%) due to palmitate treatment in the presence of $10 \mathrm{mM}$ glucose when compared to $5.6 \mathrm{mM}$ glucose (Fig. 4A). The proinsulin mRNA content was also increased (by $110 \%$ ) under the same condition (Fig. 4B). The mRNA contents of the P22 $2^{\text {PHOX }}$, gP9 $91^{\text {PHOX }}$, and $447^{\text {PHOX }}$ subunits were all increased in islets incubated with palmitate in the presence of low and high glucose concentrations (Fig. 4C-E, respectively).

Protein concentrations of GPR40, PKC, and phosphorylation (Thr 638/64I) of the conventional $\alpha / \beta$ II 


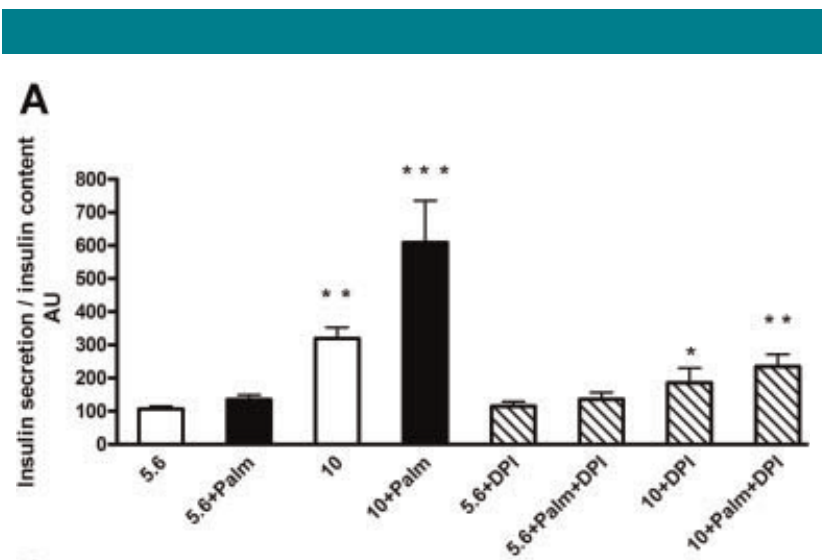

B
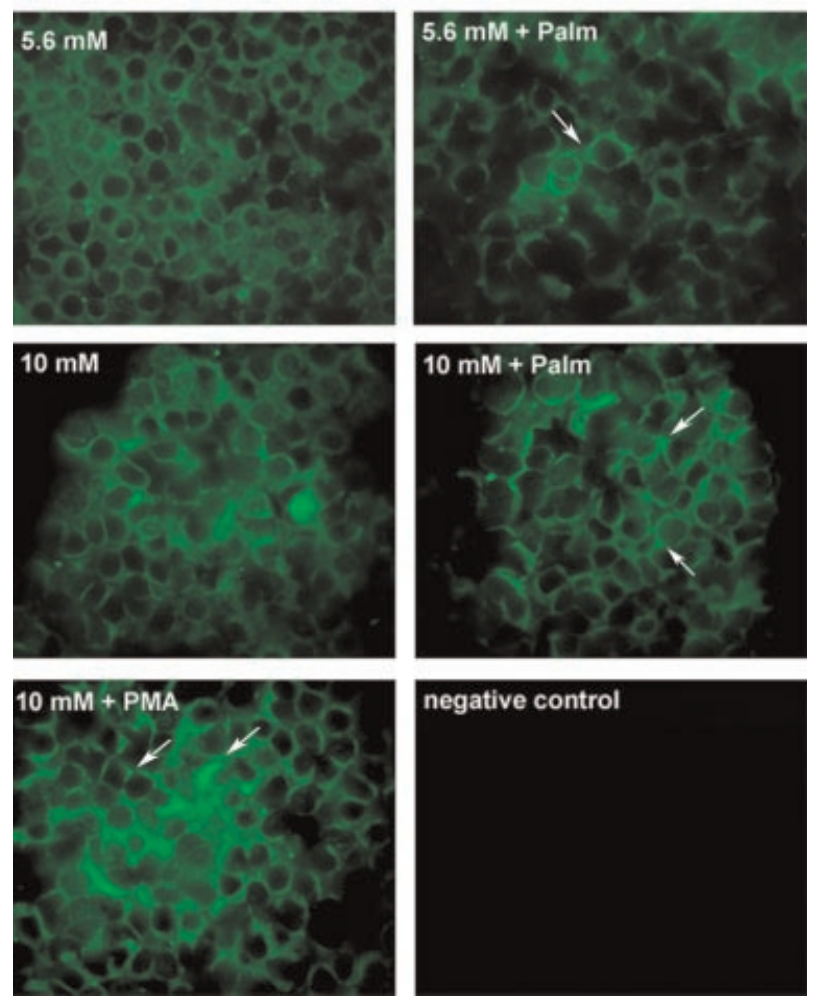

Fig. 3. Involvement of $\mathrm{NAD}(\mathrm{P}) \mathrm{H}$ oxidase activation in insulin secretion and $\mathrm{p} 47^{\mathrm{PHOX}}$ translocation induced by palmitate. A: Groups of five islets were preincubated for $30 \mathrm{~min}$ in $5.6 \mathrm{mM}$ glucose and insulin secretion was measured in function of the insulin content after 60-min incubation in $\mathrm{KH}$ with $1 \%$ BSA in the presence of 5.6 and $10 \mathrm{mM}$ glucose in the absence or presence of $1 \mathrm{mM}$ palmitate and $10 \mu M$ DPI $(n=6)$. The AU is expressed as mean \pm SEM of the insulin secretion/insulin content and normalized to the $5.6 \mathrm{mM}$ glucose control $(100 \%)$. ${ }^{* *} P<0.0 \mathrm{I}$ and ${ }^{* * *} P<0.00 \mathrm{I}$ versus control $(5.6 \mathrm{mM}$ glucose) or the respective condition without inhibitor. B: Fluorescent detection of $\mathrm{p}^{\mathrm{PHOX}}$ translocation to plasma membrane in islets preincubated in $\mathbf{5 . 6} \mathrm{mM}$ glucose for 30 min and incubated in $\mathrm{KH}$ with $1 \%$ BSA in the presence of 5.6 and $10 \mathrm{mM}$ glucose with $1 \mathrm{mM}$ palmitate (Palm) and $10 \mathrm{mM}$ glucose plus PMA (20 nM) for I h. Arrows represent increased $\mathrm{p} 47^{\mathrm{PHOx}}$ immunoreactivity near the plasma membrane. The figure is a representative image of three independent experiments.

isoforms of PKC were not altered after I h incubation in the presence of palmitate (Fig. 5). However, protein content of the $\mathrm{P} 47^{\mathrm{PHOX}}$ was increased by $60 \%$ due to palmitate in $5.6 \mathrm{mM}$ glucose and by $84.6 \%$ in $10 \mathrm{mM}$ glucose, with no change in gP91 ${ }^{\text {PHOX }}$ protein content (Fig. 5).

\section{Discussion}

Several mechanisms are involved in the control of beta cell function by FFA: synthesis of lipid signaling molecules (Nolan et al., 2006), modulation of PKC activity and insulin receptor signaling (Haber et al., 2003; Graciano et al., 2009; Nogueira et al., 2009), modulation of calcium channel activity (Warnotte et al., 1994; Olofsson et al., 2004), protein acylation (Corkey et al., 2000), and activation of cell surface receptors (Itoh et al., 2003; Fujiwara et al., 2005; Shapiro et al., 2005; Doshi et al., 2009). The present study investigated the participation of superoxide originated from $\mathrm{NAD}(\mathrm{P}) \mathrm{H}$ oxidase in the control of insulin secretion by FFA. The fatty acids are supplied to pancreatic beta cells from intracellular triglycerides and phospholipids and, from plasma FFA and lipoproteins (Nolan et al., 2006). The FFA originated from plasma triglycerides can access beta cells by the action of lipoprotein lipases (Pappan et al., 2005). Therefore, beta cells are probably exposed to higher concentrations of fatty acids in comparison with plasma, however, the actual concentration of FFA in the beta cells is not known. The concentrations of FFA range from 0.2 to $1.7 \mathrm{mM}$ in plasma, but $99 \%$ or more of the FFA are tightly bound to serum albumin so that the concentrations of unbound FFA range from 0.01 to $10 \mu M$ (Spector et al., 197I; Spector and Hoak, 1975; Hirabara et al., 2007). In this present work, to reach the unbound free fatty acid concentration of $10-100 \mu M$ in the immediate vicinity of beta cell, I $\mathrm{mM}$ palmitate was added in presence of $1 \%(w / v)$ BSA.

Palmitate increases production of ROS in aortic smooth muscle cells, endothelial cells (Inoguchi et al., 2000), skeletal muscle cells (Lambertucci et al., 2008), and adipocytes (Muller et al., 2008) through a process that is dependent on NAD(P)H oxidase. In pancreatic islets, palmitate was demonstrated herein and in a previous study (Morgan et al., 2007) to increase superoxide content in a short-time exposure through activation of $\mathrm{NAD}(\mathrm{P}) \mathrm{H}$ oxidase in the presence of $5.6 \mathrm{mM}$ glucose. Palmitate raised superoxide production also in $10 \mathrm{mM}$ glucose (Fig. 2B), but the effect was clearly more pronounced in low $(5.6 \mathrm{mM})$ glucose. This might be the result of an intense fatty acid oxidation in low glucose concentration, when glucose oxidation is low (Carpinelli et al., 2002; Hellemans et al., 2007). In fact, incubation with etomoxir demonstrated the participation of beta-oxidation in the production of superoxide induced by palmitate in pancreatic islets.

The superoxide production induced by palmitate varied with the glucose concentration (Fig. 2E) also possibly as a consequence of activation of the antioxidant defense mechanisms in the presence of high glucose. In fact, the activity of $\mathrm{Cu} / \mathrm{Zn}$ superoxide dismutase $(\mathrm{Cu} / \mathrm{Zn}-\mathrm{SOD})$ is positively correlated with glucose concentration in incubated pancreatic islets (Oliveira et al., 1999). Therefore, Cu/Zn-SOD activation possibly prevented large increases of the superoxide content due to palmitate treatment in $10 \mathrm{mM}$ glucose.

As FFA are well-known activators of conventional and novel isoforms of PKCs (Haber et al., 2003). The general PKC inhibitor, calphostin $\mathrm{C}$, was then used to investigate the participation of the PKC in palmitate-induced superoxide production. Palmitate induction of superoxide increase was correlated with $\mathrm{p} 47^{\mathrm{PHOX}}$ translocation to plasma membrane (Figs. 2A,B and $3 B$ ), which is dependent on PKC activation (Fig. 2C,D). The serine phosphorylation of $\mathrm{p} 47^{\mathrm{PHOX}}$ causes recruitment of the cytosolic components and triggers their interaction with cytochrome b558, assembling the oxidase complex (Bedard and Krause, 2007). In human monocytes, fatty acids directly activate PKC, leading to simultaneous phosphorylation and translocation of the $\mathrm{P} 47^{\mathrm{PHOX}}$ subunit to the plasma membrane (Kadri-Hassani et al., I995), as observed in our experiments (Fig. 3B) and in a previous study with a glucose stimulus (Oliveira et al., 2003). Recent studies have 


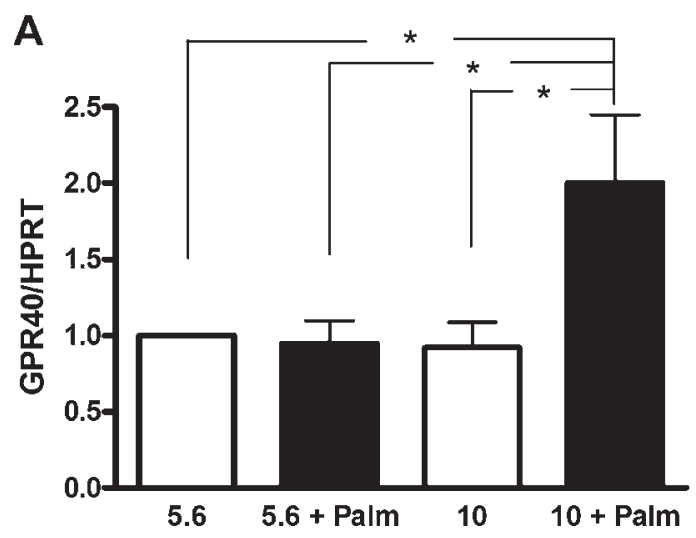

B
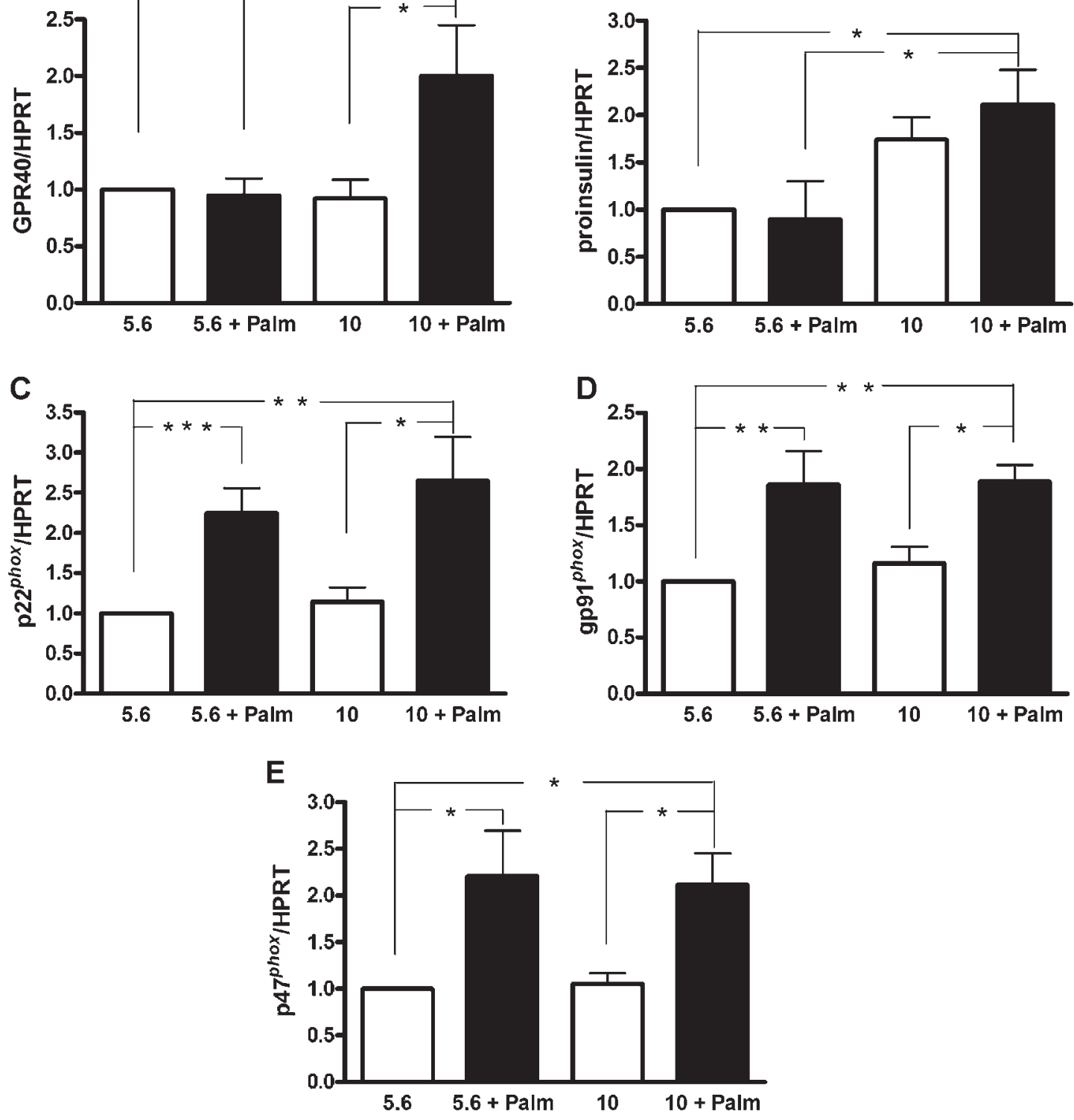

Fig. 4. Effect of palmitate on the expression of GPR40, proinsulin, and NAD(P)H oxidase genes. Groups of 300 islets were preincubated with $5.6 \mathrm{mM}$ glucose for $30 \mathrm{~min}$ and incubated in $\mathrm{KH}$ with $\mathrm{I} \% \mathrm{BSA}$ in the presence of 5.6 and $\mathrm{I} 0 \mathrm{mM}$ glucose (white bars) with I mM palmitate (Palm) (black bars) for I h. A: GPR40; B, proinsulin; C, 222 $^{\text {PHOX }}$; D, gP9 I $^{\text {PHOX }}$; and E, p47 $7^{\text {PHOX }}$ mRNA levels were analyzed by RT-PCR in relation to the housekeeping gene HPRT using $3 \mu \mathrm{g}$ total RNA. The bars represent the relative gene expression and are presented as mean $\pm S E M$. ${ }^{*} P<0.05$, ${ }^{* *} P<0.01$, and ${ }^{* * *} P<0.001$ ( $\mathrm{n} \geq 5$ independent experiments).

demonstrated the participation of conventional and novel PKCs $\left(\alpha\right.$ and $\delta$, respectively) in $447^{\mathrm{PHOX}}$ activation in lineages of fibroblasts and macrophages (laccio et al., 2007; Higai et al., 2008).

The influx of palmitate into beta cells leads to an increase of acyl-CoA concentrations, raising the diacylglycerol (DAG) content by the reaction with glycerol-phosphate (Wollheim and Sharp, 1981; Prentki and Matschinsky, 1987; Zawalich and Rasmussen, 1990), which can directly activates conventional and novel isoforms of PKC. Conventional isoforms of PKC might also be activated through an enhancement of intracellular calcium concentrations (Newton, 2003). Palmitate was demonstrated to increase calcium influx through the voltage-sensitive L-type calcium channels in high glucose concentration (Warnotte et al., 1994; Olofsson et al., 2004). DAG production and calcium influx might be involved in PKC activation and, consequently, increase of $\mathrm{NAD}(\mathrm{P}) \mathrm{H}$ oxidase activity.

Even with the higher increase in superoxide content at $5.6 \mathrm{mM}$ than at $10 \mathrm{mM}$ glucose in palmitate incubations, the relative magnitude of the palmitate-induced increase in insulin secretion is observed only at $10 \mathrm{mM}$ glucose (Fig. 3A). This is probably a result of intense local mitochondrial superoxide production in low glucose. Moreover, the cytoplasmatic superoxide production might be a contributor phenomenon for other process such as the modulation of exocytic machinery and ionic fluxes, inducing insulin secretion. Palmitate induced-insulin secretion in $10 \mathrm{mM}$ glucose was blunted by 


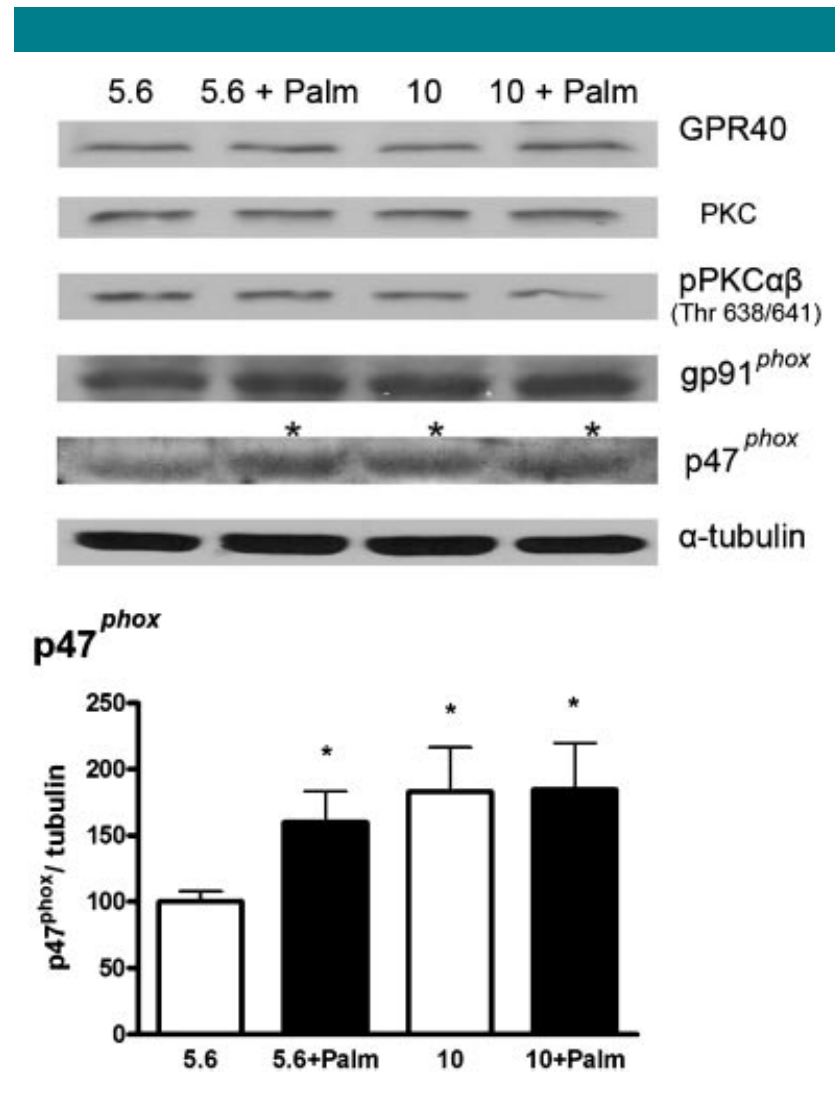

Fig. 5. Effect of palmitate on GPR40, PKC and NAD(P)H oxidase components protein levels. Groups of $\mathbf{3 0 0}$ islets were preincubated with $\mathbf{5 . 6} \mathrm{mM}$ glucose for $30 \mathrm{~min}$ and incubated in $\mathrm{KH}$ with I\% BSA in the presence of 5.6 and $10 \mathrm{mM}$ glucose (white bars) and with I $\mathrm{mM}$ palmitate (Palm) (black bars) for I h. The bars represent the relative p47 ${ }^{\mathrm{PHOX}}$ protein content as determined by optical densitometry and are presented as mean \pm SEM and normalized to control. ${ }^{*} P<0.05$ versus $5.6 \mathrm{mM}$ glucose ( $\mathrm{n} \geq 4$ independent experiments).

NAD(P)H oxidase inhibition (Fig. 3). In fact, NAD(P)H oxidase inhibition has been associated with reduced glucose oxidation, calcium influx and insulin secretion in high glucose concentrations (Imoto et al., 2008; Morgan et al., 2009). In cardiac myocytes, endotelin-I increases ROS production via $\mathrm{NAD}(\mathrm{P}) \mathrm{H}$ oxidase, which plays a key role in calcium influx through L-type calcium channels. This probably occurs due to the redox modification of cysteine residues on the cardiac L-type calcium channel (Mikami et al., 1989). The involvement of redox signaling with the process of insulin secretion has been associated with the redox proteins that regulate the activity of the exocytic machinery in beta cells, such as thioredoxin and glutaredoxin (Ivarsson et al., 2005).

$\mathrm{DPI}$ inhibits $\mathrm{NAD}(\mathrm{P}) \mathrm{H}$ oxidase and concomitantly mitochondrial complex I. These inhibitory actions are explained by the removal of an electron from flavoproteins such as flavin adenine dinucleotide and formation of phenyl radicals, which inhibit the catalytic sites of the enzymes (O'Donnell et al., 1994). Previous studies have shown that effects of DPI treatment are similar to those of down-regulation of $\mathrm{p} 47^{\mathrm{PHOX}}$ using antisense oligonucleotide, leading to reduction of superoxide and hydrogen peroxide production, insulin secretion induced by glucose, and glucose oxidation in rat pancreatic islets (Morgan et al., 2007, 2009). This observation is consistent with the results of the present study, where the incubation of pancreatic islets with DPI reduced superoxide and insulin secretion induced by palmitate. The suppression of insulin secretion stimulated with TPA (12-O- tetradecanoylphorbol-13-acetate, a PKC activator) by DPI (Imoto et al., 2008) reinforces the proposition that DAG content increases by any treatment stimulates $\mathrm{NAD}(\mathrm{P}) \mathrm{H}$ oxidase activation.

One hour exposure to palmitate did not change either the expression of proteins directly involved in fatty acid signaling, such as GPR40 and PKC, or the phosphorylation state of the isoforms $\alpha / \beta$ II of conventional PKC (Thr 638/64I), a constitutive process that is necessary for the maturation of PKC. In this process, phosphoinositide-dependent kinase-I (PDK-I) phosphorylates the conventional PKCs to render them catalytically competent, priming for the binding of second messengers, but does not directly activate them (Newton, 2003). In spite of this, however, this period of time was sufficient to induce GPR40 gene expression in incubation with palmitate and high glucose concentrations. The same was observed for proinsulin gene expression. These results indicate that the increased demand for insulin secretion raises the expression of GPR40 that has been associated with insulin secretion in beta cells (Itoh et al., 2003; Itoh and Hinuma, 2005; Shapiro et al., 2005). This is relevant in conditions such as long-time exposure to fatty acids, high fat diets and type 2 diabetes, to overcome insulin resistance by the increase in insulin secretion.

Protein expression of the organizer subunit $\mathrm{P} 47^{\mathrm{PHOX}}$ was acutely increased by the fatty acid and high glucose concentration (Fig. 5), as also previously demonstrated (Morgan et al., 2007). P47 ${ }^{\text {PHOX }}$, gP9l ${ }^{\text {PHOX }}$, and p22 $2^{\text {PHOX }}$ mRNA concentrations were increased by incubation with palmitate (Fig. 4). The expression of the components of $\mathrm{NAD}(\mathrm{P}) \mathrm{H}$ oxidase complex is regulated by activators and repressors. For example, nuclear factor-kappaB (NF-кB) stimulates expression of gP9l ${ }^{\text {PHOX }}, \mathrm{p}^{4} 7^{\mathrm{PHOX}}$, and $\mathrm{p} 67^{\mathrm{PHOX}}$ (Gauss et al., 2007; Luengo-Blanco et al., 2008) genes. In cultured human endothelial cells, NAD(P)H oxidase-dependent superoxide production is required for palmitate induction of NF- $\mathrm{BB}$ signaling (Maloney et al., 2009). However, differential mechanisms control the posttranscriptional induction of the $\mathrm{NAD}(\mathrm{P}) \mathrm{H}$ oxidase subunits, since protein concentrations of the catalytic subunit gP 9 I $^{\text {PHOX }}$ were not altered even with the increased $\mathrm{p} 47^{\mathrm{PHOX}}$ protein content.

Our results show that $\mathrm{NAD}(\mathrm{P}) \mathrm{H}$ oxidase activation by $\mathrm{PKC}$ and fatty acid oxidation is an important source of superoxide in pancreatic islets treated with palmitate. This fatty acid acutely potentiates insulin secretion, through a mechanism that also involves translocation of $\mathrm{p} 47^{\mathrm{PHOX}}$ to plasma membrane and $\mathrm{NAD}(\mathrm{P}) \mathrm{H}$ oxidase activation.

\section{Acknowledgments}

The authors are grateful to Daniela Morgan and Marlene Santos Rocha for excellent technical assistance. Thanks are due to Dr. Luiz R. G. Britto (University of São Paulo) and Mauro Leonelli (University of São Paulo) for critically reading the manuscript and excellent technical support. This study was supported by Fundação de Amparo à Pesquisa do Estado de São Paulo (FAPESP), Conselho Nacional de Desenvolvimento Cientifico e Tecnológico (CNPq), and the Instituto Nacional de Obesidade e Diabetes (INCT).

\section{Literature Cited}

Baynes JW. 1991. Role of oxidative stress in development of complications in diabetes. Diabetes 40:405-4I2

Bedard K, Krause KH. 2007. The NOX family of ROS-generating NADPH oxidases: Physiology and pathophysiology. Physiol Rev 87:245-313.

Bradford MM. 1976. A rapid and sensitive method for the quantitation of microgram quantities of protein utilizing the principle of protein-dye binding. Anal Biochem 72:248 254.

Briaud I, Harmon JS, Kelpe CL, Segu VB, Poitout V. 200I. Lipotoxicity of the pancreatic betacell is associated with glucose-dependent esterification of fatty acids into neutral lipids. Diabetes 50:315-321. 
Briscoe CP, Tadayyon M, Andrews JL, Benson WG, Chambers JK, Eilert MM, Ellis C, Elshourbagy NA, Goetz AS, Minnick DT, Murdock PR, Sauls HR, Jr., Shabon U, Spinage LD Strum JC, Szekeres PG, Tan KB, Way JM, Ignar DM, Wilson S, Muir AI. 2003. The orphan C protein-coupled receptor GPR40 is activated by medium and long chain fatty acids. J Biol Chem 278: ||303-||3||.

Carpinelli AR, Picinato MC, Stevanato E, Oliveira HR, Curi R. 2002. Insulin secretion induced by palmitate-A process fully dependent on glucose concentration. Diabetes Metab 28:3S37-3S44; discussion 33SI08-33SII2.

Ceriello A, Motz E. 2004. Is oxidative stress the pathogenic mechanism underlying insulin resistance, diabetes, and cardiovascular disease? The common soil hypothesis revisited. Arterioscler Thromb Vasc Biol 24:816-823.

Chen S, Ogawa A, Ohneda M, Unger RH, Foster DW, McGarry JD. 1994. More direct evidence for a malonyl-CoA-carnitine palmitoyltransferase $I$ interaction as a key event in pancreatic beta-cell signaling. Diabetes 43:878-883.

Corkey BE, Deeney JT, Yaney GC, Tornheim K, Prentki M. 2000. The role of long-chain fatty acyl-CoA esters in beta-cell signal transduction. J Nutr 130:299S-304S.

Crespin SR, Greenough WB, Steinberg D. 1973. Stimulation of insulin secretion by long-chain free fatty acids. A direct pancreatic effect. J Clin Invest 52:1979-1984.

Deeney JT, Tornheim K, Korchak HM, Prentki M, Corkey BE. 1992. Acyl-CoA ester modulate intracellular $\mathrm{Ca}^{2+}$ handling by permeabilized clonal pancreatic beta-cells. J Biol Chem 267:19840-19845.

Doshi LS, Brahma MK, Sayyed SG, Dixit AV, Chandak PG, Pamidiboina V, Motiwala HF, Sharma SD, Nemmani KV. 2009. Acute administration of GPR40 receptor agonist potentiates glucose-stimulated insulin secretion in vivo in the rat. Metabolism 58:333-343.

Fujiwara K, Maekawa F, Yada T. 2005. Oleic acid interacts with GPR40 to induce $\mathrm{Ca}^{2+}$ signaling in rat islet beta-cells: Mediation by PLC and L-type $\mathrm{Ca}^{2+}$ channel and link to insulin release. Am J Physiol Endocrinol Metab 289:E670-E677.

Gauss KA, Nelson-Overton LK, Siemsen DW, Gao Y, DeLeo FR, Quinn MT. 2007. Role of NF-kappaB in transcriptional regulation of the phagocyte NADPH oxidase by tumor necrosis factor-alpha. J Leukoc Biol 82:729-74I.

Goldstein BJ, Mahadev K, Wu X. 2005. Redox paradox: Insulin action is facilitated by insulinstimulated reactive oxygen species with multiple potential signaling targets [erratum appears in Diabetes. 2005 Apr; 54:I 249 Note: Kalyankar, Mahadev (corrected to Mahadev, Kalyankar)]. Diabetes 54:31I-321.

Graciano MF, Nogueira TC, Carvalho CR, Curi R, Carpinelli AR. 2009. Palmitate activates insulin signaling pathway in pancreatic rat islets. Pancreas 38:578-584.

Griendling KK, Sorescu D, Ushio-Fukai M. 2000. NAD(P)H oxidase: Role in cardiovascular biology and disease. Circ Res 86:494-501.

Haber EP, Ximenes HM, Procopio J, Carvalho CR, Curi R, Carpinelli AR. 2003. Pleiotropic effects of fatty acids on pancreatic beta-cells. J Cell Physiol 194:I-12

Harraz MM, Marden J], Zhou W, Zhang Y, Williams A, Sharov VS, Nelson K, Luo M, Paulson H, Schoneich C, Engelhardt JF. 2008. SODI mutations disrupt redox-sensitive Rac regulation of NADPH oxidase in a familial ALS model. J Clin Invest I I 8:659-670.

Hellemans K, Kerckhofs K, Hannaert JC, Martens G, Van Veldhoven P, Pipeleers D. 2007. Peroxisome proliferator-activated receptor alpha-retinoid $X$ receptor agonists induce beta-cell protection against palmitate toxicity. FEBS J 274:6094-6105.

Higai K, Satake M, Nishioka H, Azuma Y, Matsumoto K. 2008. Glycated human serum albumin enhances macrophage inflammatory protein-I beta mRNA expression through protein kinase C-delta and NADPH oxidase in macrophage-like differentiated U937 cells. Biochim Biophys Acta 1780:307-3/4.

Hirabara SM, Silveira LR, Abdulkader F, Carvalho CR, Procopio J, Curi R. 2007. Timedependent effects of fatty acids on skeletal muscle metabolism. J Cell Physiol 210:7-15.

laccio A, Collinet C, Gesualdi NM, Ammendola R. 2007. Protein kinase C-alpha and -delta are required for NADPH oxidase activation in WKYMVm-stimulated IMR90 human fibroblasts. Arch Biochem Biophys 459:288-294.

Imoto H, Sasaki N, Iwase M, Nakamura U, Oku M, Sonoki K, Uchizono Y, lida M. 2008. Impaired insulin secretion by diphenyleneiodium associated with perturbation of cytosolic $\mathrm{Ca}^{2+}$ dynamics in pancreatic beta-cells. Endocrinology 149:539I-5400.

Inoguchi T, Li P, Umeda F, Yu HY, Kakimoto M, Imamura M, Aoki T, Etoh T, Hashimoto T, Naruse M, Sano H, Utsumi H, Nawata H. 2000. High glucose level and free fatty acid stimulate reactive oxygen species production through protein kinase $\mathrm{C}$-dependent activation of $\mathrm{NAD}(\mathrm{P}) \mathrm{H}$ oxidase in cultured vascular cells. Diabetes 49:1939-1945.

Itoh Y, Hinuma S. 2005. GPR40, a free fatty acid receptor on pancreatic beta cells, regulates insulin secretion. Hepatol Res 33:17I-173.

Itoh Y, Kawamata Y, Harada M, Kobayashi M, Fujii R, Fukusumi S, Ogi K, Hosoya M, Tanaka Y, Uejima H, Tanaka H, Maruyama M, Satoh R, Okubo S, Kizawa H, Komatsu H, Matsumura F, Noguchi Y, Shinohara T, Hinuma S, Fujisawa Y, Fujino M. 2003. Free fatty acids regulate insulin secretion from pancreatic beta cells through GPR40. Nature 422:173-176.

Ivarsson R, Quintens R, Dejonghe S, Tsukamoto K, in 't Veld P, Renstrom E, Schuit FC. 2005 Redox control of exocytosis: Regulatory role of NADPH, thioredoxin, and glutaredoxin. Diabetes 54:2132-2/42.

Kadri-Hassani N, Leger CL, Descomps B. 1995. The fatty acid bimodal action on superoxide anion production by human adherent monocytes under phorbol I2-myristate I3-acetate or diacylglycerol activation can be explained by the modulation of protein kinase $\mathrm{C}$ and p47phox translocation. J Biol Chem 270:151II-15118.

Kotarsky K, Nilsson NE, Olde B, Owman C. 2003. Progress in methodology. Improved reporter gene assays used to identify ligands acting on orphan seven-transmembrane receptors. Pharmacol Toxicol 93:249-258.

Lacy PE, Kostianovsky M. 1967. Method for the isolation of intact islets of Langerhans from the rat pancreas. Diabetes 16:35-39.

Laemmli UK. 1970. Cleavage of structural proteins during the assembly of the head of bacteriophage T4. Nature 227:680-685.

Lambertucci RH, Hirabara SM, Silveira Ldos R, Levada-Pires AC, Curi R, Pithon-Curi TC. 2008. Palmitate increases superoxide production through mitochondrial electron transport chain and NADPH oxidase activity in skeletal muscle cells. J Cell Physiol 216:796804.

Lehtihet M, Welsh N, Berggren PO, Cook GA, Sjoholm A. 2003. Glibenclamide inhibits islet carnitine palmitoyltransferase I activity, leading to PKC-dependent insulin exocytosis. Am J Physiol Endocrinol Metab 285:E438-E446.

Livak KJ, Schmittgen TD. 200I. Analysis of relative gene expression data using real-time quantitative PCR and the 2(-Delta Delta C(T)) Method. Methods (Duluth) 25:402-408
Luengo-Blanco M, Prando C, Bustamante J, Aragao-Filho WC, Pereira PV, Rehder J, Padden C, Casanova JL, Newburger PE, Condino-Neto A. 2008. Essential role of nuclear factor-kappaB for NADPH oxidase activity in normal and anhidrotic ectodermal dysplasia leukocytes. Blood II2:1453-|460.

Maloney E, Sweet IR, Hockenbery DM, Pham M, Rizzo NO, Tateya S, Handa P, Schwartz MW Kim F. 2009. Activation of NF-kappaB by palmitate in endothelial cells: A key role for NADPH oxidase-derived superoxide in response to TLR4 activation. Arterioscle Thromb Vasc Biol 29:1370-1375.

Martins EF, Miyasaka CK, Newsholme P, Curi R, Carpinelli AR. 2004. Changes of fatty acid composition in incubated rat pancreatic islets. Diabete Metab 30:21-27.

Mikami A, Imoto K, Tanabe T, Niidome T, Mori Y, Takeshima H, Narumiya S, Numa S. 1989. Primary structure and functional expression of the cardiac dihydropyridine-sensitive calcium channel. Nature 340:230-233.

Morgan D, Oliveira-Emilio HR, Keane D, Hirata AE, Santos da Rocha M, Bordin S, Curi R Newsholme P, Carpinelli AR. 2007. Glucose, palmitate and pro-inflammatory cytokines modulate production and activity of a phagocyte-like NADPH oxidase in rat pancreatic islets and a clonal beta cell line. Diabetologia 50:359-369.

Morgan D, Rebelato E, Abdulkader F, Graciano MF, Oliveira-Emilio HR, Hirata AE, Rocha MS Bordin S, Curi R, Carpinelli AR. 2009. Association of NAD(P)H oxidase with glucoseinduced insulin secretion by pancreatic beta-cells. Endocrinology I50:2197-220I.

Muller G, Wied S, Jung C, Over S. 2008. Hydrogen peroxide-induced translocation of glycolipid-anchored (c) AMP-hydrolases to lipid droplets mediates inhibition of lipolysis in rat adipocytes. Br J Pharmacol I54:90I-9I3.

Newsholme P, Haber EP, Hirabara SM, Rebelato EL, Procopio J, Morgan D, OliveiraEmilio HC, Carpinelli AR, Curi R. 2007. Diabetes associated cell stress and dysfunction: Role of mitochondrial and non-mitochondrial ROS production and activity. J Physiol 583:9-24.

Newton AC. 2003. Regulation of the $A B C$ kinases by phosphorylation: Protein kinase $C$ as a paradigm. Biochem J 370:36I-37I.

Nogueira TC, Graciano MF, Anhe GF, Curi R, Bordin S, Carpinelli AR. 2009. Short-term modulation of extracellular signal-regulated kinase $\mathrm{I} / 2$ and stress-activated protein kinase/ c-Jun NH2-terminal kinase in pancreatic islets by glucose and palmitate: Possible involvement of ceramide. Pancreas 38:585-592.

Nolan CJ, Madiraju MS, Delghingaro-Augusto V, Peyot ML, Prentki M. 2006. Fatty acid signaling in the \{beta\}-cell and insulin secretion. Diabetes 55:SI6-S23.

O'Donnell VB, Smith GC, Jones OT. 1994. Involvement of phenyl radicals in iodonium inhibition of flavoenzymes. Mol Pharmacol 46:778-785.

Oliveira HR, Curi R, Carpinelli AR. 1999. Glucose induces an acute increase of superoxide dismutase activity in incubated rat pancreatic islets. Am J Physiol 276:C507-C5I0.

Oliveira HR, Verlengia R, Carvalho CR, Britto LR, Curi R, Carpinelli AR. 2003. Pancreatic beta-cells express phagocyte-like NAD(P)H oxidase. Diabetes 52:|457-| 463.

Olofsson CS, Salehi A, Holm C, Rorsman P. 2004. Palmitate increases L-type Ca ${ }^{2+}$ currents and the size of the readily releasable granule pool in mouse pancreatic beta-cells. J Physio 557:935-948.

Palsamy P, Subramanian S. 2010. Ameliorative potential of resveratrol on proinflammatory cytokines, hyperglycemia mediated oxidative stress, and pancreatic beta-cell dysfunction in streptozotocin-nicotinamide-induced diabetic rats. J Cell Physiol 224:423-432.

Pappan KL, Pan Z, Kwon G, Marshall CA, Coleman T, Goldberg IJ, McDaniel ML, Semenkovich CF. 2005. Pancreatic beta-cell lipoprotein lipase independently regulates islet glucose metabolism and normal insulin secretion. J Biol Chem 280:9023-9029.

Pi J, Bai Y, Zhang Q, Wong V, Floering LM, Daniel K, Reece JM, Deeney JT, Andersen ME, Corkey BE, Collins S. 2007. Reactive oxygen species as a signal in glucose-stimulated insulin secretion. Diabetes 56:1783-1791.

Prentki M, Matschinsky FM. 1987. $\mathrm{Ca}^{2+}$, cAMP, and phospholipid-derived messengers in coupling mechanisms of insulin secretion. Physiol Rev 67: | |85-1248.

Schonfeld P, Wojtczak L. 2008. Fatty acids as modulators of the cellular production of reactive oxygen species. Free Radic Biol Med 45:23I-24I.

Shapiro H, Shachar S, Sekler I, Hershfinkel M, Walker MD. 2005. Role of GPR40 in fatty acid action on the beta cell line INS-IE. Biochem Biophys Res Commun 335:97-104.

Spector AA, Fletcher JE, Ashbrook JD. 1971. Analysis of long-chain free fatty acid binding to bovine serum albumin by determination of stepwise equilibrium constants. Biochemistry 10:3229-3232.

Spector AA, Hoak JC. 1975. Letter: Fatty acids, platelets, and microcirculatory obstruction. Science 190:490-492.

Suvorava T, Kojda G. 2009. Reactive oxygen species as cardiovascular mediators: Lessons from endothelial-specific protein overexpression mouse models. Biochim Biophys Acta 1787:802-810

Thams P, Capito K. 200I. Differential mechanisms of glucose and palmitate in augmentation of insulin secretion in mouse pancreatic islets. Diabetologia 44:738-746.

Uchizono Y, Takeya R, Iwase M, Sasaki N, Oku M, Imoto H, lida M, Sumimoto H. 2006. Expression of isoforms of NADPH oxidase components in rat pancreatic islets. Life Sci $80: 133-139$.

Victor VM, Apostolova N, Herance R, Hernandez-Mijares A, Rocha M. 2009. Oxidative stress and mitochondrial dysfunction in atherosclerosis: Mitochondria-targeted antioxidants as potential therapy. Curr Med Chem 16:4654-4667.

Wang Y, Wang PY, Takashi K. 2006. Chronic effects of different non-esterified fatty acids on pancreatic islets of rats. Endocrine 29:169-173.

Warnotte C, Gilon P, Nenquin M, Henquin JC. 1994. Mechanisms of the stimulation of insulin release by saturated fatty acids. A study of palmitate effects in mouse beta-cells. Diabetes 43:703-7II.

Wollheim CB, Sharp GW. 1981. Regulation of insulin release by calcium. Physiol Rev 61:914 973

Zawalich WS, Rasmussen H. 1990. Control of insulin secretion: A model involving $\mathrm{Ca}^{2+}$, cAMP and diacylglycerol. Mol Cell Endocrinol 70:119-137.

Zhao H, Kalivendi S, Zhang H, Joseph J, Nithipatikom K, Vasquez-Vivar J, Kalyanaraman B. 2003. Superoxide reacts with hydroethidine but forms a fluorescent product that is distinctly different from ethidium: Potential implications in intracellular fluorescence detection of superoxide. Free Radic Biol Med 34:1359-1368.

Zhou YP, Grill VE. 1994. Long-term exposure of rat pancreatic islets to fatty acids inhibits glucose-induced insulin secretion and biosynthesis through a glucose fatty acid cycle. J Clin Invest 93:870-876. 